Portland State University

PDXScholar

$1-1-1985$

\title{
The relationship between self-esteem and physical condition as measured by the hand grip and leg press in retirement home residents
}

Anna Mae Tichy

Portland State University

Follow this and additional works at: https://pdxscholar.library.pdx.edu/open_access_etds Let us know how access to this document benefits you.

Recommended Citation

Tichy, Anna Mae, "The relationship between self-esteem and physical condition as measured by the hand grip and leg press in retirement home residents" (1985). Dissertations and Theses. Paper 225.

https://doi.org/10.15760/etd.225

This Dissertation is brought to you for free and open access. It has been accepted for inclusion in Dissertations and Theses by an authorized administrator of PDXScholar. Please contact us if we can make this document more accessible: pdxscholar@pdx.edu. 


\title{
THE RELATIONSHIP BETWEEN SELF-ESTEEM AND \\ PHYSICAL CONDITION AS MEASURED BY \\ THE HAND GRIP AND LEG PRESS IN \\ RETIREMENT HOME RESIDENTS
}

by

Anna Mae Tichy

A dissertation submitted in partial fulfillment

of the requirements for the degree of

\author{
DOCTOR OF EDUCATION \\ in \\ COMMUNITY COLLEGE EDUCATION
}
Portland state University Oregon state University
university of Oregon

1985 
TO THE OFFICE OF GRADUATE STUDIES AND RESEARCH:

The members of the Committee approve the dissertation of Anna Mae Tichy, presented May 20, 1985.
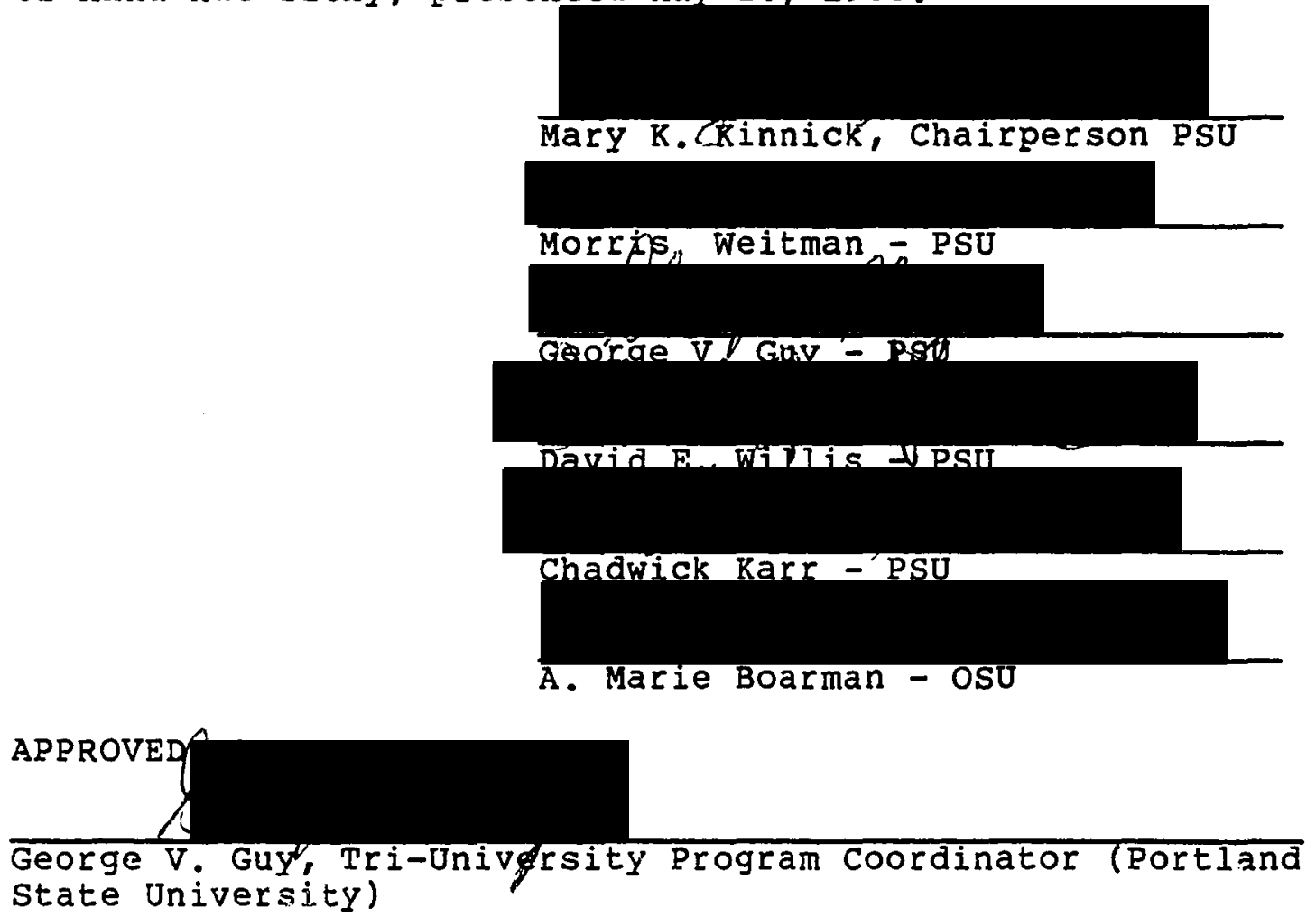
state University)

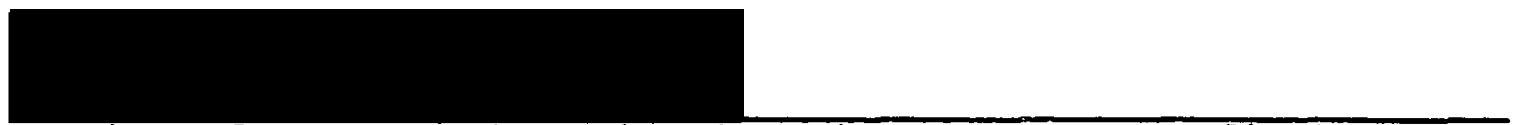

Richard A. Schmuck, Tri-University Program Coordinator (University of oreoon)

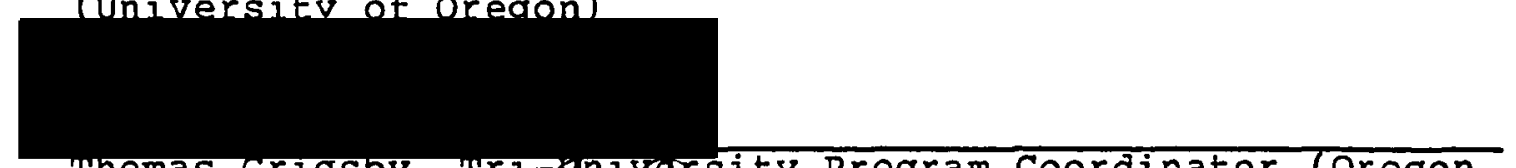
Thomas Grigsby, Iri-gniygrsity program Coordinator (Oregon
State University)

Donald J. Leud Dean, of the School of Education (Portland State University)

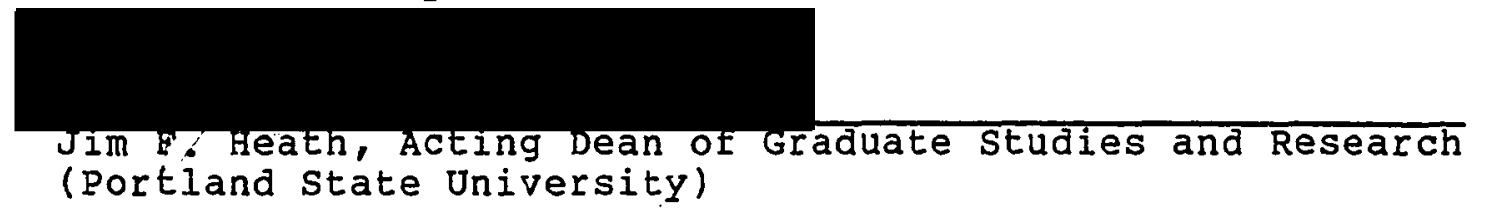


AN ABSTRACT OF THE DISSERTATION OF Anna Mae Tichy for the Doctor of Education in Community College Education presented May 20,1985

Title: The Relationship between Self-Esteem and Physical Condition as Measured by Hand Grip and Leg Press Strength in Retirement Home Residents

APPROVED BY MEMBERS OF THE DISSERTATTON COMMTTTEF.

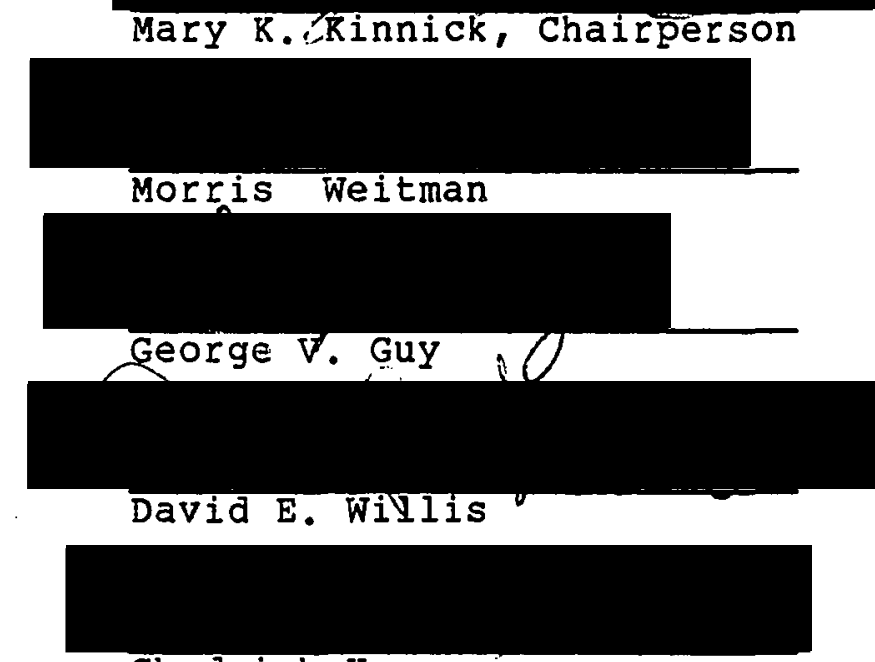

Chadwick Karr

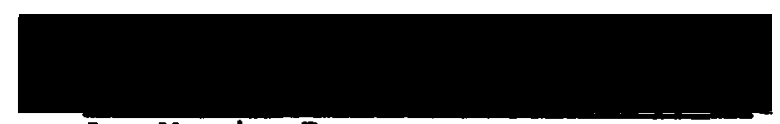

A. Marie Boarman

The relationship between self-esteem and physical condition as measured by hand grip and leg press for sixty five subjects from two retirement homes was examined. The 
study included pre- and post-test examination of selfesteem and physical condition and presentation of exercise sessions for one-half hour, four times a week for eight weeks. Two control groups were established (lecture and no treatment). The randomly assigned subjects, however, did not remain in their groups. There was cross contamination between groups and marked attrition in the exercise group. The orginally selected subjects ranged in age from 60 to 99 years ( 10 males, 55 females). At the conclusion of the study, 54 subjects remained ( 5 males, 49 females). The functional description of the subjects was "frail elderly." They were mobile and alert, but many had some physical and/or mental limitations which prevented them from living independently.

Physical condition. was determined by hand grip and leg press strength. Lafayette hand dynamometer, Model 76618, was used to determine hand grip strength. Leg press strength was measured by a specially designed procedure using a General Electric weight scale (Model EDS-1/B2). The subjects sat on a 17-inch high chair, and were directed to press downward on the scale with both feet for a minimum of five seconds. They could not hold onto the chair or lean forward.

Measures of self-esteem included Rosenberg's ten-item Self-Esteem scale and the investigator's four-item selfesteem-related behavior questionnaire (Tichy). Anecdotal records were kept during the implementation phase. 
No statistically significant relationships were demonstrated beween physical condition and self-esteem. Age and hand grip strength were significantly negatively correlated $(\underline{r}=-.39, \underline{p} \leq .01)$. The hours of activity described by the subjects and leg press strength showed a positive correlation $(\underline{r}=.34, \underline{p} \leq .01)$. Subjects' attendance at lecture sessiors and self-esteem as measured on the Tichy instrument showed a significant positive correlation $(\underline{r}=.49, \underline{p} \leq .01)$. Hours of rest reported by the subjects showed a significant negative correlation with self-esteem $(\underline{\underline{c}}=-.31, \underline{p} \leq .05)$ The subject's level of control in selection of the retirement home and self-esteem measured on the Tichy instrument showed a significant positive relationship $(\underline{F}=4.91, \underline{p}=.03)$.

The findings indicate that the physical strength of these subjects was low; their level of self-esteem relatively high. Self-esteem was found to be a fragile condition for this population and can be positively or negatively affected by physical, psychological, and emotional events.

A regular program of exercise did produce subjectperceived and investigator-observed improvement in strength level and ability to perform basic activities of daily living. Most elderly subjects, however, did not accept exercise as necessary. Rather, they believed chat as the individual ages, the body's need for exercise decreases. 
Implications are that health education programs directed toward the elderly and focused on the need for and benefits of exercise may encourage them to participate in more physical activity. Appropriate physical activity, in turn, will help maintain basic hand grip and leg press strength necessary for activities of daily living. It is likely that the ability to perform the activities of daily living would contribute to the over-all quality of life.

The definition of needs and expectations of the growing population of older citizens can be addressed by a wide variety of community resources. The comprehensive community college has a unique role in the well being of all members of its community. It has the ability to provide education which focuses on the normal aging process and positive health measures which will help to improve the quality of life for all citizens. 


\section{ACKNOWLEDGEMENTS}

I wish to acknowledge my indebtedness to the following persons and to thank them for their help and support in writing this study:

To the members of my committee for their support, generous assistance, and valuable guidance. Especially to Dr. Kinnick and Dr. Weitman for their unselfish contribution of time and recommendations toward the completion of this report.

To Mt. Hood Community College Board and the Faculty Resource Development Board for the support of my sabbatical leave in the pursuit of my professional goals.

To Elinore Nudelman who assisted in data collection and provided constant encouragement for this work. To the adminstration of the retirement homes and the residents who shared their time and energies with me as a most valuable part of the study. Their support and friendships will long be remembered and prized.

To my husband, Michael W. Tichy, who has long been my mentor and main support throughout the development of my professional career. This work is dedicated to him. 
ACKNOWLEDGEMENTS . . . . . . . . . . . . . . . . . iii

LIST OF TABLES . . . . . . . . . . . . . . . . . ix

CHAPTER

I. IDENTIFICATION OF THE PROBLEM. . . . . . . . . . 1

II. REVIEW OF THE LITERATURE . . . . . . . . . 8

Physiological Changes in Aging . . . . . . 8

Muscle . . . . . . . . . . . . . 9

Muscle strength . . . . . . . . . . . . 9

Hand Strength . . . . . . . . . . . 10

Leg Strength . . . . . . . . . . . . 10

Body Weight . . . . . . . . . . . . . 11

Bone .. . . . . . . . . . . . . . 12

Vertebral Discs . . . . . . . . . . . 13

Joints . . . . . . . . . . . . . . . 14

Flexibility ............... . . 14

Patterns of sleep. . . . . . . . . . . 15

Measuring Physical Condition of the
Older Person... . . . . . . . . 17

Psychological Changes in Aging . . . . . . . 22

Self-Esteem . . . . . . . . . . . . 22

Depression . . . . . . . . . . . . 24

Changes in Self-Esteem. . . . . . . . 27

Measures of Self-Esteem . . . . . . . 31 Butler and Haigh Q-Sort . . . . . . 32

Tennessee self-Concept . . . . . . . . . 34 Coopersmith Self-Esteem Inventory . . . 34 Bill's Index of Adjustment Values . . . 35 Rosenberg Self-Esteem Scale. . . . . 36

Interactions of Exercise, Physical Fitness,

and Self-Esteem . . . . . . . . . . 38

Interaction of Exercise and Physical

Fitness . . . . . . . . . . . 38

Exercise Program Design . . . . . . . . 41

Interaction of Exercise and Self-Esteem. . 42

III. HYPOTHESIS DEVELOPMENT . . . . . . . . . . . 44 
IV. TESTING OE INSTRUMENTS . . . . . . . . . . 55

Subjects . . . . . . . . . . . . . 56

Instruments . . . . . . . . . . . . . . 57

Procedures . . . . . . . . . . . . . 59

Results of the pre-Testing . . . . . . . . 62

V. METHODOLOGY . . . . . . . . . . . . . . . 64

subjects . . . . . . . . . . . . . . 64

The Retirement Homes... . . . . . . 71

pre-Test and Selection of subjects. . . 78

Data Collection . . . . . . . . . . . 82

Instruments . . . . . . . . . . . . 82

Self-Esteem Measures. . . . . . . 82

Physical Measures . . . . . . . . . 83

Other Measures.... . . . . . . . 86

Treatment . . . . . . . . . . . . 88

Program Presentation . . . . . . . 89

Exercise Program . . . . . . . . . 91

Progression . . . . . . . . . . . 91

Seating Arrangement ........ . 92

Safety . . . . . . . . . . . . 92

Exercise Presentation . . . . . . 93

Use of Props . . . . . . . . . . . . 94

Lecture Program . . . . . . . . . 95

Topics... . . . . . . . . . . 95

Seating Arrangement . . . . . . 96

Use of Visuals... . . . . . . . 96

Refreshments... . . . . . . . . . 96

Revised Design . . . . . . . . . . . 97

Rationale . . . . . . . . . . . . 97

Attendance Week one . . . . . . . . . 99

Revised Design... . . . . . . . . . 100

Post-Testing. . . . . . . . . . . . 101

Treatment of the Data. . . . . . . . . 101

VI. FINDINGS AND DISCUSSION . . . . . . . . . . 102

Physical Characteristics of the Sample

Population and Hypothesis Testing . . . . . 105

Age and Weight... . . . . . . . . 105

Hand Grip. . . . . . . . . . . . . 106

Leg Press. . . . . . . . . . . . . 107 
Length of Stay . . . . . . . . . . 109

Environment and Exercise Patterns. . . . 110a Attitude and Practices Related to Exercise 114 Home Provided Activities . . . . . . . 121 Recreational pursuits and selfDescribed Activity Level . . . . . 123

Participation in The Study . . . . . . . . 127 Exercise Session Attendance. . . . . . . 127 Participation and Attitude toward

Exercise Sessions. . . . . . . . . 128

Individual Exercise Patterns . . . . . 130

Ability to Perform Physical Exercise. . . 131

Effectiveness of Exercise Sessions . . . 133

Lecture Session Attendance... . . . . 135

Psychological Characteristics of the Sample

Population and Hypotheses Testing . . . . . 135

Observation Factors and Self-Esteem. . . 136

Environmental Factors. . . . . . . . . 136

Personal Appearance. . . . . . . . . 138

Resident Interactions. . . . . . . . . 139

Self-Esteem Questionnaires... . . . . 141

Age and Length of Stay . . . . . . . . 144

Activity and Rest. . . . . . . . . . . 147

Level of Control . . . . . . . . . . 149

Session Attendance . . . . . . . . . . 152

Illness and Death... . . . . . . . . . 155

Physical Condition and Self-Esteem . . . 156

VII. SUMMARY, CONCLUSIONS, AND IMPLICATIONS . . . 159

Summary. • . . . • . . . . . . . . . . 159

Limitations of the study . . . . . . . . 172

Conclusions and Recommendations. . . . . . 174

Implications for Future Research . . . . . . 180

The Role of the Community College. . . . 183

The Future. . . . . . . . . . . . . . 184

SELECTED BIBLIOGRAPHY . . . . . . . . . . . . 186

MEASURES OF SELF-ESTEEM . . . . . . . . . . . . . . 193 
vii

PAGE

APPENDIX A: Testing Instruments . . . . . . . . . . 194

Physical Measures ................ 195

Rosenberg Self-Esteem . . . . . . . . . . 196

Post-Test . . . . . . . . . . . . . . . 197

Self-Reported Activity/Rest Time study. . . . . . 198

Informed Consent. . . . . . . . . . . . . 199

Health Program Questionnaire . . . . . . . . 200

APPENDIX B: Flexibility . . . . . . . . . . 201

APPENDIX C: Anecdotal Records... . . . . . . . 204

Exercise . . . . . . . . . . . . . 205

Lecture . . . . . . . . . . . . . . 228

APPENDIX D: Exercise Program . . . . . . . . . 246

Exercise Program . . . . . . . . . . . . 247

Outline of Exercise Presentation . . . . . . 254

Props and Routines . . . . . . . . . . . 255

Stand Ups .................. 255

Standing Exercise . . . . . . . . . . 256

Chair Exercise... . . . . . . . . . 256

Props ..................... 256

soft, Big Bails.

Hard Balls... . . . . . . . . . . 259

Gloves . . . . . . . . . . . . . . 260

Wands. . . . . . . . . . . . . . . . 260

Barbells................. 263

Scarves. . . . . . . . . . . . 263

APPENDIX E: Lecture Program . . . . . . . . . . 264

Lecture Program . . . . . . . . . . . . . . 265

Outline of Lecture Presentation . . . . . . . 266

APPENDIX F: Descriptive Data. . . . . . . . . . 267

Demographic Characteristics of the Sample

(Pre-Test) . . . . . . . . . . . . . 268

Analysis of Variance between Physical Measures. . 269

Covariance between Physical Measures. . . . . . 270

Demographic Characteristics, Attitude toward

Exercise, and Daily Hours of Activity/Rest . . 271

Relationship between Measures of Self-Esteem. . . 272

APPENDIX G: Assistant's Observations. . . . . . . . 273

Surroundings. . . . . . . . . . . . . . . 273

Family. . . . . . . . . . . . . . . . . . . . 274

Religion. . . . . . . . . . . . . . . . 274

Physical Disability . . . . . . . . . . . . 274 
viii

PAGE

Inertia . . . . . . . . . . . . . 275

Death . . . . . . . . . . . . . . 276

Age . . . . . . . . . . . . . . . . 276 


\section{LIST OF TABLES}

TABLE

PAGE

I Criteria for selection of Retirement Homes. .

II study sample. . . . . . . . . . . . . 104

III Physical Condition and Age. . . . . . . . 109

IV Length of Stay, Physical Condition, and Age . 111

$\mathrm{V}$ Distance to Dining Room and Physical Condition 114

VI Acceptance of Decreased Need for Exercise and Physical Condition . . . . . . . . . 116

VII Reported Daily Hours of Activity and Rest . . 119

VIII Daily Hours of Activity and Rest and Physical Condition... . . . . . . . 120

IX Self-Described Activity Level and Recreational pursuits. . . . . . . . . 124

$x$ Self-Described Activity Level and Hours of Activity and Rest . . . . . . . 125

XI Self-Described Activity Level, Recreational Pursuits, and Physical Condition . . . . . 126

XII Session Attendance and Pre-Test Physical Condition. . . . . . . . . . . . 128

XIII Length of Stay and Self-Esteem. . . . . . . 145

XIV Age and Self-Esteem . . . . . . . . . . 147

$X V$ Hours of Activity and Rest and Self-Esteem. . 148

XVI Self-Esteem by Level of Control . . . . . . . 150

XVII Level of Control and Self-Esteem. . . . . . 151

XVIII Exercise and Lecture Attendance and SelfEsteem . . . . . . . . . . . . 153 
XIX Illness as An Excuse for Absence and Self-Esteem. . . . . . . . . . . 155

XX Pre- and Post-Test Relationships between Physical Condition and Self-Esteem . . . . 157

XXI Summary Correlations of Variables Related to Physical Condition. . . . . . . . . 167

XXII Summary Correlations of Variables Related to Self-Esteem............. 169

XXIII Demographic Characteristics of the Sample (Pre-Test)............... . . 268

XXIV Analysis of Variance between Physical Measures................. . 269

XXV Covariance between Physical Measures . . . 270

XXVI Demographic Characteristics, Attitude toward Exercise, and Daily Hours of Activity and Rest 271

XXVI Relationship between Measures of Self-Esteem 272 
CHAPTER I

\section{IDENTIEICATION OF THE PROBLEM}

The purpose of this study was to examine the relationship of self-esteem and physical condition in a population of retirement home residents. The study sought to investigate if the maintenance and/or improvement of physical condition, self-esteem and, thus, the quality of life could be affected by certain interventions.

Atchley (1977) has contended that the aging of America's citizens is a newly defined problem in our society which is accompanied by population changes, urbanization, industrialization, and fast-paced social change. Butler (1978) has noted that the increasing numbers of aging persons in the nation will have a major impact on society. The retirement years are likely to last as long as childhood, if not longer. The effect will be that of adding a whole new generation to the population. The needs of these aging persons should be at least as important to society as are the needs of any other segment. Likewise, recognition of their rights will be a responsibility of society.

\footnotetext{
Population changes have undoubtedly had a substantial impact in making the elderly more visible and their needs
} 
more obvious. In 1900 , one of every twenty-five persons in the United States was over 65. Now, the ratio is one of every nine, and by 2010--when the baby boom becomes the senior boom--it is expected to be one of every six or possibly of every five. The 25 million Americans over 65 now make up about 12 percent of the population, compared to 4 percent in 1900. If this trend continues, by the year 2000 there will be an estimated 29 million Americans who are 65 and over (U. S. Department of Commerce, 1980). Some writers (Murray, Huelskoetter, \& O'Driscoll, 1980) have referred to later maturity as the last developmental stage in life. Retirement from the work force at about 65 to 70 years of age is also closely associated with this stage in life. In reality, this span of later maturity may cover 30 to 40 years which is longer than any other developmental stage.

Although some include the entire developmental stage under the title of "old age," other authorities have offered clarifying descriptors. For example, shephard (1978) proposed the following classification scheme:

Middle age: ages 40-65, the preretirement years

Old age: ages $65-75$, the immediate postretirement period when there is relatively minimal functional impairment

Very old age: ages 75-85, some functional impairment but most individuals can still live somewhat independently 
Extreme old age: ages 85 and older, greater functional impairment and institutional care is usually needed

Others refer to the young-old, age 65 or 70 to 75 or 80 years and the old-old, age 75 or 80 years until death (Cameron, 1976). The Standards of Geriatric Nursing Practice by the American Nurses Association (1970) defines aged as that point in the life span of a person when changes of aging markedly interfere with functioning. Aging seems to refer to many of those changes associated with declining function after the person reaches maturity (Busse \& Pfeiffey, 1969).

Yet, others (e.g., Murray, Huelskoetter, \& O'Driscoll, 1980) accept the concept that the person is as old as the individual feels. Various facets of the individual including biological, psychological, and social factors contribute to that sense of age. The biological, psychological, and social aspects of the individual are interdependent, each involving certain processes. The person may not be equally old in all biological, psychological, and social aspects (Murray, Huelskoetter, \& O'Driscoll, 1980).

How each person defines old and aged depends upon self-image, personal patterns of adjustment, emotional conflicts, past experiences with elderly people, sociocultural and ethnic background, religion, and personal age (Murray, Huelskoetter, \& O'Driscoll, 1980). Thus, the 
terms "old" or "aged" have many meanings. The concept of age changes as the individual accrues more and more years of life. The attitude and the response of society to older citizens also change over time as their individuality and needs become more apparent through advocacy, political activity, and other consciousness-raising events.

Age of the members is only one parameter in the description of a population. Beyond the mere number of years lived, society will have to focus on the quality of life for those years. The technological ability to sustain life even when the individual is no longer able to breathe, digest food, maintain heart function, or even to demonstrate brain function is currently possible. Few would argue that an existence through attachment to a variety of these life-support systems for years would provide a satisfying quality of life. How society is to meet the needs of the new population for quality life is just now being defined. Randall (1977) has stated:

The greatest priority for older people is the ability and opportunity to create a quality of living that is consonant with an individual's wishes. This takes more than money--and often does not require money at all. It takes understanding of that which gives satisfaction in being alive ( $p .4)$.

Although a variety of factors may contribute to the satisfaction in being alive for any one individual, the ability to perform ordinary actions necessary for maintenance of life would seem to be a priority for most persons of any age. These so called "activities of daily 
living" are defined as routine functions usually performed on a daily basis (Carnevali \& Patrick, 1979). Activities such as bathing, dressing, moving around one's environment, retrieving commonly used objects from the environment, and feeding oneself are all considered activities of daily living. A relationship between limitations in an individual's physical condition and the ability to perform the activities of daily living is believed to exist. Ability to perform these activities requires a certain level of physical condition which may include the components of flexibility and strength.

Limitations in physical strength and flexibilicy can occur at any age; however, the normal process of aging does have some effect on the musculoskeletal system. These changes, summarized by Saxon and Etten (1978) include atrophy of muscles, loss of muscle elasticity, the loss of bone mass, and dehydration of vertebral discs. As a result of these changes, the older person may be expected to have less muscle strength, to move more slowly, and to have decreased capacity for sustained muscular contraction (Saxon \& Etten, 1978).

One's view of self and the perceived view of others toward one's self contribute to an individual's selfesteem. The term "self-esteem" has been defined as a description of an individual to himself of who he is, based upon an evaluation of his own roles in terms of their value 
to other people and to the society at large (Rosenberg, 1965). This definition of self-esteem includes more than a positive or negative attitude toward self. One connotation is that those with high self-esteem consider themselves "very good." Yet, another connotation is that they consider themselves superior to most others but inadequate in terms of certain standards imposed on themselves.

Many aspects of life have an impact on self-esteem and create stress in the older person. Losses, attendant grief, and the efforts of restitution characterize later life. Murray, Huelskoetter, and O'Driscoll (1980) have described old age as a time of psychological crises even in the presence of the more favorable socioeconomic and cultural circumstances. Social losses, some involving status and prestige, also influence the behavior and inner life of the older person. Socio-economic adversities may result from a decreased retirement income or from the inflationary spiral. Feelings of uselessness and of nonparticipation within society contribute to a further sense of loss.

What, then, is the interrelationship of how the older person views herself and her physical condition? Does high self-esteem correlate with good physical condition? or is good physical condition essential for high self-esteem? Beyond the current condition of the older person, is exercise related to changes in self-esteem and/or physical 
condition? Does exercise, as a habit in adult life, have any relationship to physical condition and/or self-esteem in the later years?

Although much research has been conducted regarding young and middle aged persons, relatively little has been conducted in regard to the older citizens in the United states. A computer search of the literature for this study produced limited results. With the descriptors "aged, retirement, and physical fitness," the result was 18 references. Combination of "geriatrics" and "self-esteem" resulted in one reference. When physical fitness, geriatrics, and self-esteem were combined as descriptors, the result was 0 references. Various combinations of these and other descriptors such as the term "health behaviors" resulted in very few additional sources.

The shift of the population toward increasing members of older people is predicted (U.S. Department of Commerce, 1980). Research in regard to the relationship between physical condition, self-esteem, and quality of life was deemed fundamental to the development of future health and education programs for older citizens by this investigator. If a relationship can be demonstrated to exist between the variables in this study, what can be done to promote physical fitness and self-esteem in the elderly? What implications does the health and well-being of the elderly have for the community college and other facets of society? 
CHAPTER II

REVIEW OF THE LITERATURE

This study investigates the relationship of selected measures of physical condition and self-esteem in older adults. Review of the literature emphasizes the physiological changes associated with aging especially in regard to muscles, strength, bones, vertebral discs, joint flexibility, physical reconditioning, weight, and sleep patterns. Psychological changes associated with age are considered with major emphasis on self-esteem. Measures of self-esteem and the interrelationship between physical condition, activity, and self-esteem are examined.

\section{PHYSIOLOGICAL CHANGES IN AGING}

Aging, the process of growing old, is a natural phenomenon that occurs in all living matter. While there are also pathological or abnormal conditions that occur concurrently with aging, the major interest of this study is the "normal" human changes that are evident as a result of growing old. Although changes in all systems of the body have been documented, only those changes relative to this study will be examined. The focus is on muscles, bones, and 
joints, and the effect of aging on mobility, strength, and flexibility. In an effort to better understand daily activity patterns in older persons, a brief review of age changes in sleep patterns is included.

Muscle

Rossman (1979) has described certain changes within the muscles themselves that can be identified with aging. Although maximum muscle strength is attained at age 25 or 30 , there is a gradual decrease in strength over time. This may be due, in part, to the loss of the number of active muscle fibers in the body and in the bulk of those fibers. Although oxygen utilization per unit of tissue is essentially unchanged, there is also a significant reduction in the activity of enzyme systems. There is a prolongation of contraction time, latency period, and relaxation period by an average of about 13 per cent and a decrease in the maximal rate of tension development. The decrease in motor function as a result of these physiological changes is compounded by poor motivation, deconditioning, malnutrition, and endocrine change. As a result of these interactions, changes specific to aging may be difficult to identify.

Muscle Strength

Muscle strength is usually referred to as the evidence resulting from a single maximum contraction. Compared with other measures of physical fitness in the 
aged, muscular strength seems to be retained for longer periods of time (Rossman, 1979). Yet, a progressive loss of muscle strength is characteristic of aging. Studies reveal a significant linear decrease in the average number of muscle cells which exceeds the relative loss of both neural components and total body mass. The number of capillaries per motor unit also is decreased (Carnevali \& Patrick, $1979)$.

Hand strength. In an early study, Burke, Tuttle, Thompson, Janney, and Weber (1953) examined the grip strength and grip strength endurance (using a hand dynamometer) of 311 males ranging in age from 12 to 79 years. Their data indicated a rapid increase in both strength variables from 12 to 25 years followed by a gradual decline across age which became more pronounced after 70 years. Petrofsky, Burse, and Iind (1975) have reported data on 83 healthy females, aged 19 to 65 , which also indicates a significant linear decrease in static grip strength as a function of chrononological age. Montoye and Lamphiear (1977) have reported similar findings in a study of males and females ages 10 to 59 .

Leg strength. Fitts (1981) has noted that the greatest loss in muscular strength with advancing age occurs in the leg and trunk muscles. He cautioned that age-related changes in body size and weight should be partialed out from age-based strength data. In addition, 
the effects of previous physical activity involvement, health status, variations in body dimensions, and other factors need to be carefully controlled if aging effects are to be interpretable (Ostrow, 1984). Body weight

In order to evaluate muscle strength as a part of this study, consideration was given to the factor of body weight related to normal aging. Whether overweight contributes to or detracts from survival is a continuing controversy. Most studies have been conducted on populations with abundant food supply and sedentary life style. When calories are abundant, a significant number of older persons can maintain an obese status. Hollifield and Parson (1959) studied 700 people over the age of 65 and found 11 per cent of the males and 16 per cent of the females to be 20 per cent or more above average weight for their height and age. They also noted a tendency for weight to plateau between 65 and 74 and to fall thereafter. Their data suggest that the incidence of overweight in this older group was at least as great as it is in younger adults. Hejda (1963) studied persons 82 to 100 years of age selected from the normal population and found moderate or severe obesity in 15 per cent of the older men and 21 per cent of the older women. However, most persons in the group studied had reached their maximum weight at around age 42 . 
There does seem to be some evidence in favor of the leaner person surviving longer. Master, Lasser, and Beckman (1960) found that for the 65 to 94 age group the percentage of underweight males in the population increased over the 30-year span from 20 to 50 per cent of the total group; during the same time span, the number of overweight men decreased from 40 to 10 per cent. For the same age groups, the percentage of underweight females increased from 20 to 55, with overweight females decreasing from 40 to 10 per cent. Thus, the indication is that those who are lean as they enter old age are more likely to survive longer than those who are overweight.

Bone

Bone is a complex tissue that undergoes change throughout life. Starting before age 40 in both sexes there is a shift from an increase in bone mass to a progressive decrease (Garn, 1975). This is characterized by gradual resorption of the interior surface of long and flat bones and a slower accretion of new bone on the outside surface. Thus, the long bones are externally enlarged, but internally hollowed-out; the vertebral end-plates are thinned, and the skull becomes slightly enlarged. At the same time, there is a loss of internal structure of the bone. As a result, the bone is weaker and more subject to fracture. 
One of the most significant age-related changes in bones is the loss of bone mass. Contributing factors to the loss of density and increased porosity of bones in the aged may be calcium deficiency due to bone resorption with age, possible age-related disturbances in protein metabolism, lack of regular and systematic exercise, and decrease in estrogen in the postmenopausal years (Spencer \& Lender, 1979). Thus, we find that the loss of bone mass (osteoporosis) is more common in slender, white, post-menopausal women than in white men, or black men and women.

Development of osteoporosis may lead to changes in back alignment. The bent or stooped posture of many older persons (called "kyphosis") and the "S" shaped sideways distortion of the spine (scoliosis) are likely to interfere with stability and balance, and thus impede locomotion. Other changes in ligaments, tendons, and bones of the skeleton also contribute to a bent or stooped body posture sometimes considered characteristic of the older adult. Vertebral Discs

Dehydration of vertebral discs leads to loss of stature, flexibility, and possible pain due to improperly separated vertebrae. Compression of spinal nerves can result from misalignment of the vertebrae. Commonly called "sciatica," this condition is painful and difficult to treat (Carnevali \& Patrick, 1979). 
Joints

Joints are surfaced with cartilage, which shows deterioration as early as the third decade. Graham (1973) attributed these changes to accumulated trauma which results in fraying and chipping. As the cartilage is eroded, the bone makes direct contact with bone and results in one form of degenerative arthritis with pain, crepitation, and limitation of movement. There is also loss of water from the cartilage, which results in a narrowing of the joint spaces, particularly of the intervertebral discs, and contributes to the loss of height. Flexibility

In addition to the development of muscle atrophy and thin joint cartilage, there is also the loss of muscle elasticity with aging. Flexibility, or adequate range of joint motion, is an essential ingredient in the physical fitness of older people. Certain age related changes do occur in connective tissue and tend to reduce ease of joint movement. These changes include increased collagen tensile strength, reduction in elastin production with advanced age, reduction of glycoprotein production and liberation resulting in dehydration of tissues and less ability to remove tissue debris (Vais \& Anasey, 1965). The literature (Adrian, 1981; Piscopo, 1981) suggested a gradual loss of range of joint motion because of the stiffer and less flexible tissues. When movement of joints becomes more 
difficult and even painful, reduced mobility usually results, because daily life as well as sports and other recreational activities require adequate range of joint motion.

Patterns of sleep

For purposes of this study, changes in patterns and need for sleep among the older population were considered important in evaluating subjects' habits of activity and rest. The daily habits of activity and rest have been shown to be related to self-esteem. Prinz (1977) has described the inability to sleep as a symptom of depression. The relationship of depression to low self-esteem has also been described by Kales and Kales (1972). Thus, the subjects' usual pattern of sleep and rest appears to have some relationship with the variables of self-esteem and, possibly, physical condition.

Kales and Kales (1972) demonstrated that human sleep patterns undergo changes with advancing age. Over-all, sleep becomes more fragmented, and awakenings during the night are longer and more frequent. All night electroencephalographic (EEG) measurements of the stages of sleep generally indicate that with advancing age there is a significant reduction in rapid eye movement (REM) sleep and a sharp decline in stage 4 sleep. Stage 4 sleep may be completely absent in some older individuals. 
Hales (1980) in a comparison between the "normal" sleep pattern of an eighty year old and a twenty year old defined the differences in sleep that occur as a part of aging. A twenty year old falls asleep in 8 minutes, spends 95 percent of the night asleep, sinks into deep non REM sleep for half an hour or more, and dreams for almost 2 hours of the night. Total sleep time averages 7.5 to 8 hours with no nap during the day.

The eighty year old, in contrast, spends one-fifth of the night awake. It takes eighteen minutes to fall asleep and the total sleep time amounts to six hours. Only a few minutes, if any time at all, are spent in stage 4 and only a little more than an hour in REM sleep. In addition, the older adult may experience numerous brief arousals. It is this frequent arousal that gives the impression of sleeplessness, even though in most instances actual sleep loss is minimal. Eighty year olds are more likely to take at least one nap a day when compared to younger adults.

Older persons are defined by Kales and Kales (1972) as needing nearly the same hours of sleep as persons at other stages of adulthood, thus the need for occasional naps. However, excessive sleep is judged to be abnormal. Kales and Kales (1972) have cautioned that when the older person gives a history of going to bed at 8:00 P.M. and trying to sleep until 7:00 A.M., something is amiss. It may 
be boredom, depression, or misinformation as to the amount of needed sleep.

Burnside (1981) has described the effects of depression on the sleep pattern in persons of all ages. The severely depressed person may have difficulty falling asleep or he may wake up early. In contrast, the mildly depressed person may seek additional sleep as release from the pressures causing the depression. Measuring Physical Condition of The Older Person Measurement of the older person's physical condition requires different limitations, modifications, and expectations when compared with the measurement of the younger person. Gallagher, Thompson, and Levy (1980) have described the older person's approach to physical activity as cautious and with lower expectations than that of younger persons. These authors found the elderly more susceptible to fatigue, less motivated and, possibly, more fearful of completing performance requirements for testing. In addition, losses in vision or hearing may lead to less understanding of explanations and demonstrations resulting in lower performance in a task. Ostrow (1984) has concluded from these findings that evaluation of actual changes in physical performance due to aging may be difficult to obtain because of the other non-physical conditions that may exist in any older individual and influence the findings. 
How the older individual views exercise and physical fitness is another variable that affects physical performance. Clarke (1977) has broadly defined physical fitness as:

the ability to carry out daily tasks with vigor and alertness, without undue fatigue, and with ample energy to enjoy leisure-time pursuits and to meet unusual situations and unforeseen circumstances.

Within the confines of this definition there are many elements of the individual which need to be considered. A holistic view of the older person is needed which includes consideration of the muscular strength and muscular endurance, cardiovascular-respiratory efficiency, flexibility, and neuromuscular integrity. Also, recognition of the effects of genetic inheritance, education, nutrition, sleep, mental attitude, and life style on physical status is critical when trying to separate out the changes that occur only as a result of aging (Ostrow, 1984).

While the evidence suggests age-related declines in various aspects of physical condition, uncertainty still remains as to how much change can be attributed to age rather than disease, disuse, or inactivity. The effect of bedrest on physical performance of even young subjects was demonstrated by saltin et al. (1968). They showed that three weeks of enforced bedrest resulted in marked cardiovascular-respiratory efficiency losses that were 
regained only after an intense period of retraining. The life style adopted by many Americans, both young and old, could often be described as "sedentary" at best. The older adult often has established a pattern of inactivity long before retirement. Thus, life style may enhance the physiological losses in physical performance due to age.

A variety of resources were reviewed in relation to assessment of physical fitness (Ebel, Neil, Bailey, \& Schechter, 1983; Ealls, Baylor, \& Dishman, 1980; Meyers, Golding, \& Sinning, 1973). Most provided a series of activities and testing situations to assess the cardiovascular, body composition, and musculo-skeletal system including resting and exercise pulse rates, step testing, skin fold measurements or underwater weighing, flexibility, range of motion, strength of upper and lower body muscles both by isotonic and isometric methods. The protocols required up to one hour to complete and some were designed to be conducted over several days. Most were designed especially for children or the younger adult. None was designed especially for the older person.

Jackson (pp. 203-234, 1983) in an extensive review of the literature has offered a functional evaluation of the elderly and organized the findings into groups. Each group is described as follows:

1. Basal Activities of Daily Living (ADL)-upper extremity function, hygiene, and dressing. 
The basal ADL appears to change least with age (Aniansson, 1980). However, the Framingham Disability Study (Jette \& Branch, 1981) found that the average healthy 75 to 84-year-old is likely to need more help to perform all basal ADLs except eating than persons 55 to 64 . The test for upper extremity mobility used four tasks which included: reaching for opposite big toe, grasping the earlobe on opposite side with arm in front of head, grasping the earlobe on opposite side with arm behind head, and fitting the hand between buttock and seat (Carrol, 1965).

2. Specific tasks were selected to test basic eating and food preparation activities and were labeled by Carrol (1965) as "Functional Kitchen Activities." The tests and the results are as follows:

pouring water from a jug to a glass was used to test forearm pronation in a power and precision activity. Among the elderly tested, 2.3 per cent of the men and 1.8 per cent of the women had difficulty in carrying out the water-pouring test.

The ability to lift a one kilogram packet onto shelves 140 to $180 \mathrm{~cm}$ high was also tested. It was found that 1.1 per cent of the men and 6.9 per cent of the women were not able to lift the glass and the weight to the shelf $180 \mathrm{~cm} \mathrm{high.} \mathrm{Complications} \mathrm{in} \mathrm{completing} \mathrm{the} \mathrm{task} \mathrm{include}$ 
the loss of height with age, locomotor/neurologic problems or positional vertigo with head/neck extension.

3. Sperling (1980) designed other tests related to activities of daily living. These included: mobility-rising from a chair (seated position), walking speed (as it related to pedestrian activity), and climbing steps (as it relates to use of public transportation).

Test of the rising from a chair was based on strength of elbow extension because many older persons may use upper extremities as assistance for this movement. The findings were that most elderly persons tested could assist themselves to a standing position if arm rests were available.

The walking test included asking the subjects to walk 30 meters unassisted. Walking speed correlated with height (taller persons tended to walk faster) but not with weight and that the average speed was $1.07 \mathrm{~m} / \mathrm{sec}$ (Petrofsky \& Lind, 1975).

Rosow and Breslau (1966) used a step test to determine ability to step onto public buses, etc. Steps of various heights were used and those up to $30 \mathrm{~cm}$ could be managed by all subjects without handrails. However, as the heights became higher more difficulty was encountered. For elderly women a positive correlation was also noted between maximum step height up/down without a railing 
and maximum dynamic muscle strength of the quadriceps muscle.

Rosow and Breslau (1966) also used a measure of

"Gross Mobility" in which they included the ability to perform heavy housework, walk 0.5 miles and climb stairs.

A substantially smaller number of subjects were found able to perform these activities than can perform all basal ADLs. Over three fourths of those 75 to 84 years old report that they are still able to climb stairs and walk at least 0.5 miles (note that these were reported rather than observed results).

PSYCHOLOGICAL CHANGES IN AGING

\section{Self-Esteem}

Many intrinsic factors play a part in the mental/emotional impact of aging (Carnevali \& Patrick, 1979). One's life history, personality, abilities, techniques for adjustment, past decisions, and regrets are carried into old age. Besides changes in muscle strength, elasticity, and flexibility described previously, a wide variety of other physical disabilities further deplete the older person. These losses frequently include losses in hearing, sight, physical attractiveness, and other vital elements of the individual's self image. In addition, there is the subjective awareness of aging, the deterioration of 
the body, the increasing rapidity of the passage of time, and the approach of death.

Rosenberg (1965) has defined the terms, "self-

concept" or "self-esteem" as how a person views oneself based on one's role in society and one's own evaluation of his/her value to other people. Within this definition there are two perspectives to consider. Although one may consider oneself better than most others, there is also the implication that the individual may not be quite equal to his/her own expectations or "ideal" self. Rosenberg's (1965) definition of high self-esteem follows:

the individual respects himself, considers himself worthy; he does not necessarily consider himself better than others, but he definitely does not consider himself worse; he does not feel that he is the ultimate in perfection but, on the contrary, recognizes his limitations and expects to grow and improve (p. 7).

According to Rosenberg (1965), low self-esteem implies self-rejection, self-dissatisfaction, self-contempt. The individual lacks respect for the self observed. The self-picture is disagreeable, and the individual wishes it were otherwise.

Rosenberg (1965) also studied how self-esteem was associated with certain socially significant attitudes and behaviors in the adolescent--participation and leadership in the high school community and concern with public affairs which may influence one's role as a citizen. The person with low self-esteem, according to Rosenberg, is more vulnerable in interpersonal relations, is relatively 
awkward with others and finds it hard to make talk, and does not initiate contacts. The individual is less likely to join in formal groups and become leaders in them and less likely to participate actively in informal group and assume positions of informal leadership. Thus, according to Rosenberg (1965):

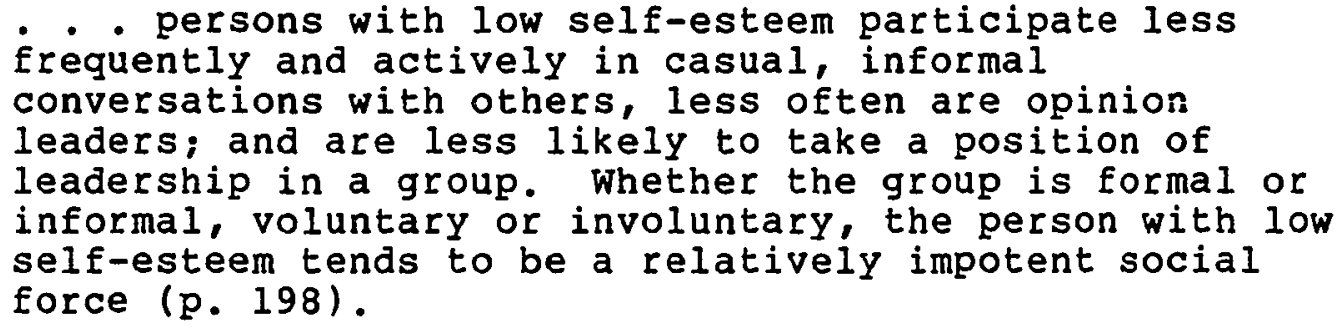

\section{Depression}

Varying degrees of mild depression may be observed in those with lowered self-esteem. Lowenthal (1968) suggested a possible cause to be reduced social and personal valuation and status in the aged. This loss of social and personal status may occur on the event of retirement and may even lead to a specific "retirement syndrome" affecting 10 to 20 percent of aged persons.

Parker (1978) in further discussion of retirement indicated that the loss of the work role may be perceived by the individual as a loss of personal value to society. These perceived and real losses coupled with the social isolation may result in a mild to moderate depression. Signs of depression include feelings of helplessness, sadness, lack of vitality, frequent feelings of guilt, loneliness, and boredom. In severe depressions, insomnia, 
early morning fatigue, and marked loss of appetite may be seen. Hypochondriasis and somatic symptoms are common. The implication is that some persons may suffer from a sense of loss and resulting depression on the event of retirement. Lowenthal (1968) has affirmed that most aged individuals have established repertoires of effective coping mechanisms which assist them in adjusting to the losses and stresses of old age. For some, though, defenses are not mobilized, are not adequate, or break down, and the individual responds with maladaptive behavior or even psychiatric disorders (Lowenthal, 1968).

Rosenberg (1965) showed a relationship between low self-esteem and depression. Those with low self-esteem scores were also more likely to appear depressed to others and more likely to express feelings of unhappiness, gloom, and discouragement. In Rosenberg's (1965) comparative study, only 4 percent of those with the highest self-esteem scores were "highly depressed." In contrast, eighty percent of those with low self-esteem scores fell into the highly depressed category.

Snyder and Swann (1978), in studies of the elderly, have stated that social labels and stereotypes of old age actually lead to lowered self-esteem and diminished feelings of control. Given that stereotypes and social labels are in a sense simple summaries of cultural expectations, such expectations might be assumed to affect 
all members of the culture, including those about whom the labels are held. If one's self-image and behavior come to portray these negative stereotypes (Langer, 1979; Rodin, 1978; Snyder \& Swann, 1978), self-esteem would decline. As self-esteem decreases, belief in one's ability to exercise control over the environment also declines. According to Rodin (1978) negative stereotyping is detrimental for all people. However, stereotyping is particularly harmful for the aged because they are a highly vulnerable population due to increased incidence of significant life changes and environmental strains.

Lack of frequent association with the aged causes many younger persons to consider the elderly person somehow "novel." Langer (1979) has shown that persons from relatively unfamiliar groups make others uncomfortable and are often avoided. These negative reactions are the result of a conflict that unfamiliar persons arouse in others. One the one hand, people are motivated to stare at unfamiliar or novel stimuli in an attempt to understand them. On the other hand, there are strong proscriptive norms that prohibit engaging in that very behavior when the novel stimulus is another person. The conflict is resolved by avoiding that person. For the elderly, this avoidance could also be experienced as abandonment. 


\section{Changes in Self-Esteem}

Just as many factors contribute to the development of self-esteem, a variety of factors can contribute to a changing self-esteem with age. According to Reichard, Livson, and Peterson, (1962) the relationship between financial status and adjustment in old age is far from simple. The psychological effect of an economic problem may be as important as the material effect. The psychological effects may be a sharpening of a sense of dependency or loss of status and self-esteem. A person's financial assets in old age may represent the measure of one's success or failure in life. The authors caution, however, that not all definitions of "success" or "failure" are the same. Some older persons may feel successful only if they are better off than their parents. Others may need much more in the way of material advantages to feel "successful." These authors also found that well adjusted subjects tended to be older than the poorly adjusted. Those individuals who were more satisfied with themselves in the past and with their position in the present were better able to accept growing old. Reichard, Livson, and Peterson (1962) have defined this acceptance as the ability to come to terms with those goals the subjects had reached, feeling that their lives had been essentially rewarding and worthwhile. 
Lieberman and Tobin (1983) studied 20 subjects regarding their self-image. The research focused on the ability of the elderly to maintain a stable self-image even in the face of highly adverse life changes affecting a wide variety of social, psychological, and physical functions. These stresses most commonly produced anxiety, depression, lessened feelings of well being, and diminished self-esteem in the elderly. Changes in physical functioning were also apparent under stress. In a study of stress reactions in the elderly, Lieberman and Tobin (1983) have described the physical deterioration and then death following the loss of a spouse in advanced old age.

Rodin (1978) has ascribed the negative self-concept held by some of the elderly to two primary sources. First, low self-esteem may arise from the many losses and changes they personally have had to endure. Second, poor selfesteem may also arise from the stereotype labeling and avoidance behavior by society in general because of a lack of understanding of the aging process.

Rodin (1978) further demonstrated that as self-esteem decreases, belief in one's ability to exercise control over the environment also declines. How one perceives herself as well as how others perceive her also affect the individual's behavior.

Rodin (1978) found that negative attributional processes deriving from feeling avoided and from feeling a 
loss of control can create at least two different types of problems for older people. These negative feelings may lower their number of coping attempts and thus detrimentally affect their health. First, there is a tendency to over-attribute most of their negative physical symptoms to aging per se, especially to the presumed physical decline with which aging is associated. Biological attributions may incorrectly focus the person away from situational and social factors such as the loss of a loved one or feeling unsafe. Rodin concluded that the focus on aging as the cause of all discomforts produces stress in the older adult because the discomforts are associated, in part, with a loss of control. Second, when events are attributed to the aging process, they are seen as inevitable; and remedial steps that could be extremely beneficial may not be undertaken. Negative self-concept in elderly persons further increases the likelihood that they will make damaging self, rather than situational, attributions in response to feelings that they are being avoided, or when they experience reduced feelings of control. Rodin (1978) cautioned that over-attribution to aging rather than to environmental sources coupled with the negative labeling process work together to decrease selfesteem and diminish active participation in life activities. Often this results in a lack of motivation to engage in a variety of behaviors, rather than an inability 
to do so. over time, and with disuse, the abilities themselves may also decline. Rodin (1980) found that restructuring the environment to make it more stimulating, and then motivating elderly people to increase their cognitive activity, leads to improvements in memory that are generalizable. While Rodin did not measure self-esteem directly, the findings were that experimental subjects were rated as "happier" and "more involved" following the intervention, and the subjects inferred that they were feeling better about themselves.

The earlier work of Rodin (1978) showed a relationship between feelings of control and health. When even relatively debilitated nursing home residents were given the opportunity to make decisions and to feel increased responsibility, thus potentially reducing their negative self-labeling, they became more involved, active and self-initiating, as well as considerably happier. In addition, they showed dramatic health-related benefits. This led the researchers to make the recommendation that there be increased opportunities for esteem building and self-control. This recommendation argues strongly for social change that provides opportunities for real control, not simply strategies that increase perceived control while options for actual control remain unavailable. 
Measures of Self-Esteem

A variety of instruments for measurement of selfesteem were examined by the investigator (Buros, 1974; Cattell and Warburton, 1967; Lake, Miles and Earle, 1973; Mitchell, 1973; Robinson and Shaver, 1980). Included in the overview were: Butler and Haigh, (1954) \& Sort Technique; Tennessee Self-Concept (1964-65); Bill's Index of Adjustment and Values (Adult Form) (1951); and Rosenberg Self Esteem (1965). Wylie's work (1974), The Self-Concept, exhaustively studied various instruments available to measure self-esteem. Her work was reviewed in regard to the concept and measurement of self-esteem.

Wylie (1974) has described the inherent difficulty in measuring self-referent cognitions and feelings in order to give a complete scientific account of human behavior. Wylie has contented that establishing the construct validity of the instrument is necesary because, by definition, the subject's cognitions and attitudes about self are private and beyond direct observation by the investigator. In common research practice, this self-report behavior has usually taken the form of a verbal response or some sort of a choice response when the subject is instructed to indicate specific conscious processes. Despite the many Iimitations, this method seems to be the only kind appropriate to this kind of construct (Wylie, 1974). 
Wylie (1974) has described the most commonly studied aspects of the phenomenal self as including such attitudes as self-satisfaction, self-acceptance, self-esteem, self-favorability, congruence between self and ideal self, and discrepancies between self and ideal self. It was her contention that these terms are not synonymous, even in a literary sense. She further described self-acceptance as meaning respecting oneself including one's admitted faults, while self-esteem or congruence between self and ideal self means being proud of oneself or evaluating one's attributes highly. Yet, Wylie has described other authors as presuming that self-acceptance is the conscious, realistic recognition of one's falling short of the ideal self. Wylie has described the instruments designed to measure specific constructs as being hampered by the intertwining and overlapping of poorly differentiated literary meanings as well as correspondingly poorly differentiated operational definitions. Thus, she has concluded that the constructs must be discussed as a group. Therefore, for purpose of this study, only measures of global self-esteem were examined by the investigator rather than other specific aspects of self.

Butler and Haigh (1954) Q Sort Technique: This instrument was interpreted by Wylie (1974) as an attempt to measure individual personality traits. subjects sort 100 cards which describe various aspects of personality by 
placing those adjectives which "are most like me" into one pile and those which "are most unlike me" into another pile. An additional sorting process involves placing the cards into piles labeled "I am" versus "what I would like to be." In the process of sorting the cards, the subjects describe themselves as they are and as they wish to be. Norms have been developed for age, grade, occupation, and sex based on a wide range of subjects. The process requires approximately one-and-a-half hours.

Wylie's (1974) evaluation of the Q sort technique was that the very small amount of available evidence gives some support to the validity of the technique as a measure of global self-regard. She found test-retest reliability to be .78. Robinson and Shaver (1980) found that convergent validity was demonstrated with correlation scores of -.61 between Tennessee Scale (1964-65) and a $Q$ sort.

With respect to discriminatory validity, Wylie (1974) found that correlation between $a$ sort and the self-ideal did not change for non-therapy subjects or for subjects awaiting therapy in the Butler and Haigh study (1954). The scale did not correlate with Guilford-zimmerman traits (1954) such as masculinity and objectivity. Predictive validity was demonstrated in the Butler and Haigh study (1954) in which the actual self and ideal self correlation increased with therapy. 
Tennessee Self-Concept (1964-65). Robinson and Shaver (1980) have described the purpose of this instrument to be measurement of an individual's self-concept in terms of identity, feelings, and behavior. It has been applied in a wide range of clinical and educational settings. In a 100-item test, subjects respond to self-descriptive statements on a one to five scale from "completely false" to "completely true" in an attempt to describe themselves. No data bearing on internal consistency was reported; however, test-retest reliability of the total score over two weeks was .92. Robinson and Shaver (1980) encouraged the use of several subscores to give a more complete picture of the self-concept. These same researchers also noted that the social desirability of the responses was not controlled.

$$
\text { Wylie (1974) took a negative view of this test }
$$

because of the non-independence of subscores. She believed this feature could lead to overinterpretation of profiles. Further, evidence has suggested that all subscores were not necessary. Wylie (1974) stated:

No justification can be offered, either from a priori analyses in terms of acceptable methodological criteria or from a survey of empirical results to justify using this scale rather than certain others which are available or better ones to be devised in the future (p. 150).

$$
\text { Coopersmith Self-Esteem Inventory (1967). Although }
$$
originally designed for use with children, this instrument has been used with all ages. It seeks to measure evaluative 
attitudes toward self in several domains with 25 items which the subjects scores according to the self-perception of "like me" or "unlike me."

Robinson and shaver (1980) found inter-item correlation for the short form to be quite low for college students $(N=453$, correlation $\underline{r}=.13)$. Convergent validity was described as .59 and .60 between Coopersmith short form and the Rosenberg (1965) for college students $(\mathrm{N}=300)$. other correlations for convergent validity between the Coopersmith short form and other scales are as follows: Bill's scale (1951), .46 and Cutick scale's (1962).37 (Wylie, 1974).

Correlation with Edwards' (1957) and Crowne-Marlowe's (1964) social desirability scales was demonstrated by Robinson and Shaver (1980) to be .44 which was considered a problem. This high correlation with social desirability and the fact that no systematic validation work has been done, coupled with the low intercorrelation between items, suggests that some further additions and selections of items might be useful. Yet, the instrument has been helpful in building a data base relating to how positive self-esteem might develop.

Bill's Index of Adjustment and Values (Adult Form) (1951). This instrument has been used by many researchers. Robinson and shaver (1980) found the reliability to be quite high. Evidence for convergent validity includes 
correlations with many different purported measures of self-regard--a wider range of such instruments than is the case for any other self-regard measure.

Although the degree of convergent validity of any of the self-regard scores from the Bill's Index of Adjustment and Values (IAV) has been found to be quite moderate, it was described by Robinson and Shaver (1980) as "good as for any other extant instrument which purports to measure global self-regard with the use of numerous items; " and the IAV is shorter and less cumbersome for the subject and experimenter than is true of a number of other instruments, e.g. the Butler-Haigh $Q$ sort technique (1954) and the Tennessee Self-Concept Scale (1964-65). Although variations in subjects and techniques do not permit definitive comparisons, there is some suggestion that the convergent validity of the simpler Rosenberg scale of self-esteem (1965) may equal or exceed that of IAV (Robinson and Shaver, 1980).

Rosenberg Self-Esteem (1965). This instrument is a brief, 10 item questionnaire which attempts to measure the self-cceptance factor of self-esteem. A Guttman scale reproducibility coefficient of .92 was obtained by Robinson and Shaver, (1980). Silber and Tippett (1965) found a test-retest correlation over two weeks of $.85 \quad(\mathrm{~N}=28)$. Silber and Tibbett (1965) found that the scale correlated from .56 to .83 with several similar measures and clinical 
assessments. Robinson and Shaver (1980) found the scale correlated .59 with Coopersmith's Self-Esteem Inventory. Rosenberg (1965) has presented considerable data about the construct validity of both this measure and selfesteem in general. Rosenberg (1965, p. 307) reported reproducibility of the self-esteem scale as 938 and scalability of items as 738 .

Rosenberg (1965) has related positive self-esteem to many social and interpersonal consequences such as less shyness and depression, more assertiveness, and more extra-curricular activities. However, many of these relationships were determined through self-reports.

In her evaluation of the overall usefulness of the instrument, Wylie (1974) stated:

All things considered, it seems that this scale deserves more research, development and application. One merit of its brief direct approach is that it does not assume that a group of items with heterogeneous content, chosen by the experimenter, and of variable and unknown salience to subjects may be summed to indicate global self-regard (p. 188).

Further support for the Rosenberg scale may be found in Wylie's statement (1974):

It is impressive that such high reliability is attainable with only ten items and that such a short scale has yielded relationships supporting its construct validity (p. 188).

Negative evalution of the Rosenberg scale included the fact that not much recent work has been done with the scale. The Guttman formula for scales has been strongly critized by Nunnally (1967) who argued that the small 
number of items and forced rectangular distribution of items in Guttman scales are artificial and likely to produce only gross, ordinal distintions among people.

INTERACTIONS OF EXERCISE, PHYSICAL FITNESS AND SELF-ESTEEM

Interaction of Exercise and Physical Fitness

Overall, the general mobility of older adults is impaired to some degree by connective tissue changes associated with age. Pickles (1983) has described loss of strength, loss of muscle and bone mass, changes in body posture, and loss of flexibility. All of these changes are similar to the physiological deterioration caused by inactivity. However, some physical changes are inherent with aging and independent of the effects of inactivity (Pickles, 1983). Even though the effects of aging will increase the risk and decrease the effectiveness of training, the feasibility and need for rehabilitation was accepted.

Exercise has been used by researchers with positive results in work with the elderly. It has been used both as a means of maintaining physical fitness and as a means of rehabilitation in cases where physical strength and flexibility have been lost. DeVries (1970) found that rehabilitation is possible in the elderly, and that older subjects respond very well to fitness training. More than 
200 men and women between the ages of 56 and 87 participated in a five-year study. He found that improved physical condition was evident even in those who had never exercised and in those who had not exercised since their teens. The fitness program combined walking, jogging, stretching, and calisthenics into a hour-long, three-times- a-week program. The subjects' physical condition, especially in the areas of cardiovascular, respiratory, and musculoskeletal function, was improved.

Frankel and Richards (1977) focused on the prevention of deterioration of physical function in the older population. They demonstrated that regular planned exercise slows many behavior-limiting changes that are bothersome to older persons. In particular, subjects reported fewer muscular aches and pains, less chronic Eatigue, and fewer problems with poor circulation.

Working with fifteen women between the ages of 65 and 82, Parks (1980) found that a program of exercise for onehalf hour, three times a week for ten weeks improved flexibility and decreased the percent of body fat and the heart rate. There was no improvement in blood pressure (systolic or diastolic), or in the subjects' anxiety level. His conclusion was that improvement in fitness for the elderly can be attained through participation in a physical training program of moderate intensity. Further, he concluded that with supervision, exercise can be safe and 
effective in reversing some of the physiological changes characteristic of aging.

Moore (1976), in work with 81 physically fit older adults, used established medical criteria for a definition of age adjusted fitness. Her findings were that continued participation in physical fitness and recreational activities along with specific health practices were linked to maintenance of physical fitness. Other factors that affected the level of fitness were nutrition, health practices: little or no use of alcohol, nicotine, drugs, and caffeine; an above average perception of fitness, health knowledge, self, and life satisfaction. The physically fit individuals also had a desire for more social interaction than did those less physically fit. She found that physical fitness and maintenance of health and strength can have definite bearing on the aging process of an individual.

Pickles (1983), in a summary of the biological aspects of aging as opposed to the changes resulting from disuse, clearly defined the need for prevention of dysfunction due to the normally occuring changes in the musculoskeletal system. He stated (1983):

The key to preventing the normal age-related changes from affecting functional capacity for ease of movement during the entire lifespan is gradually increasing adherance to a program of physical fitness (p. 35 ). Based on a wide variety of studies, Pickles further stated (1983): 
If skeletal muscles are used frequently, they show remarkably few structural changes with advanced age. The majority of changes noted in muscles of elderly persons are characteristics of disuse rather than age (p. 56).

Exercise program design. Reconditioning will improve muscle function and efficiency at all ages, but the increment of improvement clearly decreases with age. Pickles (1983) further described the importance of gradual retraining on the initiation of an exercise program for the elderly. He cited the importance of the subjects approaching the task in their own way and at their own speed, helping them to avoid mistakes in performance, and helping them to value the activity.

The development of strength in the elderly is slower than in younger persons, and the loss of any improvement gained is much more rapid in the older person than in the younger one. Thus, Pickles (1983) concluded that frequent, progressive, and continuous strength building exercises are important if the older person is to maintain and develop muscle strength. For maximum development of strength, exercise at very high intensity or force levels relative to the maximum is required. Although bouts of this intensive exercise should be repeated, the number of repetitions need only be low; two or three bouts of six to ten repetitions performed once a day usually is considered sufficient. 
Interaction of Exercise and Self-Esteem

Little research has been conducted on the interaction of exercise and self-esteem in the elderly. Mood, as one aspect of an individual's psychological response to the environment has been studied. Mood is defined as a temporary state of mind or feeling manifested by one's thoughts and actions (Thomas, 1982). Difference in the average mood between young and old adults does not seem to exist. Yet, exercise seems to produce acute positive mood change in both the elderly and young subjects. Sharkey (1979) found that subjects were significantly less tense and discouraged and more energetic after the activity session compared to the moods they reported before the session. Mood changes were also significantly greater in the exercise groups relative to the control group. However, the chronic mood effects of exercise were not demonstrated so clearly as the acute mood effects. Only measures of depression varied significantly among the activity groups. Sharkey's findings were attributed to the physical stimulation of the exercise session.

Similar findings were reported by Turner, Ward, and Turner (1979) in their work with depressed university students. In their study, students who participated in a fitness program showed significantly greater reduction in depression than the control groups. 
Shadow (1980) in researching the relationship between exercise and aerobic fitness to self-concept in $80 \mathrm{midale-}$ aged males found a significant positive relationship between self-concept and the weekly amount of exercise. However, he found no relationship between the level of aerobic fitness and self-concept nor between types of exercise and self-concept.

Parks work (1980) cited previously demonstrated that with exercise physiological changes characteristic of aging can be improved but that no change in anxiety level could be demonstrated. Research has not been identified by the investigator which directly focuses on changes in selfesteem attributable to participation in exercise. 


\section{CHAPTER III}

\section{HYPOTHESIS DEVELOPMENT}

Review of the literature and the experimenter's experience with older adults led to the development of various hypotheses that relate to physical condition, selfesteem and the relationship between them.

The ability to perform physical tasks as been demonstrated to decline with age. (Aniansson, 1980; Burke, Tuttle, Thompson, Janney, and Weber, 1953; Carrol, 1965; Fitts, 1981; Petrofsky \& Lind, 1975; Pickles, 1983; Rosow \& Breslau, 1966; Sperling, 1980); therefore, the following hypothesis was developed.

There is a negative relationship between age and the pre-test level of physical condition as measured by the hand grip and by the leg press.

The effect of bedrest and other forms of decreased physical activity has been demonstrated to affect the ability to perform physically (devries, 1970; Frankel \& Richard, 1977; Parks, 1980; Pickles, 1983; Saltin et al, 1968). Conversely, the physical condition of the older person can be improved through appropriate and moderate activity programs. The minimum frequency of participation 
in exercise to obtain material benefits was described as one-half hour, three times a week (deVries, 1970; Frankel \& Richard, 1977; Moore, 1976; Parks, 1980). Based on the relationship between exercise and activity and physical condition described in the studies cited, therefore, the following hypotheses were developed:

Those subjects who attend exercise sessions 75 per cent of the time (three out of four scheduled times per week), will show greater improvement on the post-test levels of physical condition as measured by the hand grip and by the leg press than those subjects who attend exercise sessions less than 75 per cent of the time.

There is a positive relationship between the self-described number of hours defined as daily "activity" and the posttest level of physical condition as measured by the hand grip and by the leg press.

There is a negative relationship between the self-described number of hours defined as daily "rest" and the post-test level of physical condition as measured by the hand grip and by the leg press.

Conrad (1976), in characterizing older Americans, suggested that they believed their need for exercise diminished and eventually disappeared as they grew older; tended to vastly exaggerate the risks involved in vigorous exercise after middle age; overrated the benefits of light, sporadic exercise; and underrated their own physical abilities and capacities. Older subjects evaluated as physically unfit by sidney and shephard (1982) prior to their participation in an exercise program also thought they were more active than others of their age group. No other research studies that specifically examined the 
attitudes of older adults toward physical activity were found. The following hypothesis examines the relationship of the subjects' attitude toward exercise and their actual physical condition:

Those subjects who accept a decreased need for physical exercise as one ages will show lower pre-test level of physical fitness as measured by the hand grip and by the leg press than those who accept the need for exercise as one ages.

A relationship between the need for physical exercise as one ages as described by the individual and actual participation in physical activities was not found in the literature. However, based on the previous works cited which describe the physiological need for exercise (deVries, 1970; Frankel \& Richard, 1977; Parks, 1980; Pickles, 1983; Saltin et al., 1968), its relationship to change in physical status as a part of aging, and the change in physical status as a result of physical activity programs for the aged, the following hypotheses were developed:

There is a positive relationship between the pre-test level of physical condition as measured by the hand grip and by the leg press and the distance of the residents' room from the dining room.

There is a positive relationship between the number of physically active recreational pursuits selected and the pre-test level of physical condition as measured by the hand grip and by the leg press.

Aging includes not only physical changes in the body but also the impact of all the foregoing life experiences 
of the individual. Among these life experiences is a series of regrets, losses, and a new awareness of one's own aging and the approach of death (Carnevali \& Patrick, 1979; Lowenthal, 1968; Parker, 1978). Further, these factors are associated with the individual's self-esteem (Lieberman \& Tobin, 1983; Rodin, 1978; Rosenberg, 1965; Snyder, 1980). The capability to live independently is only one of the losses experienced by the subjects in this study. This limitation in independent living was considered one of the possible reasons some residents moved into the retirement home. Further, some subjects also may have lost the competence to make decisions regarding their living arrangements, and/or families may have taken the responsibility for those decisions away from the older person. Perceived or actual control over one's life, according to Rodin (1978), has a critical impact on the older person's coping behavior. How well one is able to meet the demands of daily life is part of coping. The ability to meet these demands in a manner which is satisfying to the individual enhances self-esteem (Rodin, 1978). Accordingly, the following hypotheses were developed:

There is a negative relationship between length of stay in the retirement home and the pre-test level of self-esteem. For those subjects who state a level of control over selection of the retirement home, subjects who state much control over retirement home selection will have a higher 
level of self-esteem on the pre-test then those who state little control over retirement home selection.

Included in the coping mechanism of the individual is the ability to meet the physical demands of life, the so-called "activities of daily living" (bathing, dressing, moving around one's environment, retrieving commonly used objects from the environment and feeding oneself; (Carnevali \& Patrick, 1979). A wide variety of studies have been cited which relate to the changes in physiological status with aging and with inactivity (Aniansson, 1980; Burke, Tuttle, Thompson, Janney, \& Weber, 1953; Carrol, 1965; deVries, 1970; Fitts, 1981; Frankel \& Richard, 1977; Parks, 1980; Petrofsky \& Lind, 1975; Pickles, 1983; Rosow \& Breslau, 1966; Rossman, 1979; Sperling, 1980). In this study the physiological changes examined include: muscles, strength, bones, vertebral discs, joint flexibility, weight, and sleep.

The relationship between self-esteem and the physical ability to function within the environment was alluded to by Rodin (1980, p. 13) who stated, "As self-esteem decreases, belief in one's ability to exercise control over the enviroment also declines." Studies specifically related to the impact of loss of physical condition, aging, and self esteem were not found; however, the following hypothesis related to the relationship of these concerns is presented. 
The level of self-esteem and the level of physical condition as measured by the hand grip and by the leg press will show a positive relationship on pre-and post-testing.

\section{Larson (1978) found that good health (including} physical, mental, and emotional aspects) is the most important contributor to positive feelings of well-being in older Americans. Good health is a universal desire among the elderly and for them it also implies independence and the opportunity to live productive and longer lives (Falk, Falk, \& Tomashevich, 1981). Closely related to well-being and good health are the individual's self-concept and body image. There is a greater discrepancy between self-described body image and their real body among individuals who are inactive and unfit (Kreitler \& Kreitler, 1970; Shephard, 1978).

Some researchers have demonstrated a relationship between self-esteem, social behaviors, and depression (Rodin, 1978; Rosenberg, 1965). The literature also has shown a relationship between depression, anxiety, and physical complaints (Eromm, 1947; Horney, 1950; Rosenberg, 1965). Unless proven otherwise, however, physical complaints should be considered organic rather than psychological in nature. Yet, the factors of low selfesteem and depression may have some relationship with the motivation to participate in retirement home activities. 
The relationship between an aging individual's physical, mental and emotional status is complex. A wide variety of physical complaints are reportedly common in those with low self-esteem and/or depression (Fromm, 1947; Horney, 1950). Not only does a loss of self-esteem contribute to physical complaints, the loss of physical health contributes to a loss of self-esteem and a resulting negative attitude toward aging (Rodin, 1980); therefore, the following hypothesis is presented:

For those subjects who supply a reason for absence from exercise or lecture sessions, the number of times illness is used as an excuse will show an inverse relationship with the pre-test level of self-esteem.

Attendance at the lecture and/or the exercise sessions represents a voluntary matter on the part of the subject. According to Rosenberg (1965),

satisfaction of doing things with others. Now it is
obvious that if a person tends to distrust others and
if, furthermore, he assumes they dislike him, then he
would tend to avoid such groups (p. 202).
For the subjects in this study, there is also the consideration that they might be seeking to meet some personal need such as the need for special attention through attendance.

The underlying motivation for participation in the lecture and/or exercise sessions cannot be determined in this study. The actual participation in the scheduled activities, however, was expected to show some relationship 
with self-esteem. Therefore, the following hypotheses are presented.

There is a positive relationship between the pre-test level of self-esteem and the number of exercise sessions attended.

There is a positive relationship between the post-test level of self-esteem and the number of exercise sessions attended.

There is a positive relationship between the pre-test level of self-esteem and the number of lecture sessions attended.

There is a positive relationship between the post-test level of self-esteem and the number of lecture sessions attended.

In addition to attendance at lecture and/or exercise sesions, the subject's daily routine of "activity" and "rest" was examined for a relationship with self-esteem. "Activity" described in this study was that time spent by individual outside their rooms and presumably in association with others. "Rest," described as sleep, nap, or rest time, accounted for time spent away from association with others. These relationships were examined in the following hypotheses:

There is a positive relationship between the self-described number of hours defined as daily "activity" and the post-test level of self-esteem.

There is a negative relationship between the number of hours defined as daily "rest" and the post-test level of self-esteem.

Because self-esteem has been defined as one's view of oneself (Rosenberg, 1965) and the sum total of life experiences comprise that view (Carnevali \& Patrick, 1979; 
Rodin, 1978), the number of years one has lived has limited impact on the development of self-esteem. As a result, the following hypothesis was developed:

There is no relationship between age and the pre-test level of self-esteem.

The reasons that individuals cite for moving into a retirement home may or may not include physical condition. Lieberman and Tobin (1983) found that some individuals continue to live in their homes after good judgment would dictate that they seek assistance to maintain their current health status. They also found that continued, independent living could lead to accelerated deterioration of physical condition for these individuals. For persons with deteriorating health, moving into a retirement home with adequate nutrition, hygiene, and other support services available, may result in improved physical condition; concurrently, however, other individuals within the home may be experiencing gradual deterioration due to inactivity and age. The following hypothesis, therefore, is presented:

There is no relationship between the pre-test level of physical condition as measured by the hand grip and by the leg press and the subject's length of stay in the retirement home.

Because the programs of exercise and lecture were to be presented in the home, problems with transportation were deemed not applicable to attendance patterns of the 
residents. The residents in the homes were required to have mobility adequate to attend meals in the dining room and to maintain some level of order in their own rooms. As a result, the following hypothesis was developed:

There is no relationship between attendance at lecture and/or exercise sessions and physical conditions as measured by the hand grip and by the leg press.

The National Adult Physical Fitness survey (Clarke, 1973) revealed that when subjects were asked if they felt they were getting enough exercise, the percentage of those responding affirmatively increased with age. Likewise, the majority of older adults investigated felt that they engaged in enough physical activity for people their age. Sidney and shephard (1982) found that the physically unfit individuals felt that they were more physically active than others of their age group. The evidence suggests that as individuals age, there is a gradual development of increasingly negative attitudes toward the need and importance of physical exercise. Further, those who exercise the least feel that they are more active than those who engage in exercise more often. The older subject is also more likely to overestimate the workload of a particular activity than are younger subjects (Bar-or, 1977 ).

Based on the studies cited, therefore, the following hypothesis is developed: 
There is no relationship between the self-described daily activity level and the post-test level of physical condition as measured by the hand grip and by the leg press.

The network of relationships between the various hypotheses is complex. Although self-esteem is expected to have some relationship with physical condition and length of stay in the retirement home, no relationship is expected to exist between length of stay in the retirement home and physical condition. In contrast, both self-esteem and physical condition are expected to show some relationship with the reported hours of activity and rest. Participation in the exercise/lecture series also is expected to show some relationship with the levels of physical condition and self-esteem. 
CHAPTER IV

TESTING OF INSTRUMENTS

Testing of 13 residents in a non-participating retirement home was conducted using the Rosenberg selfesteem scale. A behavior-related self-esteem questionnaire was also administered as one step in instrument development and will be correlated with the Rosenberg scale in statistical analysis.

There were several purposes for pre-testing the instruments. First was the opportunity to practice the interviewing technique to to be used by the investigator and assistant with retirement home residents. The Rosenberg scale and the four-item questionnaire were read to the subjects. The ability of the interviewer to elicit an accurate response from the subject was critical. The concern was that subjects would respond only with a "socially acceptable" answer rather than with one that reflected their true feelings. A review of questionnaire results was then conducted to determine if adequate variation in scores on the Rosenberg and behavior-related self-esteem questionnaire could be obtained through the interview technique. 
The retirement home used for the pre-testing had 70 residents and, thus, was similar in size to the two homes selected for the study. It was located within the portland city limits. The operational aspects of the home were also similar to the study-selected homes in the provision of meals for all residents, drug administration service by contract, laundry, housekeeping and personal services.

Telephone contact with the retirement home administrator was made to ask permission for the conduct of the pre-test. After a brief description of the study, the expectations of the subjects and use of the information were given, the administrator agreed to allow the residents to participate.

Two members of the staff directed the investigator and assistant to a variety of resident rooms and remained within hearing distance during the interviews. Some interviews were also conducted in the dining room and lounge areas without the presence of the staff.

Both the investigator and assistant were able to establish rapport with residents in a short period of time and, thus, were able to enlist their cooperation in data collection.

Subjects. The age of the subjects in the pre-tested group ranged from 62 to 93 with a mean of 76.5 years. The length of stay ranged from one month to 96 months with an 
average length of stay of 22.5 months. Nine women and four men were interviewed.

Instruments. The self-esteem measures used in this study were the Rosenberg self-esteem scale and a four-item questionnaire developed by the investigator and believed to be related to subject's social behavior which is further believed to have some relationship to the subject's selfesteem (Rosenberg, 1965). See Appendix A for a copy of each of these instruments.

The Rosenberg scale contains ten direct statements regarding feelings about self. The subject indicated agreement or disagreement with the statements. The intensity of the subject's feelings were determined by asking about the strength of agreement/disagreement. Responses were immediately recorded.

The questionnaire with four items focused primarily on the subject's behavior in relation to others in the setting. Selection of the items was based on questions used by Rosenberg in determining the social consequences of low self-esteem in the adolescent population (Rosenberg, 1965). The items were reworded by the investigator to make them more appropriate for retirement home residents; yet, the intent of the newly stated items was to focus on similar social interactions described by Rosenberg (1965). Rosenberg (1965) lists a variety of questions designed to learn something about the nature and extent of 
the subject's network of social relationships in the high

school. These questions include:

"Does the student have a group of friends and acquaintances with whom he engages in ordinary day-to-day conversation? If so, does he speak up forcefully and emphatically in such discussions or is he the quiet one in the group? Do friends and acquaintances seek him out, ask his advice, solicit his opinion? Does he join school clubs. . ? Does he go out for the teams, . . work on the Yearbook. . ? Is so, what is his role in such organizations? Is it a dynamic, active role which catapults him into a position of leadership, or does he remain a passive member who goes along with the group? . . . . Is he an alert and lively participant who makes an impression on his peers, or is he one of the inconspicuous, nearly invisible, members of the class who simply occupies a seat?

Rosenberg's items (1965, pp. 191-217) and the

variations used in this study are presented as follows:

Rosenberg pp. 192-194: "About how many hours do you spend, in a average week, on extracurricular activities in school?"

hours per week

Since you entered high school, have you ever belonged to.. glee club or choir?

Yes

No

Variation: How likely are you to join in activities held here in the retirement home?

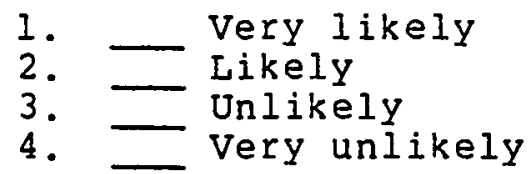

Rosenberg, p. 201: How often do you take position of leadership in high school group you are with?

1. Often or sometimes
2. $\begin{aligned} & \text { Rarely } \\ & \text { 3. }\end{aligned}$ 
Variation: How likely are you to be a volunteer to help with a party at the retirement home?

$$
\begin{aligned}
& \text { 1. Very likely } \\
& \text { 2. - Likely } \\
& \text { 3. Unlikely } \\
& \text { 4. - Very unlikely }
\end{aligned}
$$

Rosenberg (1965), p. 316): In discussions of public affairs, I think I would prefer to say nothing at all than to say somethng that will make people angry with me.

\section{Agree}

Disagree

When you and your friends discuss international questions, what part do you usually take?

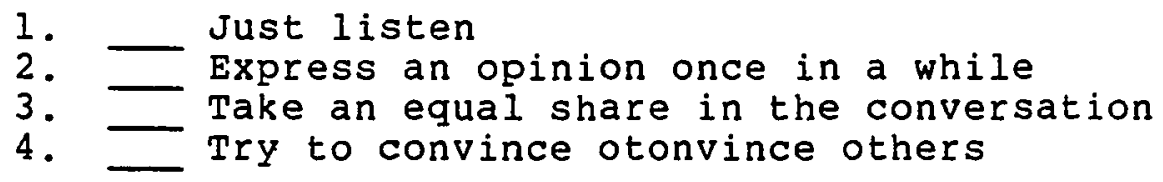

Variation: How likely would you be to express a personal opinion in a group discussion regarding a topic of interest?

$$
\begin{aligned}
& \text { 1. Very likely } \\
& \text { 2. - Likely } \\
& \text { 3. Unlikely } \\
& \text { 4. - Very unlikely }
\end{aligned}
$$

If someone new was seated at your table in the dining room, how likely would you be to speak first?

$$
\begin{aligned}
& \text { 1. } \begin{array}{l}
\text { Very likely } \\
\text { 2. } \\
\text { 3. } \text { Likely } \\
\text { 4. Unlikely }
\end{array} \text { Very unlikely }
\end{aligned}
$$

procedures. The scale and the questionnaire were read to the subjects by an assistant. This method of administration was selected for two reasons. First was the concern for the adequacy of vision in the subjects and secondly, the subjects' familiarity with filling out questionnaires was doubted. This particular age group was expected to have 
little positive experience in completing questionnaires or forms. (older citizen groups often complain of the complexity and difficulties older persons have in completing Medicare forms even though they are simple and require minimal factual information.) Difficulty in understanding what was expected of them and completion of the task were seen as complicating factors in gathering the self-esteem data. Further, motivation to complete the questionnaire without an individualized approach was thought to be minimal.

Although it was hypothesized that reading the scale and the questionnaire to the subjects would prevent these factors from complicating collection of data, the impact of direct questioning by the assistant on the subjects' responses was undetermined. Approximately ten minutes were needed to complete the two questionnaires.

The procedure for gathering the self-esteem data involved several steps. The assistant identified herself to each subject with her name and the fact that she was helping gather information for a study. She asked permission to question the subject. If permission was granted, she entered the subject's room and stated that she had a few questions to ask and that it would take only a few minutes of the subject's time. She then instructed the subject to indicate agreement or disagreement with the statements about to be read. The assistant would then read the 
statement. When the subject indicated a response, the assistant would then ask, "How strongly do you feel about that? Do you strongly agree (disagree) or do you only agree (disagree)?" The responses were recorded without comment and the next item asked. On completion of the instruments, the assistant thanked the subject and left the room. If the subject refused to allow the assistant or investigator to enter the room, the subject was asked if another time would be more acceptable. If the subject again refused, he or she was thanked and the assistant or experimenter left without further comment. of fifteen residents approached, two refused to participate in the pre-testing of the instrument.

The assistant maintained a uniform approach to subjects and presented the instruments in a uniform manner. Some subjects, however, needed the statement repeated and the assistant did so without elaboration. Some subjects seemed to need additional time to establish rapport. Rapport was deemed necessary in order to ensure that the subjects would share responses with negative connotations with the assistant. The variety of scores obtained suggests that the subjects responded to the items according to their true feelings and not according to what they might believe was "socially acceptable."

One of the major interfering factors in regard to completion of the instruments was deafness present in many 
of the subjects interviewed. Rather than reading the questionnaire to some of these persons, it was necessary to allow one or two to read and mark their responses themselves. The assistant remained present to answer any questions that might arise.

Results of the pre-Testing. The responses showed variation in self-reported feelings regarding self and behaviors with others. The Guttman and Likert methods were used to score the Rosenberg instrument, and the likert method was used with the self-esteem behavior instrument. No difficulties other than deafness of subjects was encountered. High scores on the Rosenberg self-esteem scale and the self-esteem behavior questionnaire whether scored according to the Guttman or the Likert scale indicate high levels of low self-esteem. The results of the Rosenberg self-esteem scale scored according to the Guttman method ranged from 0 to 3 (with a maximum possible of six). When scored according to the likert method, the range was from 10 to 27 with a maximum possible score of 40 . The mean was 1.32 with the Guttman method and 17.64 with the Likert method. When scored according to the likert method, the self-esteem behavior questionnaire scores ranged from 6 to 16 (with the highest possible score of 16) and had a mean of 10.21 .

The results of the limited pre-testing suggested that there was a desired variation in responses even when the 
instruments were administered by an assissistant reading the items and the subjects responding verbally.

Testing of the post-test questionnaire was conducted at another retirement home that was larger than either the original pre-test home or the homes used in the study. Four volunteers responded to questions verbalized by the investigator, and the responses were recorded. The post-test questionnaire focused on the reason for coming to the retirement home, daily activities, choice of recreational activities, and attitude toward exercise in relation to aging. The purpose of testing this instrument was to practice the examiner's interviewing technique and insure subject's understanding of the questions asked. 


\section{CHAPTER V}

\section{METHODOLOGY}

This study examined the impact of participation in a regular program of exercise on certain aspects of physical condition and self-esteem in the elderly. Orginally planned as a pretest-posttest control group experimental design, it was redesigned as a descriptive study when the randomly assigned groups became cross-contaminated during the period of implementation. A more complete description of the conditions causing the redesign is presented in the later section titled, "Rationale" (Study Redesign).

This study was designed to use subjects from two retirement homes with residents randomly assigned to one of three groups: experimental (exercise), control one (lecture), or control two (no intervention). subjects were pre- and post-tested.

SUBJECTS

The population identified for this study was adults over the age of 60 who resided in a retirement home. The subjects ranged from age 61 to 99 with a mean of 83.80 . Most had some physical or mental limitation that prevented 
them from living independently. Many had difficulty with mobility and walked with either a cane or a walker. Two were declared legally blind. Others suffered from a variety of chronic conditions including diabetes, heart disorders, arthritis, osteoporosis, Alzheimer's, and liver disease. While some had obvious physical or mental limitations in the ability to care for themselves, others appeared physically capable of living independently. Why those who appeared capable of independent living selected residence in a retirement home was undetermined.

Retirement home residents were selected as the study population in order to control for factors of nutrition, socialization, and, especially, transportation. Several studies (Heyman \& Polansky, 1969; Leinbach, 1977) cite transportation as a major concern for persons over 65 . It is clear that facilities and activities open to the elderly in the community can be useful only to the extent to which transportation is accessible.

Daniewicz (1974) discribed residential settings in a discussion of the need for community support systems. As the individual moves closer and closer to dependent living, the need for community service increases. Hospitals and mental institutions. were classified as farthest away from independent living. Moving away from the intensity of care and dependency found in hospital patients toward more independent living, he provided the following continuum: 
first, extended care facilities which require considerable nursing care, homes with less nursing coverage (usually titled "nursing homes"), boarding homes or group custodial care, and then independent living. According to this description, retirement homes would fall into the category of boarding homes or group custodial care. The retirement home provides a variety of services including meals, housekeeping, and personal care.

Lieberman and Tobin (1983) indicated that while only five per cent of the population 65 and older currently reside in institutions, this includes approximately one million Americans. Institutional type of living accomodation for the elderly is expected to expand in the future. These authors cited the lack of alternative services (such as housekeeping and meal services) in the community as a reason for this expansion. Further, they identified the fact that, with an older population that includeds survival to the eighth, ninth, and even tenth decade of life, one's children are themselves likely to be quite old and unable to meet the needs of dependent parents. The ease of access for testing and presentation of the program to the older population was also a consideration in the selection of retirement home residents as subjects for the study.

Two retirement homes were to be selected to increase the extent to which results would be generalizable. The 
homes were to differ in philosophy, style of administration and location within the city. Table I lists the criteria for selection.

The homes had to be located in the same district of the Portland metropolitan area to make daily visits by the investigator feasible. It was anticipated that considerable time for set up and clean up after each session would be necessary. Thus, homes in the northeast and southeast districts were considered first in order to reduce travel time for the investigator.

In order to standardize the living conditions of the subjects of this study, certain standards for the homes to be selected were established. The homes were required to provide a central dining area and at least the main meal for residents. These criteria were established to help ensure that the subjects would be adequately nourished. Additional consideration was that central dining would provide a minimum amount of socialization for all residents.

Another criterion was that general housekeeping, linen supply, and 24-hour supervision be provided. Common standards of service which address the needs of a certain population are more likely to attract those with common needs or desires and level of personal functioning. The residents of many retirement homes are called "frail elderly." This implies that they are no longer able to 
maintain their own homes and meet their own nutrition and safety needs alone. Yet, they are not so debilitated that they need 24 hour nursing supervision such as might be obtained in a nursing home.

One requirement established by the retirement homes was that the residents must be ambulatory, however, they may use crutches, walkers, or canes. Residents also had to be able to maintain some cleanliness and order in their own room. The minimum was that they were able to make their bed each day. Changing of linen was managed by staff.

Some residents may have difficulty meeting personal hygiene needs as previously discussed. These special needs were met by the home through a special contract with the resident.

Homes of similar size were needed for comparison. Residents in each home were to be randomly assigned to one of three groups. In order to assure a large enough data base for analysis, a population of approximately sixty residents was considered minimum for selection. Finally, consent of the administrators of the homes and a favorable attitude toward the study to be conducted were essential. Efforts were made to inform the home administrators of the general purpose and expectations of the study as well as what :rould be expected of the residents and of the staff. Seet Table I. 


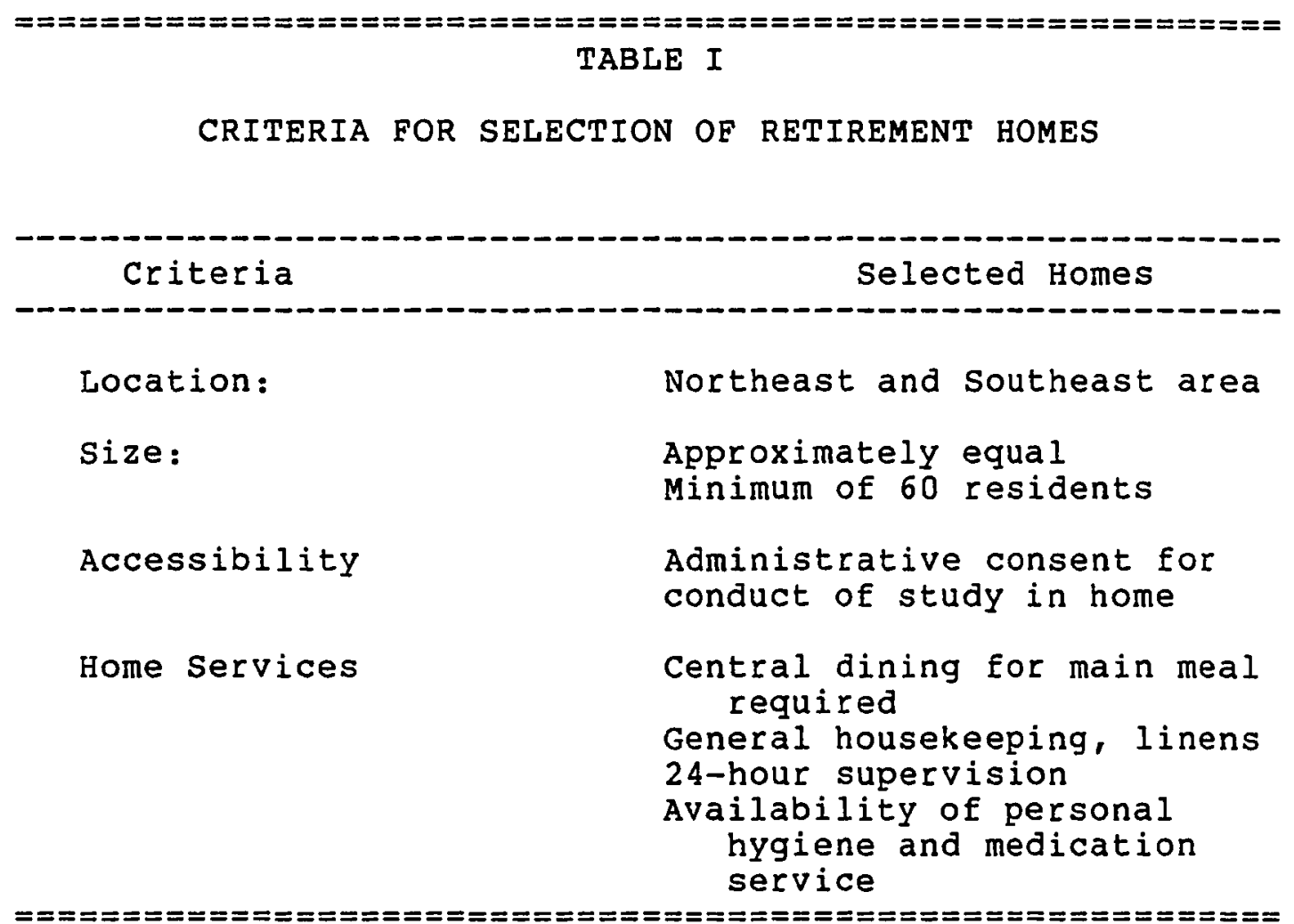

The telephone directory listed nearly one hundred retirement homes within the metropolitan area; however, only homes within the geographic area selected were considered. A total of seven homes which seemed to meet the above criteria were called. The administrators were then inteviewed over the phone about their possible participation in the study. Of those interviewed either in person or over the phone, one commented that they already had an extensive physical exercise program in operation. Two were not interested in becoming part of a study. 
Two other retirement home administrators agreed to participate in the study. However, upon a visit to the homes and discussion with the activity directors, it was determined that the residents were unable to respond to the questionnaires because of their mental condition. In addition, there was some concern that they would be unable to participate physically in the exercise program at the level planned for the study.

The prescreening resulted in contact with two administrators who expressed interest in participating in the study. The telephone conversation was followed by an interview with the head administrator who, in both instances, reaffirmed interest in participating. Tours of the facilities were provided, and suggestions for possible locations for the exercise and lecture groups were made. A general commitment was made by the administrators of both homes to cooperate in any way that they could to help the study succeed. Other visits to the homes provided opportunities to meet with the residents and staff, to discuss the study in a general way, and to ask for cooperation. Both staff and residents seemed interested although not too clear on what would be expected of them. Tentative dates for pre-testing, program implementation, and post-testing were established. 


\section{The Retirement Homes}

The homes differed in resident age, size, type of location, and underlying philosophy. The A home was a non-profit home owned and operated by the General German Aid Society. It was located near shopping, medical, and banking facilities, and city buses stop at the door. The immediately adjoining neighborhood was primarily business while across the street (a busy city arterial) there were modest, middle income homes. Large, well landscaped park-like grounds surrounded the home. The large dining area was on the main floor and looked out over a fountain and landscaped area. The rooms were roomy in appearance, newly refurbished with carpeting, white walls, and dark woodwork. Each room had an adjoining bathroom and large window. Monthly room rates were moderate for retirement homes, varying with size, and range from $\$ 505$ to $\$ 565$. This included: three meals per day, weekly maid service, all linens, and personal laundry if desired.

The step-wise development of the A home had led to various adjoining structures. The original building was three stories high and constructed of brick. The adjoining structures were constructed of wood siding painted brown with partial brick facing. Large windows were present throughout. The adjoining structures were connected by hallways. The distance to the dining room from many 
resident rooms was noteworthy (139 feet average) when the age and possible physical impairments of the residents were considered. The population in the $\mathrm{A}$ home included 68 residents, 22 men and 46 women.

The B home was a religious sponsored non-profit home located in a more residential area that had some proximity to a small shopping center. Blocks of older, white painted homes with grassy yards, flowers, and deciduous and evergreen trees surrounded the home on three sides. Bus service was available nearby. The building itself was of white stucco, two story construction in basically a long rectangular design. Two sides of the home were bounded entirely by sidewalks. One of these was adjacent to a major city street. While the A home had been newly refurbished, the B home had not.

According to the brochure published by the $B$ home, special emphasis was placed on the spiritual interests and needs of the residents. Daily devotionals, weekly Bible studies and sunday church were available. A pastor met regularly with residents regarding spiritual needs. The $B$ home had 56 residents, eleven men and 45 women.

Costs were deliberately kept as modest as possible in order that the $B$ home could be of service to all persons who desired residency there. The monthly cost for a single room in the B Home ranged from $\$ 490$ for a small room with 
no bath to $\$ 510$ for a larger room with a private bath. In comparison to other retirement homes, this cost was low. Resident rooms were brightly painted in a variety of colors, and the carpets varied from room to room. The building itself was quite old, and resident rooms were considerably smaller when compared to A home. Each room had its own window. Approximately 508 of the rooms had private bathrooms. The remaining either had a partial bath shared between two rooms or no connecting bath. Complete bathrooms including tubs were available for each three or four resident rooms. The building seemed to have been constructed all at one time so that the floor plan was primarily corridor style with rooms on both sides. There were a few rooms on short hallways extending to the west. The dining room was located in the basement but had a window wall on one side. The dining area looked out onto a small courtyard.

Both homes were primarily designed for single occupancy although some double rooms did exist. There was one husband and wife couple in each home. Both homes also provided a variety of large and small recreation and meeting rooms on each floor. Chairs and restrooms were provided at convenient intervals, and both facilities had an elevator for resident use. Residents could use either the home's furnishings or provide their own. 
Home $B$ had a regular activities director but Home $A$ did not. Efforts by the A home administrator to win approval for an activities director from her Board of Directors had not yet been successful although that had been a high priority for her. Both homes published a monthly calendar to show the various activities available each day and which was distributed to residents and posted in various locations in the home. Extra copies were also available for those outside the home who might be interested.

An intercom system was frequently employed to alert residents of ongoing or future activities. The speaker system was available only in the dining room of the A home. In the B home, the intercom system was connected to all rooms, recreation areas, and hallways. Each resident room in A home had a private telephone. Although several residents had private phones, most residents in the $B$ home used free public phones placed in a variety of areas throughout the home.

Three rather large central meeting rooms were provided in the $B$ home and were used frequently by residents throughout the day. They were furnished with davenports, overstuffed chairs, and television sets. One recreational room also included a pool table. The $A$ home had small lounges available in different locations throughout the home and provides television, library books, 
and lounge chairs. Some of these included refrigerator and stoves so that residents could prepare some foods for themselves or guests if they wished. The A home also had one large size room which housed the pool table and provided space for the home-sponsored exercise program and craft activities. The $B$ home had a craft room located in the basement and adjoining the dining room. Residents in the $B$ home did not have access to a stove.

By special arrangement, both homes did provide some drug administration to individual residents according to the standards set by the state of oregon. Personal care to include routine baths and laundry was provided to residents at additional cost. However, neither home provided nursing home care. In the event of serious illness or injury, the resident would need to move to a hospital or nursing home until recovered.

Staff members in both homes seemed to take considerable time to visit with the residents and provide emotional support. In some cases and without compensation, staff even provided personal shopping or otherwise met the special needs of residents who lacked family assistance. The families of residents were observed to visit during the times while the investigator was in the home. Those residents without visitors seemed to be those most advanced in age and those who simply had outlived their closest relatives and friends. 
The administrator for each home was salaried. Titles and distribution of responsibilities, however, varied somewhat betweeen homes. In addition to the administrator, each home averaged 14 staff persons per week. The distribution of part- and full-time workers was approximately equal between the homes with five workers with less than 24 hours per week in the $A$ Home and six in the $B$ Home. Categories of employees include cooks, maintenance workers, housekeepers, laundry workers, and personal care providers. Both homes provided staff supervision 24 hours per day. General observation of personal appearance was that the residents of $A$ home were usually better groomed than those of $B$ home. Contributing factors may have included a more equal male-female ratio, higher or lower socio-economic status, retirement home environment, peer pressure, or other unknown elements.

The rooms of the $B$ home were much more likely to have books stacked around in corners or a bird in a cage. The storage space in the A home rooms was much larger when compared to that in the $B$ home. Personal pets were not allowed in the $\mathrm{A}$ home.

The size of the rooms and the presence or absence of personal possessions complicated the physical assessments of residents. In the $B$ home, it was often difficult to find a place to position the chair so that the resident could do 
a range of motion movement without hitting some other piece of furniture. This problem was not encounted in the $A$ home.

The small size of the room may also have some effect on the physical condition of the residents in the $B$ home. In most instances, their physical condition seemed more limited than that of the residents of the A home. A home residents, by the sheer physical size of their rooms and the distance required to walk to their own bathroom and to the dining room, did get more exercise than $B$ home residents doing the same activities. Measurements taken of both homes showed that 22 of the 32 residents in the $B$ home participating in the study had less than a hundred feet to walk to the dining room whereas only 8 of the 33 residents in the $A$ home in the study had less than a hundred feet to walk to the dining room. Examples of differences between the two homes is provided below:
A HOME
B HOME

$$
\begin{aligned}
& \text { Smallest room (square feet) } \\
& \text { Largest room (square feet) } \\
& \text { Dining room (square feet) } \\
& \text { Median distance from } \\
& \text { resident room to dining room }
\end{aligned}
$$

81

Walking path

1530

1434

on grounds on city sidewalks

Program room (square feet)

387.5

882 
Pre-Test and selection of subjects.

pre-testing of the residents was conducted over a period of a week immediately preceding initiation of the exercise and lecture programs. At least three attempts were made to contact each resident for each of the two tests. If no contact could be made to complete all aspects of testing, the resident was excluded from the study. For a variety of reasons some residents of each home were not included in the study. The total number of residents, those included in the study and those not included, are presented below.

Total

Selected Excluded
A Home 68

32
B Home
56

32

$\begin{array}{lrr}\text { Husband/Wife } & 2 & 2 \\ \text { Too Ill } & 8 & 3 \\ \text { Refused } & 5 & 6 \\ \text { Not Found } & 18 & 9 \\ \text { Spoke No English } & 2 & 0 \\ \text { Younger than 60 yrs. } & 1 & 1 \\ \text { In Home for Meals Only } & 0 & 2 \\ \text { On Vacation during Study } & 0 & 1 \\ \quad \text { Total } & 36 & 24\end{array}$

The sample population did not include members from the black, Hispanic, or native American communities, and the only Asian subject was excluded because of high blood pressure. Although one home was established by a particular religious group, the residents represented a variety of 
religious beliefs. The other home also had persons of various religious preferences.

In preparing for the random assignment, difference in the subjects' length of stay in the retirement home was considered an important variable. It was believed that persons newly admitted to the retirement homes might be suffering from increased feelings of loss and possibly depression if, in the process, they were required to give up their long-time home. The effects of moving to an entirely new environment were thought to be disruptive for older persons and to have some effect on self esteem. ordinary attrition in the retirement home population occurs because of lack of resident (or family) satisfaction with the retirement home setting, improvement in whatever physical and/or mental condition of the resident that necessitated retirement home care, transfer to nursing homes or hospitals in the event of resident illness, or because of death. Difference in length of stay (LOS) of residents was apparent when comparing the two homes. The A home had been in the process of remodeling for the past two years and had allowed its population to decrease merely by not admitting new members following resident attrition. On the completion of the remodeling project, new members were admitted. This resulted in a large population of residents who had lived in retirement home $\mathrm{A}$ for eleven months or less, very few between 12 and 47 months and another large 
group of residents who had lived there for 48 months to 84 months.

In contrast, the B home population showed normal attrition and replacement. As a result, the $B$ home had very few residents who had been there 11 months or less. The remainder of the population in the $B$ home was more or less evenly distributed across time with the longest resident living there 108 months.

In order to control for the variable of length of stay, (LOS) a blocking procedure was used. This provided for comparisons among and between groups that were not necessarily equal in size but for which the variable of length of stay was controlled. Blocking was also included in relation to the $A$ home since some of the residents were identified as participating in an scheduled exercise program on a regular basis. These persons, identified as "chronic exercisers" were considered another control group in the $A$ home.

In each home, an experimental group (exercise) and two control groups (lecture and no treatment) were selected. Blocking was used as a technique to control for length of stay. Those subjects who had been in the retirement home for eleven months or less were considered as one block. This was dictated by the administrative action to limit the population in the $A$ home during 
remodeling. A second block of subjects who had been in the retirement home for more than twelve months was identified.

In the A home, fifteen residents who had been in the home for eleven months or less were randomly assigned to the three groups (exercise, lecture, and no treatment). Eleven residents who had been in the home for twelve months or more were randomly assigned to the exercise and lecture groups.

The group of seven residents in the $A$ home who were currently involved in their own daily exercise group were assigned to the lecture group. This was done to avoid interfering with their group activities or contaminating the effects of the exercise treatment of this study.

In the $B$ home, those five residents who had been in the home for eleven months or less were assigned to the exercise group. Twenty-six residents who had been in the home for twelve months or more were randomly assigned to all three groups.

Length of stay (LOS) measured in months was established for each subject. Numbers were assigned to each subject, and a grid was established for random assignment of subjects to one of the three groups. As a result of the blocking method for length of stay and retirement home, the groups established were composed of the following number of members: 


$\begin{array}{lccc}\text { Home } & \text { Exercise } & \text { Lecture } & \text { Control } \\ \text { A } & 13 & 13 & 7 \\ \text { LOS }<12 & (8) & (6) & (7) \\ \text { LOS } \geq 12 & (5) & (7) & (0) \\ \text { B } & 14 & & \\ \text { LOS }<12 & (5) & 9 & 9 \\ \text { LOS } \geq 12 & (9) & (0) & (0)\end{array}$

DATA COLLECTION

\section{Instruments}

Self esteem measures. The rationale for selection of the Rosenberg self-esteem scale was described in Chapter III. The Rosenberg ten-item self-esteem scale and the fouritem self-esteem behavior scale used in the instrument pre-test were used in the main study. (A copy of each of the self-esteem instruments is in Appendix A.) The same procedure was implemented and included the use of the same assistant. The use of an assistant to do the testing was considered of major importance because of the prolonged contact with the investigator during the treatment phase of the study. The relationship expected to develop between the investigator and the subjects during the course of the study would not, of course, have impact on the pre-testing for self-esteem. The eight weeks of frequent interaction with the investigator, however, was believed to have some possible effect on the responses of the subjects in regard 
to self-esteem. To prevent this situation from influencing the post-test responses, an assistant whom the subjects saw only during the pre- and post-test periods was used. Physical measures. The two instruments chosen for this study include an electronic scale by General Electric and a hand dynamometer manufactured by Lafayette Instrument Co. The electronic digital scale (General Electric Model EDS-1/B2) provided a specific factor in the assessment of the downward leg press. That is, the subject must be able to sustain downward pressure for a minimum of five seconds before a reading can be obtained. This prevents the subject from exerting a quick downward push that may cause an ordinary scale to indicate a high level of momentary thrust rather than the ability to maintain a sustained pressure. A sustained thigh muscle contraction facilitates rising from a sitting to a standing position (Ebel, Sol, Bailey, \& Schechter, 1983, p. III-7).

All subjects were examined in their own rooms. The investigator provided a straight backed chair for the subjects so that standardization of the leg press procedure could be attained.

Subjects were seated in the straight backed chair and instructed to allow the hands to hang freely at their sides and not to grasp the chair. They were also instructed to hum during the time of the downward press in order to prevent them from holding their breath. Breath holding 
during physical exertion is a problem because of certain physiological changes which occur in blood pressure, circulation, and heart rate. There is an increase in intrathoracic pressure, slowing of the pulse, decreased return of blood to the heart, and increased venous pressure (Thomas, 1982). The medical term for this action is the "Valsalva maneuver." In an older population with possible compromised cardiovascular system, these consequences of breath holding while exerting pressure were seen as possibly dangerous (devries, 1974; Shepard, 1978).

Measures were taken of the subjects while exerting presssure downward with both feet. This is a rather complex maneuver, and communicating all aspects of it to a hard-ofhearing person was difficult. Also, the ability to process this information seemed limited for some subjects.

The hand grip test was more easily accomplished. The investigator demonstrated the use of the hand dynamometer for each subject (Lafayette, Model 76618, Lafayette, IN). The subject was instructed to allow the arm to extend downward and then they were asked to "squeeze it" as hard as they could. The measure of each hand was taken. Repeated measures demonstrated that the first attempt was usually the best. Fatigue became evident by the third attempt when the value attained was two or more kilograms less than the first measure. Some residents were unable on any attempt to raise the indicator to even one kilogram. These persons 
also seemed debilitated in other ways, and the lack of hand grip strength was deemed consistent with apparent lack of general physical strength.

Body weight was measured on a General Electric electronic scale. Some difficulty was identified in this measure since the scale was designed to record the weight attained after a period of five seconds. Some individuals were so debilitated that they were unable to step onto the scale and release the hold on a walker or other support for five seconds. Thus, the potential for error in this measure was identified. The question of validity was recorded for subjects who experienced this difficulty.

Additional measures of flexibility of the head/neck, shoulder and knee were attempted in the pre-test. In spite of the frequent use of these measures in physical therapy settings, there was no reproduceability of findings in this study. As a result, these measures were abandoned. Full discussion of these procedures and results is presented in Appendix B.

Determination of physical measures was usually accomplished within ten minutes. However, the difficulty in communicating with the hard of hearing was also evident in these measures and particularly in the leg press. As a result, additional time was needed to instruct this type of subject and to gain his/her cooperation. 


\section{Other Measures}

A post-test questionnaire in addition to the other measures was used to determine the subject's perceived level of control in selection of the retirement home. Each subject was asked, "Why did you select this retirement home?" The answers were categorized into three groups: those who stated some level of control in home selection, those who did not, and those whose answers could not be determined as belonging to either the control or no control group. Even with additional questioning, some persons' responses to the questions were unspecific and level of control was undetermined.

From a provided list of ten recreational pursuits, the subjects were asked to select three that were the most likely to be done. The list contained five active and five inactive categories. For reporting purposes, only the recreational pursuits considered "active" were counted. Thus, the minimum score would be zero for no active pursuits chosen to three for all active pursuits chosen. The choices available to the subjects included:

Active
Visiting
Eating in a Restaurant
Shopping
Walking
Exercise

Active Inactive

Resting Reading Watching Television Crafts (while sitting) Listening to Music or Playing an Instrument 
In addition, the subject was asked during the post test to describe activity level in relation to other persons of similar age. The responses included: "very inactive, inactive, active, very active." Points were assigned to each response with "very inactive" receiving one point. Each increasingly active response was awarded respectively two, three, or four points with "very active" receiving the highest score (four points).

The subject's attitude toward the need for exercise was obtained by asking about agreement or disagreement with the Eollowing statement: "The body's need for physical exercise decreases as one grows older." Scoring of these responses included the awarding of points. Those who "strongly agree(d)" were awarded one point on a scale of one to four. Those who "strongly disagree(d)" were given four points.

Effectiveness of program publicity was also evaluated by asking about awareness of the health program being presented in the home and session attendance.

In addition to eliciting responses to specific questions, the subjects were asked to "Describe your usual daily activities." Beginning with arising time, the subject was taken through the day's activities by asking, "What did you do next?" or "How long did it take you to do that?" The 
responses were recorded in 15-minute intervals. Post-test questionnaires are in Appendix $A$.

Daily records regarding each session were kept by the investigator. Included were comments regarding the types of activities, topics discussed, and responses of subjects. A copy of this record is included in Appendix $C$.

\section{TREATMENT}

Upon the completion of random assignment to groups, the the subjects were notified of the group in which they had been placed. This was done by placing cards with each subject's name on it at his/her table place with an invitation to the appropriate session and providing information regarding time and place. The cards were color-coded; blue for the exercise group, red for the lecture group, and yellow for the control group and non-participants. The reaction of the residents was one of interest and some excitement. They compared the various colored cards as to content and identified who of their friends were involved or not involved. Persons who were either assigned to the control group or who were not included at all were given cards thanking them for helping with the study. In this way, all persons were acknowledged and thanked for their participation and/or interest in the study. 
Then the treatment phase of the study began. Using the original study design, two actual treatments were administered, exercise and lecture. Program Presentation

The program presented consisted of an exercise and a lecture period conducted in each retirement home for onehalf hour, four times a week on Monday, Tuesday, Thursday, and Friday. The A home exercise and lecture presentations were held in the library, one of the small rooms provided for resident use. It was located at the end of a hall on the same floor as the dining room and some resident rooms. Exercises were done from 9 until 9:30 A.M. The lecture sessions were held from 10 until 10:30 A.M.

In order to avoid contamination of the exercise and lecture groups, it was necessary to separate the leaving of one group from the arrival of the other. In addition, it was believed that some subjects would want to visit either with each other or with the investigator. For these reasons the groups were separated by a time interval. A half-hour interval was selected to allow for a period of socialization with subjects from either the exercise or the lecture groups without encouraging intermingling of the two groups. Also, one resident was unable to walk the distance from her room to the library. Consequently, the investigator needed to bring the subject by wheelchair to 
the lecture session. This also was done during the time interval between sessions.

The B home exercise and lecture presentations were held in the afternoon. Exercises were done in the recreation room from 1 to $1: 30$ P.M., and the lectures were conducted in the same room from 2 until 2:30 P.M. While some residents in the $B$ home needed much assistance to be seated, none needed transportation by wheelchair. The recreation room was adjacent to the dining room in the basement of the home.

The times for the programs in each home were selected to avoid conflict with ongoing activities and were presented at a time when residents would be most likely to participate. In the A home, however, the exercise session was scheduled to conflict directly with the regularly held, home sponsored exercise program. Because the study was to be conducted for only eight weeks, it was important to maintain the integrity of the on-going group. Also, it was important to keep chronic exercisers out of the study's randomly assigned exercise group. Although the exercise sessions did follow regular meal times by one half-hour in both homes, the possible negative effect of exercise following food intake by less than two hours was considered minimal. The exercises planned were of a limited nature and did not seriously challenge the cardiovascular system of even this older population. The focus of the exercise was 
on strength building and flexibility and not on the development of endurance.

Exercise Program

The exercise program utilized Peery's (1976) range of motion exercises and the Frankel and Richard (1977) program of exercise for older adults. Peery's (1976) exercise program was specifically designed for the older population and stresses a system of movements including circles, lifts, stretches, swings, and twists of joints and body parts. Its design promotes flexibility and full range of motion of joints without extreme stresses on the individual joints and muscles. Conducted within the self-imposed limits of the participants, there is little or no danger of injury or other adverse effects for the older adult attempting to complete the series of exercises. The exercises are all performed while the participant remains seated in a chair.

In a similar manner, the Frankel and Richard (1977) program provides a series of more vigorous exercises that may be performed either in a chair or standing with chair support. Both programs stress the importance of performing all activities within the level of comfort for the exercisers. The pace and number of repetitions were adjusted to individual needs of group members.

progression. The progression of exercise was from chair sitting to standing with chair support. In addition, 
the subjects were directed to increase the number of repetitions progressively. The Peery (1976) exercises including circles, lifts, stretches, swings, and twists were always used in the exercise sessions. Initially, they were used as the only activitiy until the ability of the group could be assessed. Later, the number of repetitions and the intensity of the exercises were increased as the tolerance improved. Standing exercises were introduced cautiously. Careful assessment of each member's ability to participate was made with each exercise (whether Peery's or Frankel/Richard) but especially with the Frankel/Richard (1977).

Seating arrangement. Subjects were arranged so that eye contact was maintained with each person and the investigator. Clear visualization of each subject during the exercise period was held essential so that any adverse effects of activity could be identified early and action taken to protect the subject.

Safety. Difficulty in performing standing exercises even with chair support was particularily evident in the $B$ home. Upon the first attempt at standing exercise, several residents were so unsteady that their safety seemed jeopardized. Unwilling to single out certain residents as "less fit" than others and, thus unable to do a major activity, standing exercises were not used until later in the program when the safety of these residents could be 
maintained. Residents were always encouraged to do only what they were "comfortable doing," and some were directed to stop or to do a substitute activity when a problem was apparent. Total exclusion from these standing exercises, however, seemed to be so discriminating that it was believed that individual self-esteem would be negatively affected.

Subjects' inability to perform the exercises were related to lack of strength, flexibility, and endurance. The variety of balls used for hand strengthening exercises were introduced primarily to accomodate the levels of hand strength found in the subjects. Those subjects suffering from lack of flexibility and, thus, limited in performance of even Peery exercises, were encouraged to do as much of those activities demonstrated that were "comfortable." Appropriate adaptation of the exercise was encouraged so that subjects could perform but within their own limits. All subjects were told that should they become tired or short of breath, they should stop an activity and rest. The positive aspect that exercise should feel "good" was repeated frequently.

Exercise presentation. Each exercise was demonstrated before the group participated, and names were given some activities to enhance recall. Efforts were made to use past life experiences as part of the activities. For example, one exercise designed to increase hip extension (from the 
chair sitting position) was described as riding a scooter up hill. The subjects sat sideways on the chair, positioned their hands as though holding onto the handlebars of a scooter. They were then directed to move the outside leg from the front to the back (hip flexion to hip extension) as though pushing themselves up a hill. After three repetitions of this movement, the subjects were told to put both feet together and to "hold on tight" as they would bounce on the chair and "ride down the hill." In a similar manner, swimming and skiing motions were imitated with appropriate verbal prompts.

Use of props. Different kinds of props believed to increase interest and provide for strength building and flexibility activities were also used. Soft balls were provided to assist in the development of hand strength. Cloth balls stuffed with foam rubber were "kneaded like bread dough." Handballs (approximately 2.5 inches in diameter and made of soft rubber), and toy footballs (approximately six inches long and made of plastic) were squeezed with either fingers or thumbs. These handballs and footballs were also used to press down upon in an attempt to improve leg press strength. The residents demonstrated a great deal of concern about "throwing balls." Most expressed the fear that they would be hurt if they didn't catch them. So, activities were confined to holding and squeezing the balls, and no throwing was allowed. 
Wands, scarfs, and gloves were also used to provide variety and encourage participation. All of the regular exercises could be adapted to use one or another of the props. Props were rotated weekly with the balls and one other prop being used each day. Outline of the exercise program with specific exercises and props is presented in Appendix D.

\section{Lecture Program}

The lecture program was a series of planned presentations based, in part, on requests by the subjects. The first meeting explored a variety of health topics hypothesized to be of interest to retirement home residents. Additional topics were suggested by members of the groups. As a result, a program of health topics of particular interest to subjects of both groups were researched and presented in a lecture/discussion format. The lectures were supplemented with handout and audiovisual materials as available.

Topics. The topics included for discussion were: hypertension, heart disorders, diabetes, bone and joint disorders, vision and hearing problems, digestive, kidney, and bladder disorders. There was no attempt to pre- and post-test for knowldege. The primary purpose of the lecture program was to provide the same amount of contact hours as the exercise program and, thus, to provide control for the 
Hawthorne effect. An outline of the topic presentations with objectives is presented in Appendix E.

Seating arrangement. The residents were seated in rows with accommodations made for those in walkers or wheelchairs. Every effort was made to maintain eye contact with each subject during the presentation. Questions were encouraged. The house intercom was used in the $B$ Home to enhance communication. No microphone was available in the $A$ Home. However, the A Home residents complained less about not being able to hear.

Use of visuals. Slide presentations and flip charts were the most commonly used visual aids. Flip charts were especially valuable because of the problem of deafness encountered in this population. The visuals assisted in clarifying the material being discussed, provided for quick review when topics were discussed for more than one day, and seemingly were enjoyed by the residents.

Refreshments

Refreshments for both groups were planned by the investigator to encourage praticipation. However, the administrator in the $B$ Home asked that treats not be provided on a frequent basis. His concern was that the residents would then expect refreshments whenever volunteer activities were presented. He also had some concern that the nutritional needs of the residents could be better met by the home. Frequently, snack foods such as biscuits, 
toast, cookies, muffins, etc. were placed in the recreation room by the kitchen staff for the B home residents. Coffee, tea, and juice were also available. The $\mathrm{A}$ home did not leave food out for residents. However, at 3 P.M. each day, the home provided "coffee time" for residents in the dining room. Treats were also sometimes provided. The plan for frequent refreshments for participation in the program was revised to include an initial and a concluding party.

\section{REVISED DESIGN}

Certain limitations of the original design became evident as the investigator began to work with the subjects. As a result, the study design was revised to be descriptive. The original set of hypotheses was restated to reflect the change from experimental to descriptive design. An additional set of post hoc hypotheses was developed. Rationale

Following the pre-testing and upon initiation of the exercise and lecture groups, many residents did not want to participate. A variety of motivating activities were initiated. Individualized invitations were distributed at the meal just before the sessions were presented. Subjects' names were learned and used frequently to provide personalization in the program. Subjects were invited to contribute to the exercise session by describing personal experiences that were satisfying and enjoyable in regard to 
the activity. Some did suggest new exercises which were then incorporated into the sessions. Personal experiences in regard to the lecture topics were shared and discussed. Subjects randomly assigned to groups but who were not participating were approached individually and reinvited to attend. The usual response was, "No, I'm not interested." Every attempt was made to see these subjects frequently and to maintain a non-threatening relationship with the hope that eventually they would choose to attend and participate. However, these efforts did not increase attendance by randomly assigned subjects.

Concurrently, however, persons other than those randomly selected began to join the groups. Members of the control and exercise groups and even some residents not included in the study began to attend the sessions. The lecture session, overall, was the more popular program of the two offered. This occurred in both retirement homes. One element that may have contributed to this selfselected participation was the fact that the rooms used were those commonly available to residents throughout the day. Another may have been the communication of subjects with non-subjects at meals and other times through various home activities. Exercise was more often rejected by the subjects selected as members of the original exercise group. Also, exercise was less often selected by those not 
initially selected for participation in the study and by

those in the lecture or control groups.

In order to identify more clearly the pattern of

attendance of all groups, the attendance during week one of

the program is presented.

Attendance Week One

A Home Exercise

$\begin{array}{ccc}\text { Originally } & \text { selected } & \text { Self-Selected } \\ \text { Selected } & \text { Attended } & \text { Attended }\end{array}$

Monday

Tuesday

Thursday

Friday

13

13

13

13

$\begin{array}{ll}5 & 0 \\ 4 & 0 \\ 5 & 0 \\ 4 & 0\end{array}$

A Home Lecture

Monday

Tuesday

Thursday

Friday

Monday

Tuesday

Thursday

Friday

Monday

Tuesday

Thursday

Friday

\section{3}

13

13

13

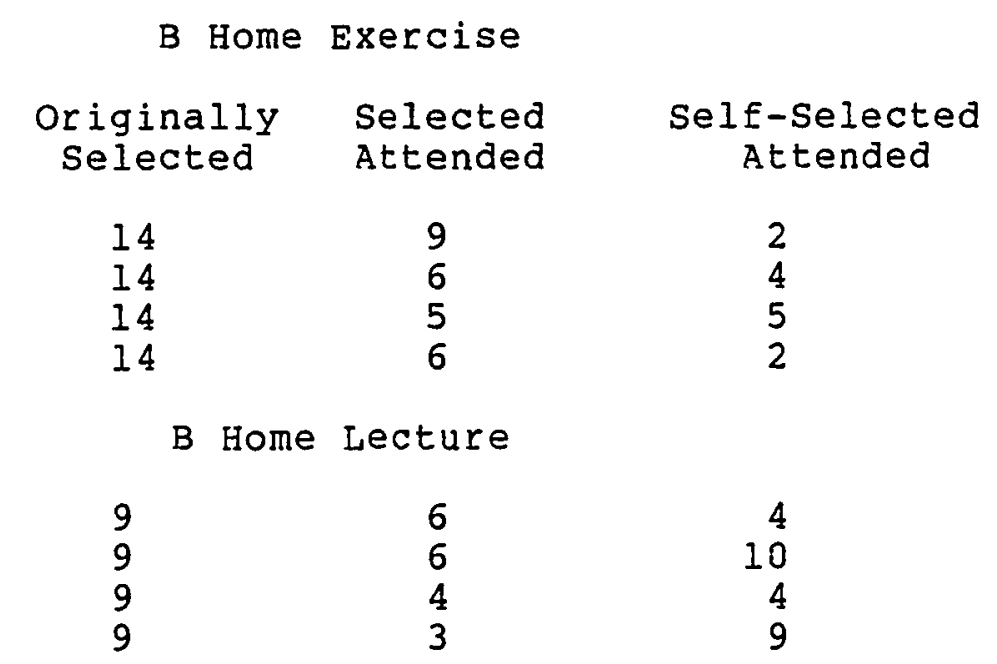


Revised Design

Because the original randomly selected members of the groups were not attending, the study was redesigned to be descriptive. Persons who attended either the exercise and/or lecture groups were invited to come again. No effort was made to exclude any who wished to participate. Invitations were written for each new person who attended and placed at his/her tableplace for the meal preceeding the sessions. Again, names were learned and used to personalize the program for these new members.

Persons who had been randomly selected but who chose not to attend were no longer given invitations until and unless they did, in fact, come to a session at a later time. The intercom system in both homes was used to announce the time of the sessions and to invite all residents to attend. As new residents moved into the homes, they, too, were invited through personal invitation to attend the sessions.

One particular precaution was used in the invitation to new persons to attend. Those who had been excluded because of health reasons identified on pre-testing or had not been pre-tested at all were encouraged to attend the lecture rather than the exercise sessions when they began to participate. 
post-Testing

As new subjects began to participate in the study and others dropped out, it became apparent that some pre-and post-test data would be unavailable. Some subjects who had been tested and selected now refused to participate. The result was incomplete data for some subjects. Treatment of the Data

The data were analyzed using the Radio Shack TRS-80 home computer program for advanced statistical analysis (26-1705). Because documentation of the correlation formulas used was not available, tests of the program results were conducted by comparing the results of the computer data analysis with samples provided in the Hinkle, Wiersma and Jurs (1979) text, Applied Statistics for the Behavioral sciences. No differences in the correlations were found. 


\section{CHAPTER VI}

\section{FINDINGS AND DISCUSSION}

The purpose of this study was to examine the relationship between self-esteem and physical condition in a retirement home population. Further, the study sought to determine if a regular program of exercise had any effect on the existing physical condition of the subjects.

The original experimental design of the study was changed to a descriptive design when the randomly assigned subjects began to participate in the study in ways other than their originally assigned roles. Lack of random sampling made analysis of the data using inferential statistics technically inappropriate. Such analysis of these data, however, was conducted in an effort to provide direction for further study regarding the relationship between self-esteem and physical condition of retirement home residents.

This chapter presents a general description of the sample and statistical analyses of the data from both the physical and the psychological measures. In addition, an analysis of the anecdotal data collected by the investigator is included. 
The unequal number of subjects for whom pre- and post-test data were available resulted from two major events. Some residents of the retirement home originally were not included in the study or were not tested because they were not available or did not meet the criteria of age ( $\geq 60$ years), physical condition, or willingness to participate. At some point in the treatment phase, however, they began to attend either the lecture or exercise sessions and were willing to participate in the post-test measures. Another factor contributing to the unequal numbers was the fact that some subjects who originally participated in the pre-testing were not available for post-testing. Five of the originally selected 65 subjects were either hospitalized or moved to a nursing home before post-testing was completed. Six originally selected subjects refused the post-test. Thus, from the original 65 subjects, complete pre- and post-test scores were available for 54 subjects. Further examination of the $A$ and $B$ Home subjects as well as the male members of the homes was also conducted. Of the 33 orginally selected A Home subjects, 27 remained at the end of the sessions. A similar attrition pattern was found among the B Home subjects. The thirty-two originally selected $B$ Home subjects had reduced to 27 subjects by the end of the study. Table II illustrates the number of subjects originally selected, male/female distribution, and attrition in both homes. 


\begin{tabular}{|c|c|c|c|c|}
\hline \multicolumn{5}{|c|}{ STUDY SAMPLE } \\
\hline & Male & $\begin{array}{l}\text { Home } \\
\text { Female }\end{array}$ & Male & $\begin{array}{l}\text { Home } \\
\text { Female }\end{array}$ \\
\hline Original Sample & 6 & 27 & 4 & 28 \\
\hline $\begin{array}{l}\text { Moved to nursing } \\
\text { home or hospital }\end{array}$ & 2 & 1 & 1 & 1 \\
\hline Refused post-test & 1 & 2 & 1 & 1 \\
\hline 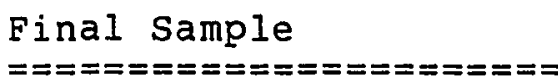 & $\begin{array}{l}3 \\
===\end{array}$ & $=\stackrel{24}{==}=$ & 2 & $== \pm====$ \\
\hline
\end{tabular}

The physical measures used in this study were the hand grip measured in kilograms with the hand dynamometer and the leg press measured in pounds with an electric weight scale. The self-esteem measures included the Rosenberg self-esteem scale and a four-item questionnaire designed by the investigator. The Rosenberg scale was scored according to the Guttman and the Likert methods. The self-esteem behavior questionnaire (Tichy) was scored according to the Likert method.

Some data were collected only on post-testing. For example, the residents' discussion of their attitude toward exercise, hours of activity and rest, description of their level of activity, and selection of recreational pursuits were all obtained in post-testing only. Consequently, only 
post-test data were used in testing the hypotheses examining these relationships. Likewise, if the data were obtained in pre-testing or related to the subjects' initial physical or psychological status, the correlations that were computed were with other pre-test data.

This chapter will include a description of the subjects and the testing of the hypotheses. Unless otherwise indicated, the $\underline{\underline{r}}$ correlation reported is the Pearson $\underline{r}$.

\section{PHYSICAL CHARACTERISTICS OF THE SAMPLE POPULATION} AND HYPOTHESIS TESTING

Age and Weight

The resulting study population closely resembled the overall population of the two homes in age. The mean age of the total population of the two homes $(N=127)$ was 83.85 with a standard deviation of 7.77 years. In order to focus more closely on the population most commonly found in retirement homes, two persons less than 60 years of age were excluded from the study. Subjects examined in pre-testing and included in this study $(N=65)$ had a mean age of 84.44 with a standard deviation of 6.58 years. The range was from 60 to 99 years of age. There is no significant difference between this mean and the means of the females of the $A$ and B Homes or the entire male population.

More than 70 percent of the total population was female (92 females/35 males). This is consistent with the projected longer 1 ife span of females compared with males 
(Piscopo, 1985). More than 85 percent of the subjects included in the orginal study group were females ( 55 females/10 males).

Body weight of the study subjects showed a mean of 131.63 pounds with a standard deviation of 22.92. The range was from 70 to 199 pounds. The female mean weight was nearly the same as the males ( 131 and 132 respectively). The A Home subjects were statistically significantly heavier than the $B$ Home subjects (A Home mean weight $=138.81$ pounds, standard deviation $=23.21$, range $=100-199 ; B$ Home Mean weight $=$ 124.71 pounds, standard deviation $=23.74$, range $=70-189)$. Correlation between age and weight showed significant negative relationships of -.32 for all subjects and -.38 for the B Home subjects. The A Home subjects had a non-significant correlation of -.28 . These findings are consistent with reports in the literature. Several studies demonstrated that there is a gradual loss of weight in aging, and there is some evidence to suggest that the leaner person is more likely to survive (Hejda, 1963; Hollifield \& Parson, 1959; Master, Lasser \& Beckman, 1960). A complete report of the findings related to age, sex and weight is presented in Appendix F.

Hand Grip

The mean score obtained in the hand grip was 19.41 kilograms with a range of 0 to 50 and a standard deviation of 12.61. The females of the $\mathrm{A}$ Home demonstrated a 
non-significant, higher mean hand grip strength than the $B$ Home females $(20.70$ kilograms with a standard deviation of 12.33 and 18.25 kilograms with a standard deviation of 12.95 respectively). The males from both homes had a statistically significant greater hand grip strength mean of 37.70 kilograms with a standard deviation of 15.66 when compared to women. Analysis of variance in the difference in hand grip means between men and women is presented in Appendix F.

\section{Leg Press}

The leg press scores ranged from 21 to 67 pounds, had a mean of 39.84 and a standard deviation of 9.85 pounds. The A Home females demonstrated a statistically non-significant but greater leg press strength than the B Home females (41.39 pounds with a standard deviation of 11.16 and 38.28 pounds with a standard deviation of 8.54 respectively). The males from both homes had a leg press mean of 37.70 pounds with a standard deviation of 15.66 . The male leg press mean was statistically not significantly different when compared with the female leg press mean ( 39.83 and standard deviation of 10.28). See Appendix F.

No correlation between hand grip and leg press scores could be demonstrated. There was, however, a significant positive relationship between body weight and the leg press score $(\underline{r}=.48)$ that was not demonstrated between weight and the hand grip score $(\underline{r}=.17)$. This strong relationship suggests that weight be taken into account when examining 
leg press scores; consequently, control for weight by using a part correlation was used. In this procedure, analysis of the correlations between leg press and other variables were conducted with the influence of weight statistically removed from the leg press strength measure according to a method described in Hinkle, Wiersma and Jurs (1979).

The hypothesis examining the relationship between physical condition and age was:

There is a negative relationship between age and the pre-test level of physical condition as measured by the hand grip and by the leg press.

For all subjects the correlation between hand grip and age was highly significant in a negative direction $(-.43)$. The A Home subjects also demonstrated this significant negative relationship $(\underline{\underline{r}}=-.68)$. However, the $\mathrm{B}$ Home subjects demonstrated a low positive relationship $(\underline{r}=.05)$. The demonstrated loss of hand grip strength with age is consistent with findings reported in the literature (Burke, Tuttle, Thompson, Janney, \& Weber, 1953; Petrofsky, Burse, \& Lind, 1975). In contrast to the relationship between age and hand grip strength, the relationship between age and pre-test leg press was not significant either for the total group tested or for either sub-group. The hypothesis was rejected. See Table III. 


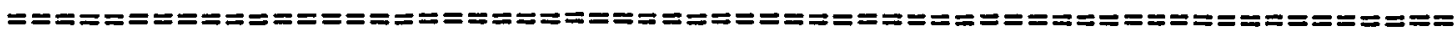

TABLE III

PHYSICAL CONDITION AND AGE

Variables

Hand Grip $\underline{\underline{r}}$ Leg Press $\underline{r}$

Age and Pre-Test Physical Measures

All Subjects $(\mathrm{N}=65)$

A Home $(\mathrm{N}=33)$

B Home $(\overline{\mathrm{N}}=32)$

$-.43 * * \quad-.06$

$-.68 * * \quad-.26$

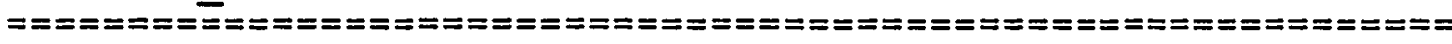

$\underline{p} \leq .01$

Length of stay

Length of stay was considered an important variable in the original design of the study. There was a statistically significant difference in the length of stay between the $A$ Home and the $B$ Home residents $(\underline{F}(1,63)=4.1, \underline{p}=.04)$ due to a three-year refurbishing project undertaken in the $A$ Home. The administration of the $A$ Home allowed the resident population to decrease by normal attrition and did not replace residents as they left. Residents left the retirement home due to illness (causing a move to a hospital or nursing home) or death. A large number of new residents were admitted after the refurbishing project. As a result, nearly two-thirds of the residents in the A Home had lived there twelve months or less while less than one-sixth of the B Home residents fell into this category.

Although marked difference in the residents' length of stay existed between the homes, its lack of relationship 
with physical condition was expressed in the following null hypothesis:

There is no relationship between the pre-test level of physical condition as measured by the hand grip and by the leg press and the subject's length of stay in the retirement home.

The Pearson $\underline{\underline{s}}$ correlation between the length of stay and physical measures was limited because of the negatively skewed distribution of the scores. The high number of tied ranks in the physical measures (e.g., twenty out of thirtythree for the hand grip scores) prevented use of the Spearman rho coefficient.

The blocking method used in randomly assigning subjects to the experimental and control groups was used in examining these data. One block contained subjects who had lived in the retirement home 12 months or less, and the other contained all subjects who had lived there more than 12 months. Analysis of variance was used to test the hypothesis. The E ratio for the B Home subjects' hand grip strength with length of stay was 4.36 with a probability level of .04. Only five $B$ Home residents lived there twelve months or less while 27 residents lived there more than twelve months. No other $\underline{E}$ ratio was statistically significant. The results lend support to the null hypothesis.

Because of the statistically significant difference in the means of the physical measures for the two age groups, 
an $E$ test of the relationship between length of stay and age was also conducted. No statistically significant relationship was demonstrated. See Table IV. Environment and Exercise Patterns

The most striking environmental aspect encountered was the difference in the physical size of the homes. Some descripton of the homes was provided in Chapter V. This section provides an examination of the structure of the homes and the observed patterns of exercise of the residents.

Although the major hallways (on two floors) accommodated both the staff and residents in the $B$ Home, there were many short and long hallways for staff and residents to use in the A Home. The halls were narrower in the $B$ Home and often crowded with cleaning carts and working staff. In the A Home, the halls were up to 10 feet wide and eaily accomodated the housekeeping carts and traffic. Further, the halls often had a dead-end sitting area with a chair and table by a window. Walking around the halls several times a day as a private method of exercise and recreation was much more commonly mentioned by the A Home residents than by the $B$ Home residents.

The physical size of the rooms also provided greater oppotunity for movement for the A Home residents without the need to leave their own rooms. They had greater distance to 


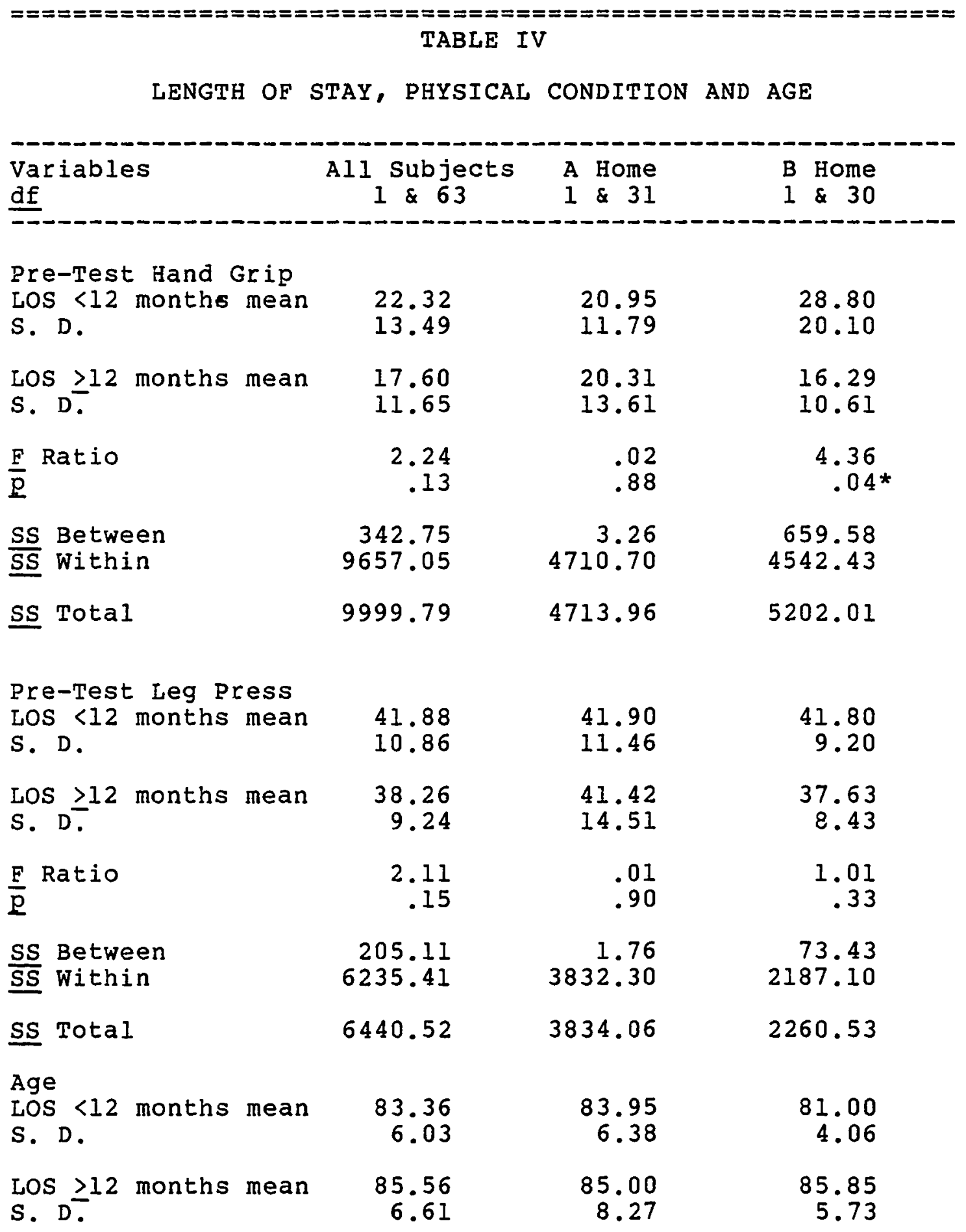




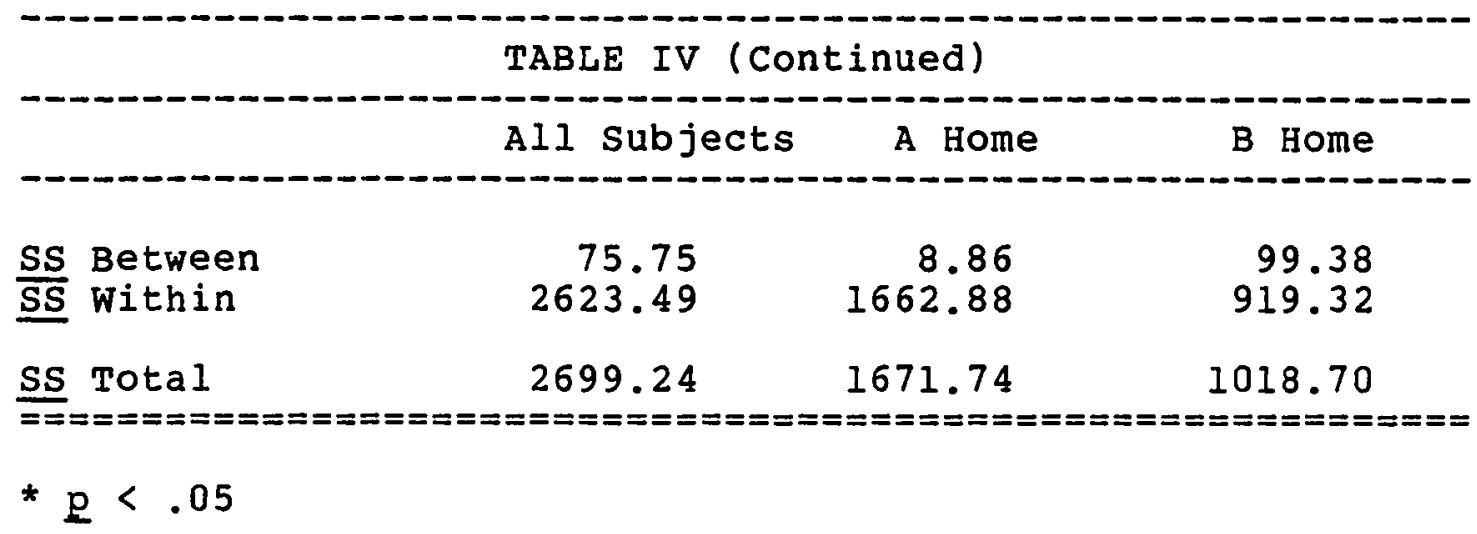

walk from the bed to the bathroom, from closet to chair, etc. Some residents of the B Home did not have facilities in their own rooms, requiring them to walk farther to the bathroom than the A Home residents. However, these residents constituted a minority in the $B$ Home.

Both homes had elevators available for resident use. The B Home also had a stairway which was a convenient approach to the dining room for some residents. Several residents described using this stairway when going to the dining room (in the basement), but only one described climbing the stairs in returning to her room. No A Home resident described using the stairway when traveling to or from the section of the A Home which was more than one story high. Although the A Home elevator reduced the effort needed to go from one floor to the next, the distance from the elevator to the dining room was more than some of the $B$ Home rooms to the dining room. 
The A Home design required additional effort by some residents to reach the dining room. Residents from one area of the home as well as those who used the elevator had to walk up a 40-foot ramp with a 30-degree incline in order to reach the dining room. The only other approach to the dining room for these persons included a short flight of stairs and a longer distance to walk. Those residents using walkers could choose the ramp as an alternative to the physical barrier of the stairs.

Examination of the distances in the $A$ and $B$ Home revealed that the mean distance from the resident rooms to the dining room in the A Home was 139 feet while it was only one-half that distance (70 feet) in the B Home. While only 14 percent of the rooms in the $A$ Home (10 of 73 ) were less than 100 feet from the dining room, nearly 78 percent $(41$ of 53) rooms in the $B$ Home were in this category. The hypothesis which examines this relationship is:

There is a positive relationship between the pre-test level of physical condition as measured by the hand grip and by the leg press and the distance of the residents' room from the dining room.

No statistically significant relationship between these variables was found. Examination of the sub-groups also revealed non-significant relationships. The hypothesis was rejected. See Table V. 


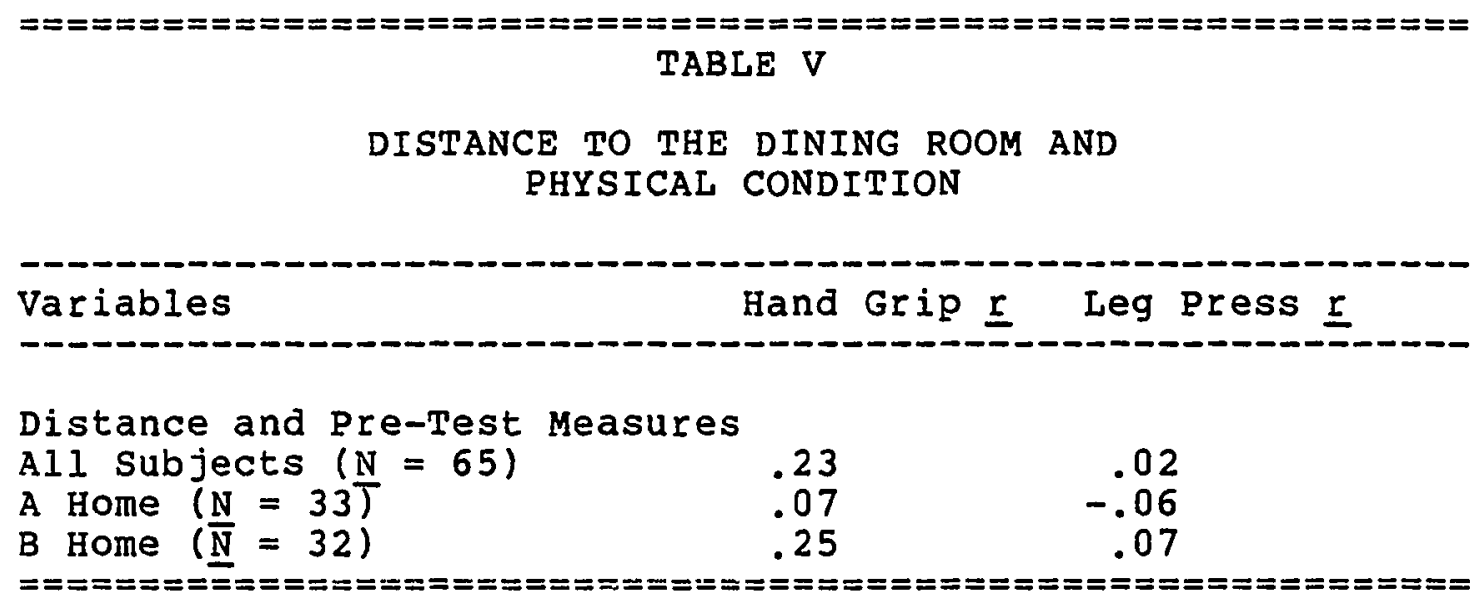

Attitude and Practices Related to Exercise

In addition to the physical measures taken, an attempt was made to determine certain attitudes and practices related to physical condition and activity. subjects were asked to respond to a statement regarding the body's need for physical exercise as one grows older. Nearly sixty-eight percent of the subjects ( 34 out of 54) accepted the statement that the need for exercise decreases as one grows older. The hypothesis was:

Those subjects who accept a decreased need for physical exercise as one ages will show lower pre-test level of physical fitness as measured by the hand grip and by the leg press than those who deny the decreased need for exercise as one ages.

The analysis of the data revealed no statistically significant difference in regard to physical condition between those who accepted this statement and those who denied it. The findings, however, showed that those who 
accepted the decreased need for exercise as one grows older had less hand grip strength than those who denied the statement ( 17.72 and $20.80 \mathrm{kilograms}$ respectively). This trend was also found in the sub-groups of the $A$ and $B$ Home subjects.

In contrast to the findings regarding the hand grip strength, those who accepted the statement had a higher mean leg press strength than those who denied it $(40.63$ and 37.36 pounds respectively). The hypothesis was rejected. See Table VI .

Some consideration was given to the environment in relation to the physical activity of residents. Safety is a special concern for those who work with the public, and each home took precautions in order to provide a safe environment for their residents. These safety precautions were particularily evident in coming to and going from the homes. The A Home had nine exterior doors which were electronically monitored. Each time an exterior door was opened, a light would flash on a centrally located display board. Doors were kept locked during the nighttime hours to prevent possible intruders from entering. One could exit from the doors at any time. During the daylight hours, residents could freely enter or exit from a number of the doors.

Although the $B$ Home did not have the electronic monitoring system and had only four exterior doors readily available to the residents, many of these same precautions 


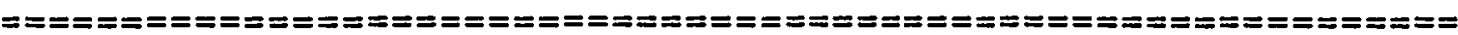

TABLE VI

ACCEPTANCE OF DECREASED NEED FOR EXERCISE

AND PHYSICAL CONDITION

\begin{tabular}{lccc}
\hline Variables & $\begin{array}{c}\text { All Subjects } \\
\text { df }=1,52\end{array}$ & $\begin{array}{c}\text { A Home } \\
1,25\end{array}$ & $\begin{array}{c}\text { B Home } \\
1,25\end{array}$ \\
\hline Hand Grip & & & \\
Accepted mean & 17.72 & 20.07 & 14.73 \\
S. D. & 11.50 & 13.59 & 7.73 \\
Denied mean & 20.80 & 23.82 & 17.11 \\
S. D. & 12.07 & 10.44 & 13.49 \\
F Ratio & .76 & .57 & .25 \\
D Level & .61 & .56 & .63 \\
SS Between & 105.4 & 86.5 & 105.4 \\
SS Within & 7188.4 & 3794.1 & 2854.3 \\
SS Total & 7293.8 & 3880.6 & 2882.4 \\
& & & \\
Leg Press & 40.63 & 41.94 & 39.31 \\
ACcepted mean & 9.88 & 10.97 & 8.81 \\
S. D. & 37.36 & 40.55 & 34.18 \\
Denied mean & 9.67 & 10.51 & 7.97 \\
S. D. & 1.45 & .11 & 2.38 \\
F Ratio & .23 & .74 & .13 \\
D Level & 138.6 & 12.7 & 171.5 \\
SS Between & 4988.6 & 2909.7 & 1801.1 \\
SS Within & 5127.2 & 2922.4 & 1972.6 \\
SS Total & & &
\end{tabular}

were observed. One additional precaution was found in the $B$ Home in regard to the access to the building that was not present in the A Home. Regardless of the time of day, a resident would have to ring the office in order to gain 
entrance to the home. The person at the door would identify $\mathrm{him} /$ herself through an intercom system; then the door would be opened electronically.

More than 81 percent of the $A$ Home residents $(22$ out of 27) specifically stated that they walked either indoors or out-of-doors for some part of their daily activity. Only 44 percent ( 12 out of 27 ) of the $B$ Home residents reported walking as a part of their daily activity. The A Home staff member commented on the activity of the residents saying, "As soon as breakfast is over, the door monitoring board lights up like a Christmas tree. They (the residents) scatter like leaves in the wind." Although certain small groups of $B$ Home residents were observed walking out-of-doors on various occasions, it did not seem that this was a regular activity.

The daily routine of the subjects was examined by asking them to report their activities of the previous day (see Chapter IV, page 87). Their responses were recorded in fifteen-minute intervals. (See the form placed in Appendix A.) "Activity" was defined as time spent out of the room, a minimum type of exertion. "Rest" was defined as those times described by the subjects as time spent "resting, napping or sleeping" in their rooms. These definitions of activity and rest did not account for all 24 hours of the day. Therefore, another category which included time the resident described spending in the room not otherwise described as resting was 
established. The mean hours of activity were 5.84 with a standard deviation of 3.24. The range was from 1.25 hours to 14.75 hours. Twenty-four percent of the subjects examined reported three or less daily hours out of their rooms (13 out of 54 subjects) including meal times. The males reported nearly two more daily hours out of their rooms than did the females from either home. A summary of the subjects' reported hours of activity is presented in Table VII.

The hours of rest reported by the subjects had a mean of 10.73 hours with a standard deviation of 2.96. Eleven percent of the subjects reported spending more than half of their time resting ( 6 out of 54). The range of time spent "resting" was 7.00 to 20.51 hours. The B Home subjects spent nearly two hours more per day "resting" than did the A Home subjects. They also spent fewer hours in "activity". See Table VII.

The remaining time spent in the room but not described as "rest" ranged from 6.85 to 7.93 hours. The A Home subjects spent one hour per day more in room activities other than resting than did $B$ Home subjects. Room activities not including resting were watching television, reading, praying, hand crafts, etc. 


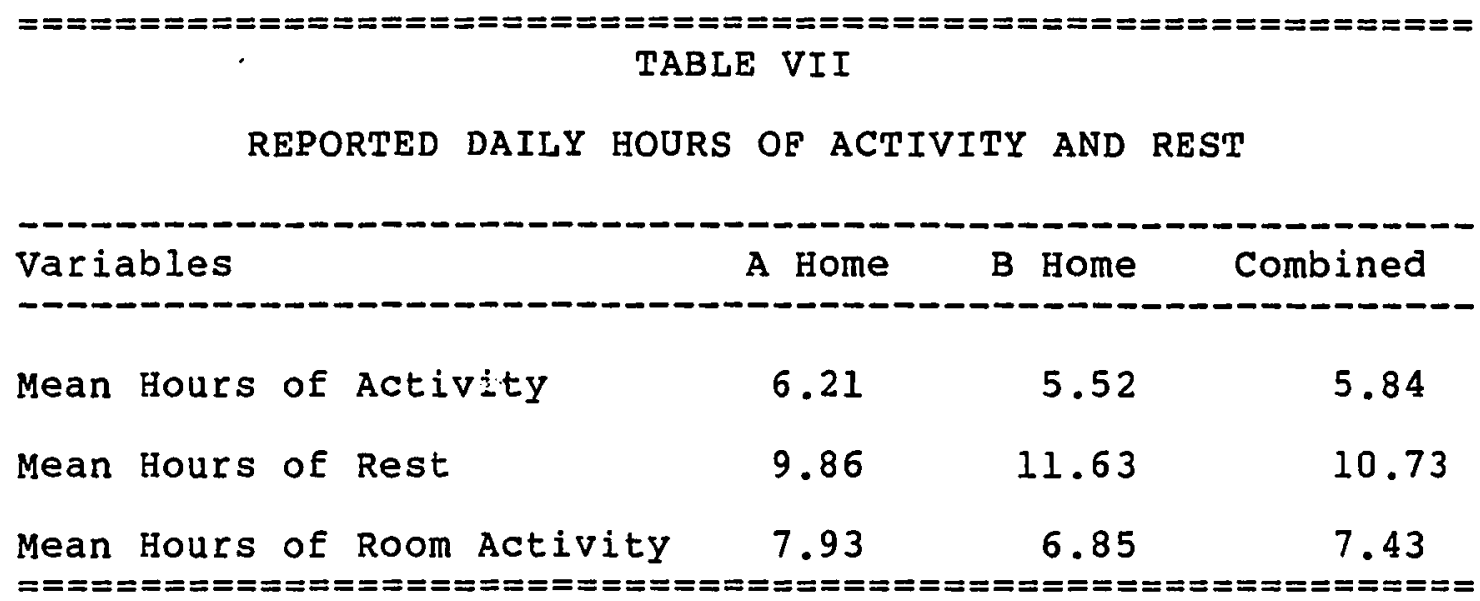

statements examining the relationship between activity and rest and physical condition presented in this study included:

There is a positive relationship between the self-described number of hours defined as "activity" and the post-test level of physical condition as measured by the hand grip and by the leg press.

There is a negative relationship between the self-described number of hours defined as "rest" and the post-test level of physical condition as measured by the hand grip and by the leg press.

Testing of the first hypothesis showed a statistically significant relationship between the hours of activity and the hand grip scores for the total population and the $A$ Home subjects. No statistically significant relationship between these variables was found among B Home subjects.

The relationship between the hours of activity and the leg press scores also showed statistically significant positive relationships when the total group and the $A$ Home 
subjects were examined. The $B$ Home subjects continued to demonstrate a positive, though not significant relationship. The hypothesis was not rejected. See Table VIII. Examination of the relationship of hours of rest with hand grip scores showed a statistically significant negative relationship when the total group and the $A$ Home subjects were examined which was not present for the $B$ Home subjects. The relationship between hours of rest and the leg press scores was examined for the total group and the sub-groups; none was found. The hypothesis was rejected. See Table VIII for presentation of the results.

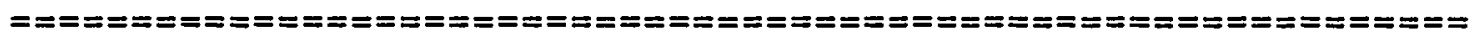

TABLE VIII

DAILY HOURS OF ACTIVITY AND REST

AND PHYSICAL CONDITION

Variables

AlI subjects $(N=54)$

A Home $(\underline{N}=27)$

B Home $\underline{\underline{N}}=27)$

Hand Grip $\underline{\underline{r}}$

Leg Press $\underline{E}$

Daily Hours of Rest
All Subjects ( $N=54)$
A Home $(\underline{N}=27)$
$B$ Home $(\underline{\bar{N}}=27)$
-.18
$-.48 * *$
$-.22$

.21

.04

$.34 *$

$.57 * *$

.14

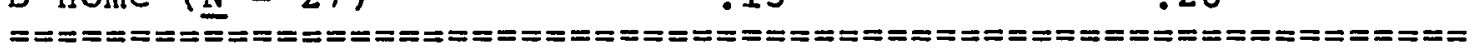

$* \mathrm{p} \leq .05$

$* * \mathrm{p} \leq .01$

The lack of a strong negative relationship between the hours of rest and physical measures was unexpected. 
According to Saltin et al. (1968) prolonged bedrest can produce significant physiological changes even in the young. Loss of bone mass and decreased cardiovascular function were the major findings in the saltin study.

Some hours described as "activity" by subjects in this study actually may mean "resting" in a location other than the resident's room. Many times residents were observed sitting in the recreation room or lounge fast asleep. Although this time would be recorded in the study as "activity" because the resident was out of his/her room, the energy expended was minimal. However, the time described by the residents as "resting" was actually time spent reclining on the bed rather than sitting in a chair.

The stronger positive relationship demonstrated in the A Home subjects between hours of activity and physical condition was conjectured to be due to the nature of their "activity" hours. A Home subjects were more commonly walking; the $B$ Home subjects were more frequently attending study groups, entertainment, and/or "visiting."

Home Provided Activities

Another factor that may have some relationship to the activity level of residents was the home sponsored exercise programs. The A Home held six-days-a-week half-hour exercise sessions. These exercise sessions included range of motion exercises and marching through the hallways. The $B$ home had a park bureau staff person who came weekly for a one-hour 
activity program which included chair exercises and range of motion but few standing activities.

The A Home (at the time of the study) did not have an activities director to plan a recreational program for the residents. Yet, the administration did provide a monthly calendar of events. The calendar examined included three events which could be considered "active." That is, the resident was required to expend more energy than would be required in just sitting and watching or listening. These included a shopping trip, a "resident's trip" (in this case, a fishing expedition to a stocked fishing pond for some hands-on fishing), and an outdoor picnic. Not included in this accounting was the regularily scheduled exercise program.

The B Home has had an activities director for some time and also produced a calendar of events for each month. The calendar for the same month examined for the A Home was also examined for the B Home. Although a great many events were scheduled throughout the month, only five could be considered "active." These included two scheduled "Baking with Nan" events, an outdoor picnic, a tour to a local small town and a shopping trip. (Following implementation of the study, however, three exercise sessions a week have been conducted under the direction of the activities director in the B Home.) 
Recreational Pursuits and Self-Described Activity Level

The next area of examination included what recreational pursuits the subjects would select and their self-described activity level. The subjects were provided a list of ten recreational pursuits (five active and five inactive) and asked to select three they would be most likely to do. The proclivity of the subjects to select non-active recreation was illustrated by the fact that 18 subjects selected no active pursuits while only one selected three active pursuits from the 1ist provided. For further definitions of the active and inactive pursuits, please see Chapter IV, page 86 .

Eighty-two percent of the subjects who described themselves as "active" or "very active" (33 of 40 ) selected none or only one active recreational pursuit. Yet, 79 percent of the subjects who described themselves as "inactive" or "very inactive" (11 of 14) also selected none or only one active recreational pursuits. The one subject who selected three active recreational pursuits that she would be most likely to do also described herself as "very inactive." It seems that individual definitions and role models of "active" and "inactive" persons differ widely. Table IX shows the comparison between the self-described activity level and the number of active recreational pursuits selected. 


\begin{tabular}{|c|c|c|c|c|}
\hline \multirow[b]{2}{*}{ Activity Level } & $\begin{array}{l}\text { ED ACTI } \\
\text { TIONAL }\end{array}$ & $\begin{array}{l}\text { ITY LE } \\
\text { URSUIT }\end{array}$ & $\begin{array}{l}\text { VEL AND } \\
\text { :S }\end{array}$ & \\
\hline & $\begin{array}{c}\text { Recreat } \\
0\end{array}$ & $\begin{array}{c}\text { Number } \\
\text { ional } \\
1\end{array}$ & $\begin{array}{l}\text { Pursuits } \\
\text { Purs }\end{array}$ & $\underset{3}{\text { Selected }}$ \\
\hline Very Active $(\underline{N}=18)$ & $\begin{array}{c}6 \\
(338)\end{array}$ & $\begin{array}{c}10 \\
(568)\end{array}$ & $\begin{array}{c}2 \\
(118)\end{array}$ & 0 \\
\hline Active $(\underline{N}=22)$ & $\begin{array}{c}5 \\
(238)\end{array}$ & $\begin{array}{c}12 \\
(548)\end{array}$ & $\begin{array}{c}5 \\
(238)\end{array}$ & 0 \\
\hline Inactive $(\underline{N}=9)$ & $\begin{array}{c}5 \\
(568)\end{array}$ & $\begin{array}{c}3 \\
(338)\end{array}$ & $\left(1 \frac{1}{18}\right)$ & 0 \\
\hline Very Inactive $(\underline{N}=5)$ & $\begin{array}{c}2 \\
(408)\end{array}$ & $\left(\begin{array}{c}1 \\
\left(20 \frac{8}{8}\right)\end{array}\right.$ & $\frac{1}{(208)}$ & $\frac{1}{(20 \%)}$ \\
\hline Totals & 18 & 26 & 9 & 1 \\
\hline
\end{tabular}

The relationship between activity hours and selfdescribed level of activity was examined. The results were statistically significant in a positive direction only for the B Home subjects. The obtained relationship between hours of rest and the self-described level of activity was negatively statistically significant for all subjects and for those in the $B$ Home. See Table $x$. 


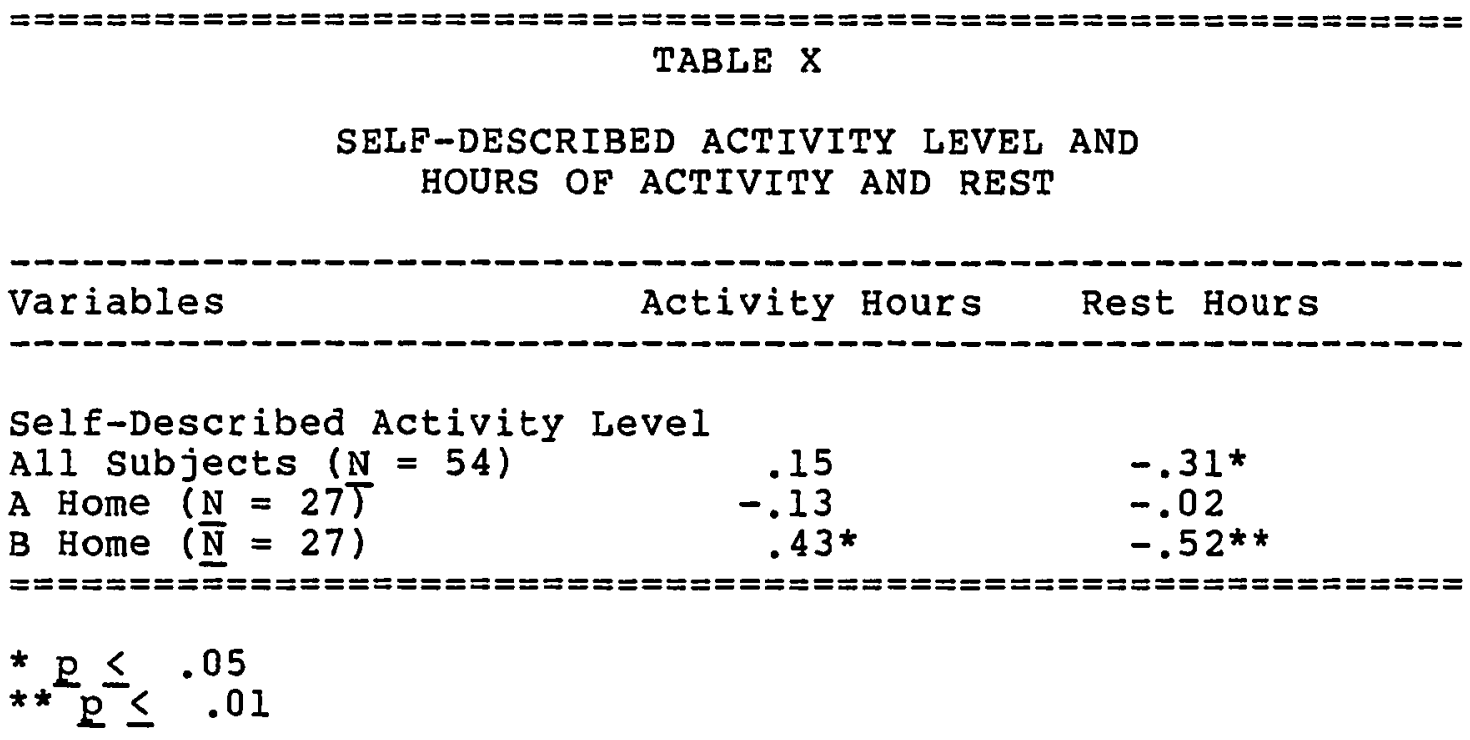

The data indicate a relationship between how the subjects described their level of activity and their reported hours of activity and rest. Those who described themselves as "active" or "very active" had fewer hours of rest than those who described themselves as "inactive" or "very inactive." However, only in the B Home subjects was the relationship between self-reported hours of activity and self-described level of activity statistically significant. The relationships between self-described activity level and recreational pursuits and physical condition were examined in the following hypotheses:

There is a positive relationship between the number of physically active recreational pursuits selected and the pre-test level of physical condition as measured by the hand grip and by the leg press. 
There is no relationship between the self-described daily actvity level and the post-test level of physical condition as measured by the hand grip and by the leg press.

No correlation could be demonstrated between the number of active recreational pursuits selected and the pre-test hand grip or leg press scores either in the total group or in the sub-groups. The hypothesis was rejected. See Table XI.

No statistically significant relationship was demonstrated between the self-described daily activity level and the post-test hand grip strength in any groups tested. These data supported the null hypothesis. See Table XI.

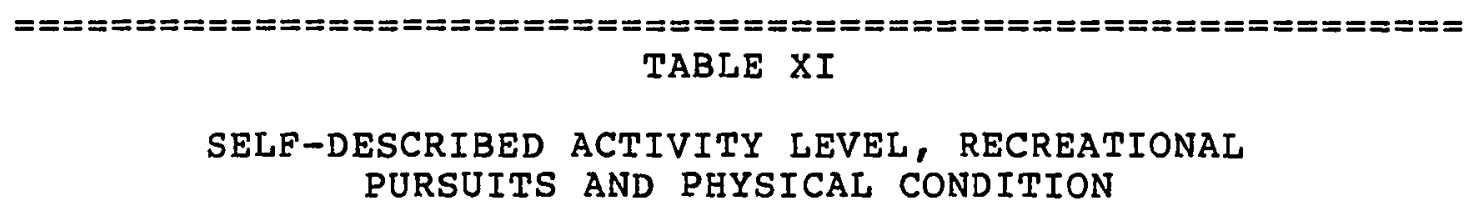

These findings are consistent with the research of Clarke (1973) who found that the majority of elderly persons believe that they have enough physical activity for persons 
their age. However, the results of the physical testing did not support the work of sidney and Shephard (1977) who found that physically unfit individuals believed they were more physically active than others of their age group. Participation in The Study

Exercise session attendance. Attendance at the exercise sessions was a concern throughout the implementation phase of the study. Most of the subjects originally selected failed to attend. Of the original subjects, only 22 percent ( 6 out of 27 ) attended eight or more times (out of 32 sessions) Only seven others self-selected the exercise sessions as an activity and attended eight or more times.

of the ten female subjects in the A Home selected for exercise, only one attended eight or more times. Only one male of the three selected attended the exercise sessions at this level. Attendance of the female subjects in the $B$ Home was somewhat better. Four of the eleven originally selected female subjects attended eight or more times. However, none of the three males selected attended eight or more times. The following hypothesis examines the relationship between pre-test scores and attendance at program sessions:

There is no relationship between the attendance at lecture and/or exercise sessions and the pre-test physical condition as measured by the hand grip and by the leg press. 
Examination of the relationship between the number of sessions attended and the pre-test physical measures showed no statistically signficant correlations. The null hypothesis was supported. See Table XII.

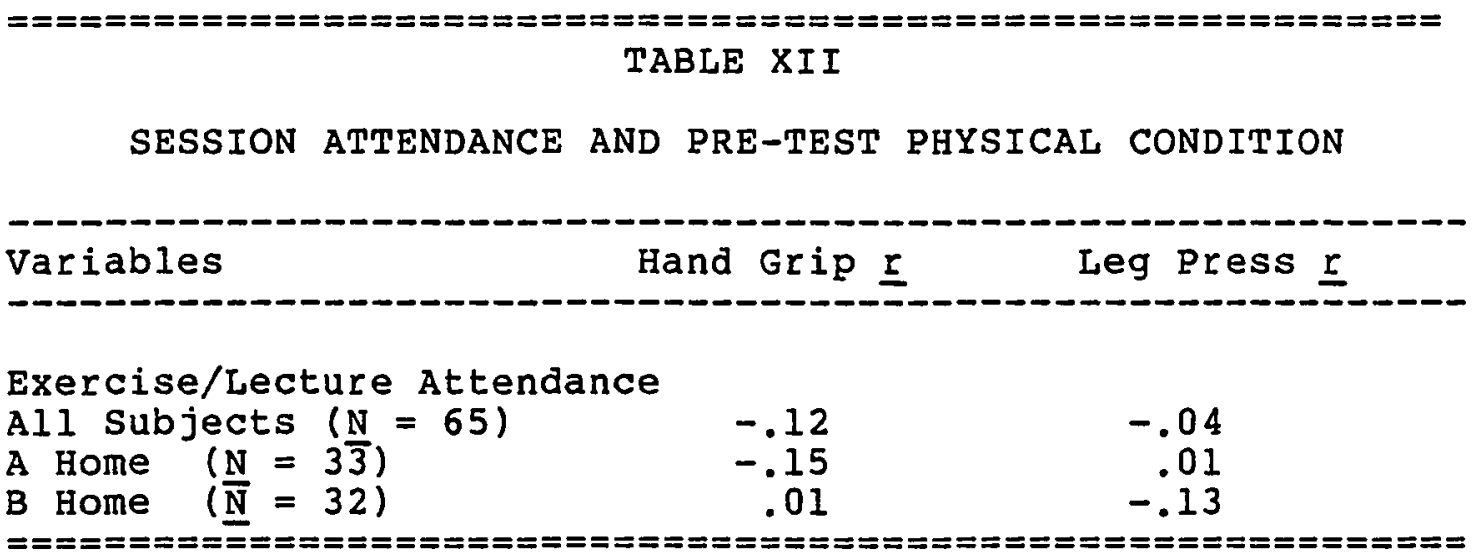

Participation and attitude toward exercise sessions. The need to explain and excuse their physical limitations was present in both the $A$ and $B$ Home subjects. The early sessions frequently were taken up by rather involved explanations of why one or another of the subjects could not exercise or had limitations in movement. It was evident that much fear regarding the effects of exercise and, particularly, of "overdoing" was a major concern for most of the subjects. One subject in the A Home described her "hernia" which would "come out" if she exercised, and, if it did, the doctor told her she would "have to have surgery and would never live through it." Following that recital, she did come occasionally to the exercise sessions but only watched. When 
encouraged to participate in the mild range of motion exercises, she would smile and continue to watch. Two subjects stated that they had been told by their physicians "not to exercise" because of some health problems. Four subjects reported being specifically told that they needed to exercise. One of these was told to "walk every day" but she didn't "like to" and so she did not. Three subjects (one from the A Home and two from the B Home) gave evidence of personal reading or research about exercise and health. Many, however, did not demonstrate even rudimentary knowledge regarding how to exercise or the neea for it.

Specific reference to age as a reason for not exercising or for limitation in performance was expressed by only two subjects, both men and both in the $A$ Home. Yet, one described himself as "active" and reported ten daily hours out of his room. He also mentioned that he had a senior bus pass which he used nearly every day just to "get out and around." He was a regular attendee at the exercise sessions and attended one-fourth of the lecture sessions.

The second gentleman who said that he was "too old" to exercise also regularly rode the bus to town, sat out-of-doors and visited with anyone who cared to stop to talk. His total hours of self-reported hours of activity was 13.25 per day. He attended the exercise sessions only seven times and never attended the lecture sessions. 
No one in the $B$ Home suggested age as a reason not to exercise. In fact, one ninety-year-old female made a point to say that she was glad of the opportunity to exercise provided by the study. She mentioned that she had been participating in an aerobic class at the YMCA the previous year and before that was in a swimming program. But, she added, "I haven't done anything for a whole year and now I am out of shape!"

Individual exercise patterns. There was more evidence of individual routines of exercise described in the daily hour-by-hour assessment of activity. This was especially true in the A Home subjects. According to the results of the hour-by-hour assessment, the A Home subjects were much more likely to be walking or exercising during their time out of their rooms.

The prolonged impact of unusual activity or a change in routine was evident in both homes. Many of the residents attended church services and/or family gatherings on the weekends. Often the groups were more lethargic and less able to respond during the exercise sessions on Mondays. This carry-over of fatigue to the following day seemed to have greater impact on the $B$ Home subjects than on the A Home subjects. When the park bureau provided the weekly morning exercise sessions in the B Home, many of the regular attendees of the study sessions would come to both. During 
the afternoon exercise session they would be more tired and less able to function than usual.

Ability to perform physical exercise. The observations made during the exercise sessions regarding the ability of the residents to $r$ ise out of a chair and stand revealed that the $B$ Home residents had much greater difficulty getting out of a chair and standing upright without wavering than did the $\mathrm{A}$ Home residents. It is not clear whether this was due solely to a lack of muscle strength, to a combination of poor muscle strength and poor coordination, or to some other, unknown reason.

With the repeated practice of getting in and out of a chair, the leg strength and/or coordination needed for this movement seemed to improve for nearly all subjects. The subject with the greatest difficulty on arising from a chair at the onset of the exercise sessions seemed to make enough progress that the serious concern for her safety during this activity was relieved. Further, she expressed great appreciation that she could rise from a chair with less effort. One subject in the B Home also commented, "Now it's easier to get out of the tub (bathtub)." There was general assent among the other seven group members to this statement.

The evidence of poor hand strength was determined when some subjects were unable to dent the small racquet balls with either their thumbs or other fingers or with the use of 
all fingers of both hands. This limitation was accommodated by providing softer plastic balls which afforded less resistance to compression. The subjects who used the softer balls at the beginning of the sessions were also using them at the end of the sessions. Subjects were always given the choice of which ball they wanted to use.

All of the subjects seemed to enjoy the kneading and massaging activities with the very soft, cloth-stuffed balls. Although the purpose of these exercises was to improve the upper back and tricep muscle groups as well as hand strength, there was no objective evidence that this goal was accomplished.

The range of motion exercises did relieve the observable stiffness and limitation in movement in some subjects. This was most apparent in two male subjects of the A Home who originally exhibited the greatest amount of stiffness and joint limitations. It seemed that most subjects found the range of motion exercises the least threatening and the most easily performed. Yet, some subjects did have difficulty following directions and/or demonstrations of the exercises.

The extreme level of drowsiness during the lecture sessions observed in the B Home residents may have occurred from a variety of physical or psychological conditions. Although a number of causes were considered, boredom was eliminated since those who had no interest in the 
presentations simply did not come or came and then left. The time of day may have had some bearing on the sleeping behavior. Mid-afternoon on a summer day may promote more sleepiness than the mid-morning. Also, the room temperature during the sessions tended to be warmer in the $B$ Home recreation room than in the A Home library. This may have contributed to the increased dowsiness in the B Home. The mean temperature during the lecture sessions in the A Home was 74 degrees and 78 degrees in the $B$ Home. Another contributing factor could be the general vigor of the A Home subjects when compared to the B Home subjects. Exercise promotes circulation to all parts of the body including the brain while sedendary habits tend to slow circulation (Pickles, 1981). It may be that the $B$ Home subjects had reduced blood flow due to inactivity. The effects of post-meal change in blood flow was considered equal in both homes since the lecture sessions followed the meals by two hours in each home.

Effectiveness of exercise sessions. Some beneficial effects of the exercise sessions on the physical performance of the subjects was observed. Although the intensity of the exercises provided was low, certain improvements did occur. First of all, the range of motion exercises did increase the reported and observed ability to move joints in those most limited in this activity. Second, the coordination and leg press strength did improve for those most limited in this 
activity and, also, for some who apparently did not have a serious problem initially. Third, there was little evidence that the hand exercises conducted in the sessions did, in fact, have any effect on the hand grip strength for those subjects who attended 75 percent of the time. The hypothesis testing the relationship between the exercise session attendance and physical condition is:

Those subjects who attend exercise sessions 75 percent of the time (three out of four scheduled times per week), will show greater improvement on the post-test levels of physical condition as measured by the hand grip and by the leg press then those subjects who attend exercise sessions less than 75 per cent of the time.

Minor changes in the hand grip and leg press strength measures were positive in those who attended exercise sessions 75 percent of the time. However, the small number of subjects who attended at this level (six) prevented statistical analysis of the data. The mean pre-test, post-test hand grip scores of these subjects was 21.29 and 22.00 kilograms with standard deviations of 7.94 and 7.85 respectively. The pre-test, post-test hand grip scores of those who did not participate to this level showed a negative trend with means of 18.56 and 18.26 with standard deviations of 11.03 and 9.14 kilograms respectively. The leg press scores showed some improvement in all subjects as well as among those who attended 75 percent of the time. For subjects who attended 75 percent of the time, the pre- and post-test leg press scores were 36.00 and 44.17 
pounds with standard deviations of 11.78 and 6.41 respectively. For those who did not attend at this level the leg press pre- and post-test scores were 40.19 and 45.01 pounds with standard deviations of 9.97 and 9.59 respectively. These data could not be used to test this hypothesis because of the small number who attended the exercise sessions 75 percent of the time.

Lecture session attendance. Attendance at the lecture sessions was more consistent among the originally selected subjects and those who self-selected the lecture sessions as an activity. More than 77 percent of the original subjects (17 of 22 ) attended lecture sessions eight or more times. In addition, 24 subjects self-selected the lecture sessions and attended eight or more times.

Eighty-one percent ( 9 of 11 ) of the originally selected A Home female subjects attended lecture eight or more times. Eighty-nine percent ( 8 of 9 ) of the originally selected females in the B Home attend at this level. Yet, neither of the two males originally selected in the A Home attended, and no male was selected in the $B$ Home.

PSYCHOLOGICAL CHARACTERISTICS OF THE SAMPLE POPULATION AND HYPOTHESES TESTING

The self-esteem of the subjects was examined through the use of the Rosenberg and Tichy instruments. However, additional data were collected through a daily anecdotal record. The observed relationships that existed between the 
environment of the homes and its impact upon the residents' self-esteem level was examined. Further, observation of staff and resident, resident to resident, and residents to investigator were recorded. In addition, the appearance of the residents as an indicator of feelings of self-worth also was observed. Observational Factors and Self-Esteem

Certain residents in each of the homes had specific limitations in remembering and following instructions, and some were depressed and/or debilitated. Most, however, were observed by the investigator and the assistant to be mentally alert and interested. The residents interacted with the staff, each other, the investigator, and the assistant. Responses to the study questions were appropriate and thoughtful. Some subjects responded to questions that required the use of memory by stating that they did not "remember." Others indicated a lack of memory by saying (in a response to questions about daily activity and rest), "I just go when they call me," or "I get up when the bell rings."

Environmental factors: Although there were differences in the relationships that existed between residents and staff, the staff in both homes exhibited a high regard for the residents. The differences perceived in the relationships between staff and residents in the two homes 
did not affect resident self-esteem as demonstrated on the self-esteem instruments.

Staff in the A home wore a modified uniform which included white pants or skirt and brightly colored uniform tops. Every encounter between staff and resident observed was warm, friendly, and business-like. The relationship between resident and staff tended toward the employer/employee style with the resident as the employer. The conversations observed usually focused on specific needs of residents, home function, or other matters of a less personal nature.

The B Home staff did not wear uniforms of any description, and the same warm relationships were observed. However, the relationship seemed more like that of a parent/child with the resident acting as the parent. The residents were observed to ask staff about their families, activities on days off, and for other personal data. Iikewise, staff would ask residents about their family visits, etc.

The residents, even those with memory problems or other limitations, were treated as adults and with care and concern in both homes. When a resident became lost or confused as to where to go or what to do next, the staff would merely walk along with her/him to the appropriate place and make light conversation along the way. Efforts were made to reorient the individual and to minimize the 
importance of the memory loss. When one resident lost her music and became quite disturbed, various staff members scurried around looking for the music and tried to reassure her that it would be found.

The environment provided by both homes seemed to emphasize the adult characteristics and positive abilities of the residents and play down what limitations they might have had. At the same time, whatever assistance was needed was provided in a non-judgmental and supportive manner. The general observation of this investigator was that the selfesteem of the residents was supported and protected in each home through the actions and attitude of the staff.

Personal appearance: As an objective observer in both homes, it seemed to this researcher that there was some difference in the socio-economic status of the residents of the two homes. More often, the A Home residents were dressed in a variety of summer dresses or pant suits which appeared relatively new. The $B$ Home residents more often wore housedresses or loose-fitting robes. While access to personal financial reports was not available, only four of the residents in the $A$ Home were observed receiving welfare payments. Twelve of the B Home residents received similar welfare support.

Although socio-economic status could be one reason for style of dress, another could be the general physical atmosphere of the home. The $B$ Home tended to be warmer (in 
temperature) and the resident rooms smaller and with less air movement. There were many trees and shrubs shading the $A$ Home while the $B$ Home was exposed to the sun on the east and south sides.

Another explanation for the style of dress could be the more formal relationships that seemed to exist between residents and between residents and staff members in the $A$ Home. This more formal setting could give rise to the expectation that one is "dressed" when seen in "public." Also, the A Home subjects were more likely to go outside the home for walking, shopping, or other activities. In contrast, the B Home subjects had more of a"family-type" relationship among themselves and also with the staff. Further, since some of the residents did not have a bathroom in their own room, they undoubtly had to walk in the hall in nightdress and/or robes at some times of the day or night. This was not true of the A Home residents. All had bathrooms in their own rooms.

\section{Resident interactions: The perceived "formal"} relationships that seemed to exist among $A$ Home residents in contrast to the $B$ Home residents had an interesting impact on the lecture sessions. When A Home subjects first came to the library for lecture sessions, the room was generally quiet with only very private conversations going on between one or two small groups of subjects. They were generally subdued. The room had the atmosphere of a church service or 
a serious meeting. Later, however, the group members began to interact. A subject who was feeling poor was counselled and supported by several of the other subjects. There was more openness in asking each other how they felt and the exchange of general pleasantries. Likewise, the incidence of serious, private conversations between some subjects increased. Later in the sessions it was also noted that various residents began to arrive in small groups of two or three, whereas they previously had arrived singly. In contrast, the $B$ Home subjects walked into the lecture sessions with ongoing conversations. There were open disagreements and scoldings as well as general laughter and almost sibling-like interactions. The formal atmosphere of the A Home was never found in the B Home. Likewise, the open arguments of the B Home were never found in the A Home. However, there were jokes and laughter in both.

In the $A$ Home there was also evidence of a budding romance and at least one long-standing one. There was no evidence of this in the B Home. There were fewer eligible males in the $B$ Home which may have limited the development of relationships of this nature.

Another difference observed in the $A$ Home was that first one and then more and more of the residents joined in to help put away chairs and generally straighten the library following the lecture. Although questions of a personal nature were asked during the lecture sessions, several also 
used this time to ask questions pertaining to their own health or the health of some family member. In contrast, only one resident in the $B$ Home consistently wanted to help clean up the room and put away chairs. Questions of a personal nature most often were asked during the $B$ Home lecture session, if at all.

The A Home residents were such a questionning group that many of the same presentations took ten to fifteen minutes longer in the $\mathrm{A}$ Home than in the $\mathrm{B}$ Home. The $\mathrm{B}$ Home residents generally were interested but tended to be more passive.

\section{Self-Esteem Instruments}

Psychological measures used in this study were the Rosenberg self-esteem scale and a behavioral self-esteemrelated questionnaire (Tichy). The Rosenberg instrument was scored using the Guttman and Likert methods (Rosenberg, 1965). The Tichy instrument was scored using the Likert method.

Examination of the relationship between scoring the Rosenberg self-esteem scale according to the Guttman and the Likert methods demonstrated an extremely high, statistically significant positive correlation. When the Rosenberg instrument was correlated with the behavioral self-esteemrelated questionaire (Tichy), a statistically significant positive relationship was also demonstrated. Reports of the 
various correlations performed between the self-esteem instruments are presented in Appendix F.

Scores for the Rosenberg and the Tichy instruments were arranged so that those subjects with the lowest scores exhibit the highest level of self-esteem (Rosenberg/Guttman $=0 ;$ Rosenberg/Likert $=10 ;$ Tichy/Likert $=4)$. To prevent misunderstanding of the inverse relationship between the score of the self-esteem measures and the level of selfesteem, the correlation signs (+ and -) will be reversed when reporting the results of the analyses of the selfesteem measures.

On pre-testing, all subjects demonstrated a relatively high level of self-esteem with a range of 0 to 6 on the Guttman-scored Rosenberg. The mean was 1.68 with a standard deviation of 1.19. When the Rosenberg instrument was scored according to the Likert method, the subjects' range was 15 to 28 with a mean of 20.15 and a standard deviaton of 3.00 . Using the Likert scored Tichy instrument, the subjects demonstrated a range of 4 to 16 , a mean of 9.69 and a standard deviation of 3.12 .

Examination of the $A$ and $B$ Home subjects showed only slight differences in the self-esteem levels of the Guttmanscored Rosenberg instrument (mean 1.92 and 1.47 , standard deviation of 1.34 and 1.12 respectively). This finding was consistent when the instrument was scored according to the Likert method ( $\mathrm{A}$ home mean $=20.58$, standard deviation $=$ 
2.77 ; B Home mean $=19.58$, standard deviation $=3.18$ ). The Likert-scored Tichy instrument also showed little variation in the self-esteem behavior score between the $A$ and $B$ Homes (means $=10.26$ and $9.18 ;$ standard deviation $=2.87$ and 3.18 respectively).

The males had a Guttman-scored Rosenberg mean of 1.51; a Likert-scored mean of 21.18 , and a Likert-scored Tichy mean of 11.13. These scores indicate only a slightly lower self-esteem level among males when compared with females. Manifestations of high- and low-level self-esteem were not as clear cut as expected. One of the residents with relatively low measured self-esteem, who was ill and depressed, could be supposed to have low self-esteem based on observing his demeanor and responses. One of the oldest residents, however, also had very low self-esteem that was not evident in talking with her. She had a very full life and spoke positively of the past and her contributions to her profession. It was not until the post-test interview that she admitted that she felt as though she "had lived too long."

A male resident was having a problem with impotence due to a medication he was taking. His self-esteem was very low on the pre-test. Later, the medication problem was corrected and his self-esteem score was very high on the post-test. Another resident attended nearly every exercise and lecture session and conversed with other residents when 
approached. There was little evidence of the very low level self-esteem she had. She did indicate on post-testing, however, that she had little control over her placement in the retirement home and believed that "it (her move to the retirement home) was not necessary." Another female resident had demonstrated very high self-esteem on the pre-test. Later, she became ill and depressed. Her score on the post-test indicated the lowest level of self-esteem. Age and Length of stay

In the orginal design of the study, length of stay was considered an important variable in relation to self-esteem. The hypothesis pertaining to this relationship is:

There is a negative relationship between the length of stay in the retirement home and the pre-test level of selfesteem.

The blocking method described previously was used to examine the relationship between length of stay and the self-esteem measures. A statistically significant relationship between Guttman-scored Rosenberg self-esteem scale and length of stay in the B Home subjects was found. Stronger relationships were demonstrated when the Rosenberg scale was scored according to the Likert method and on the Tichy instrument. The B Home subjects demonstrated statistically significant relationships between self-esteem and length of stay, and the total group demonstrated a statistically significant relationship with the 
Likert-scored Rosenberg. All relationships, however, were in a positive direction. The hypothesis was rejected. See Table XIII.

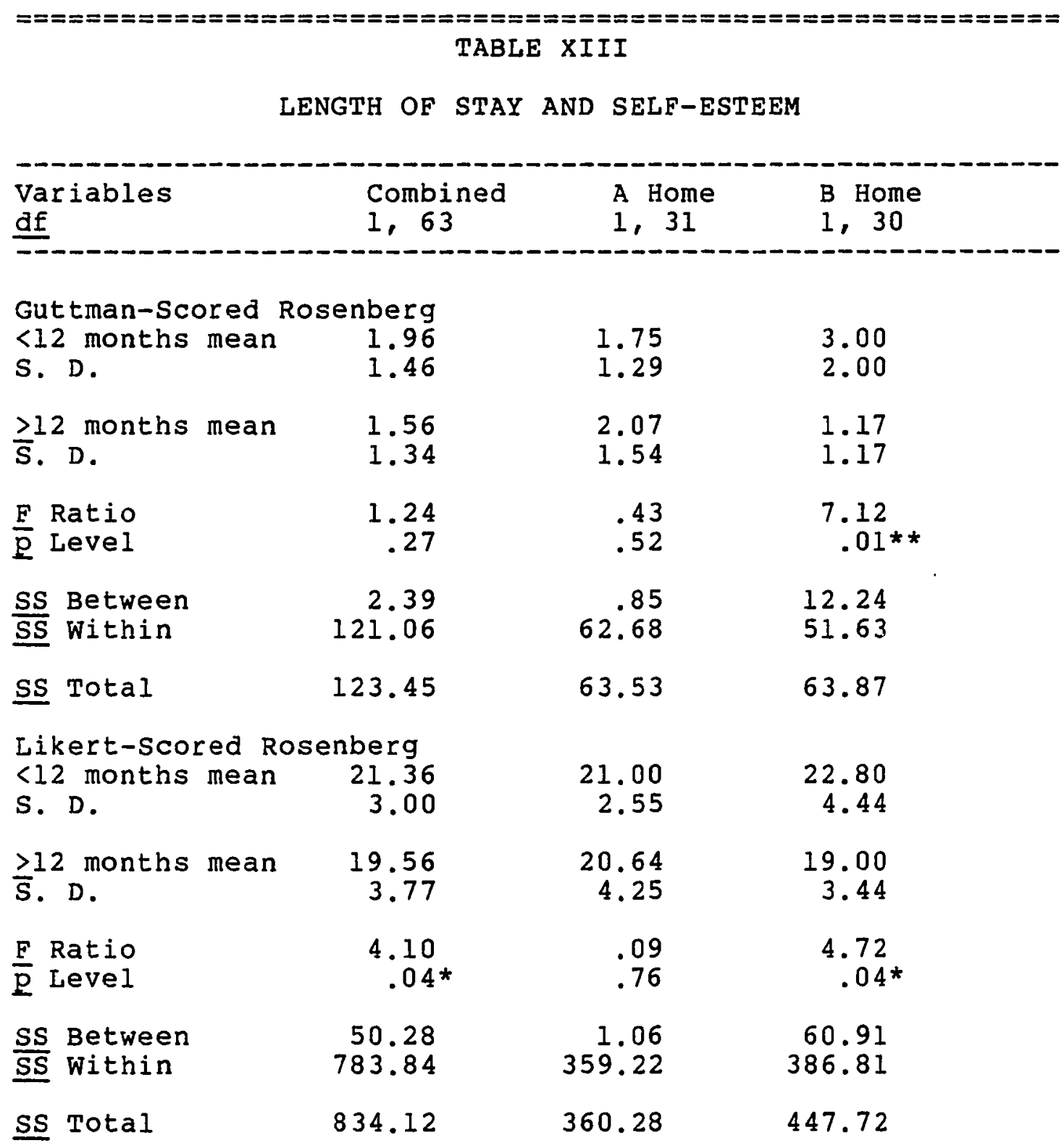




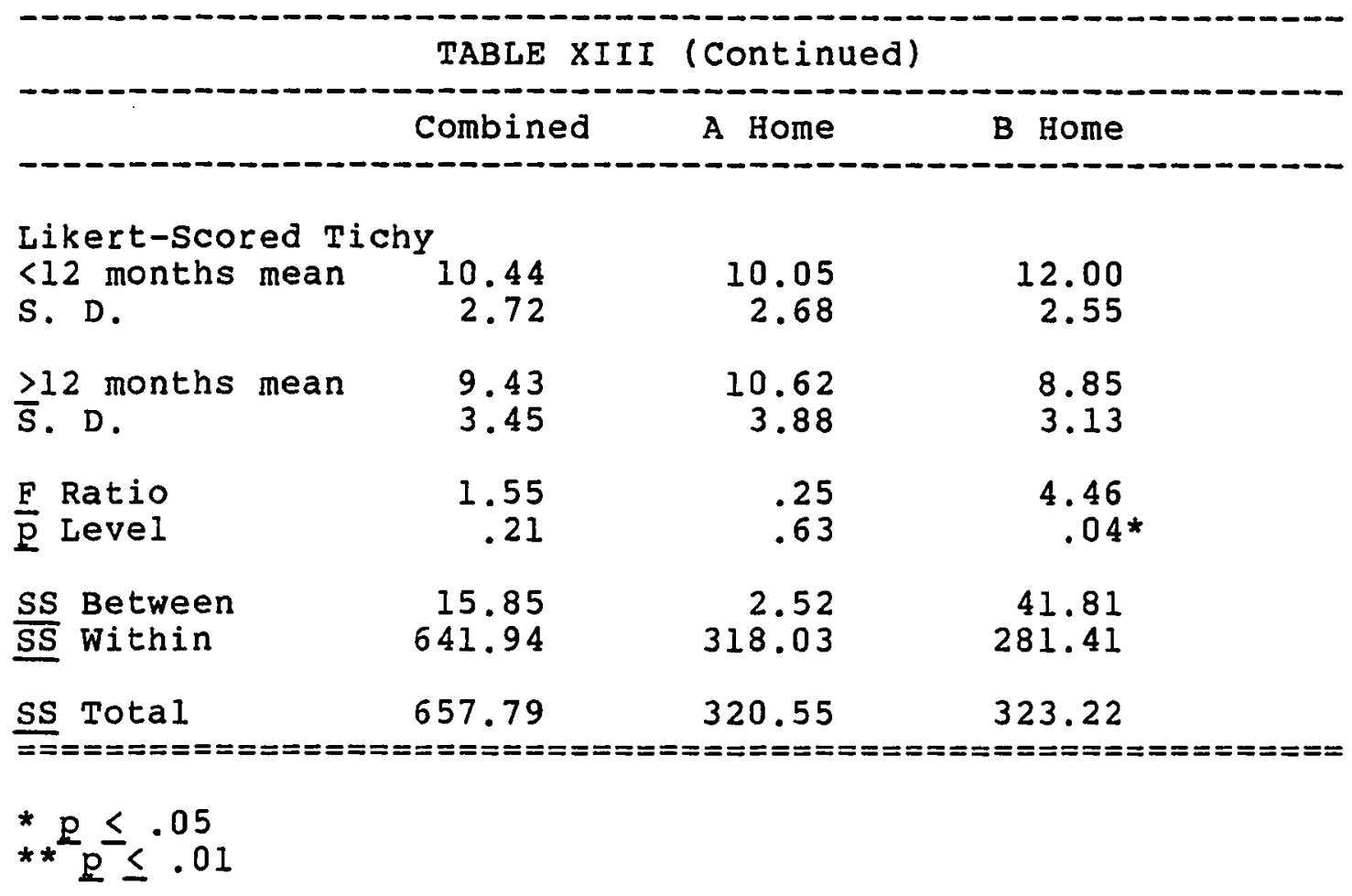

The relationship of age and self-esteem was examined in this hypothesis:

There is no relationship between age and the pre-test level of self-esteem.

The examination of the self-esteem failed to show any relationship with age. Therefore, the null hypothesis was supported. Table XIV illustrates the findings. 


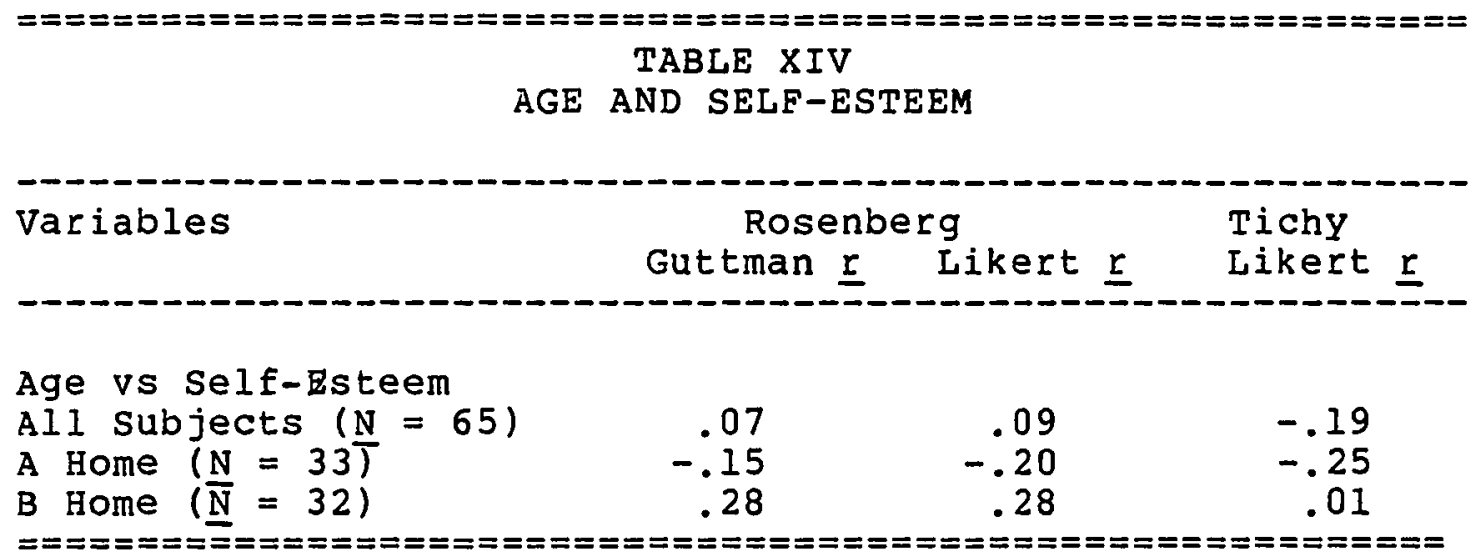

\section{Activity and Rest}

The relationship of the self-reported hours of activity and rest with self-esteem was examined in the following hypotheses:

There is a positive relationship between the self-described number of hours defined as daily "activity" and the post-test level of self-esteem.

There is a negative relationship between the number of hours described as "rest" and the post-test level of self-esteem.

No statistically significant relationship was found between the hours of activity and the post-test level of self-esteem in the total group or in the sub-groups. The hypothesis was rejected. See Table XV.

Examination of the second hypothesis demonstrated a statistically significant negative relationship between the Likert-scored Rosenberg instrument and self-esteem for the total group. The Tichy instrument failed to demonstrate a 
statistically significant relationship in any group. The hypothesis was not rejected. See Table XV.

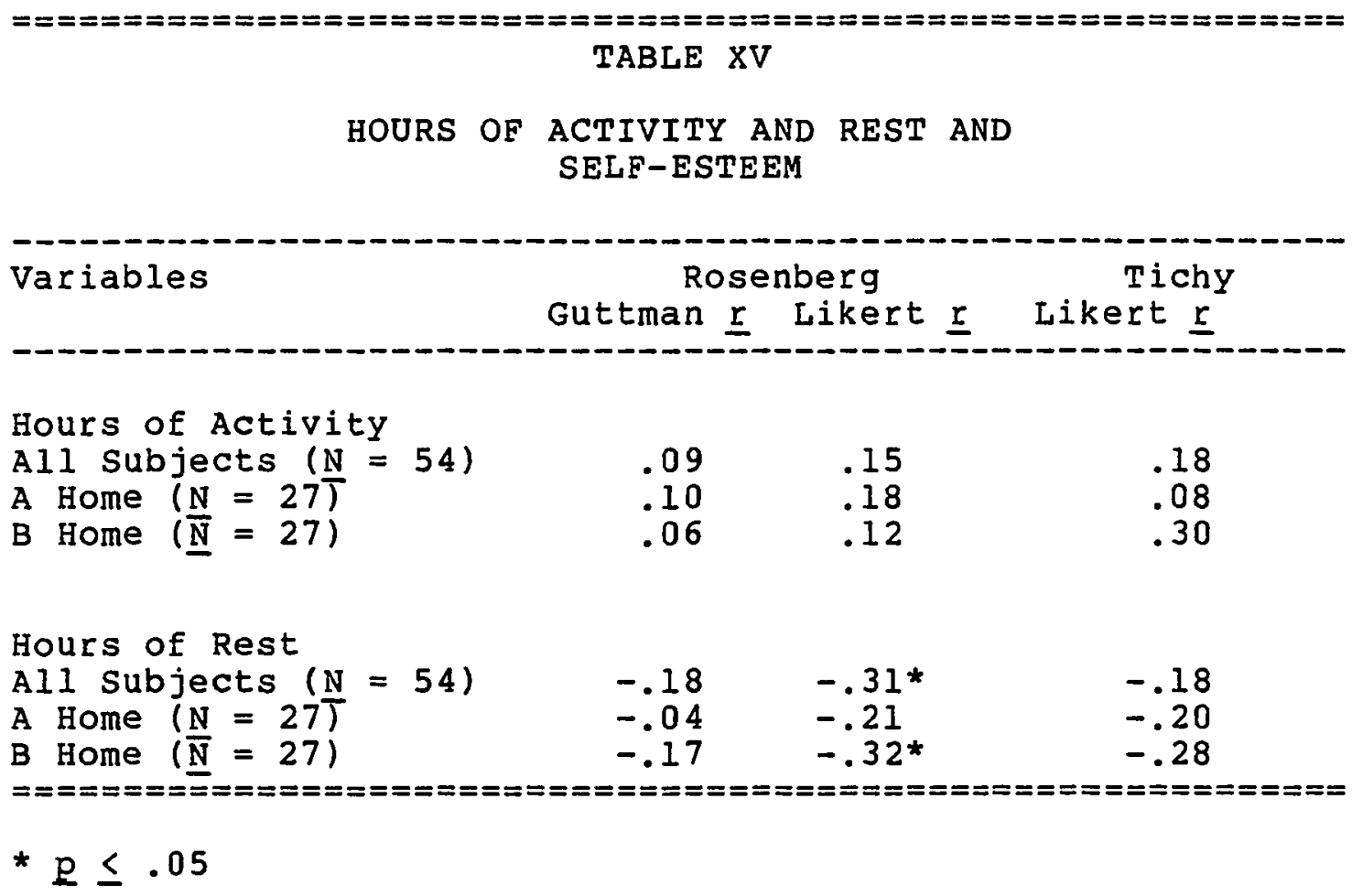

From these analyses, however, it can be determined that the hours of rest more frequently related negatively to the level of self-esteem for all subject groups. The withdrawal from social interaction through sleep was similar to Rosenberg's (1965) findings regarding the lack of social interactions among students with low self-esteem. Likewise, Kales and Kales (1972) found that older persons need nearly the same amount of sleep as adults at other stages of 1 ife ( 8 to 10 hours). They also discussed the relationship of excessive need for sleep as an indication of depression. 
Yet, a high level of activity hours was not significantly related to high self-esteem.

Level of Control

Assessment of the level of control over the selection of their place of residence was attempted by asking subjects their reason for selecting this retirement home. Of the 54 subjects questioned, 76 percent (4I subjects) indicated some level of control. This finding was consistent in both homes. The level of control expressed by the subjects was in response to the question, "Why did you select this particular retirement home?" Examples of the responses indicating some control included: "It is a christian home," or "We looked at a lot of different ones, and this is the best one," or "It is so clean and nice here." Responses indicating little or no control were: "I didn't select this home; my son (daughter) just put me here," or "I had a lovely apartment; there was no need for me to come here." The hypothesis which examined this relationship was:

For those subjects who state a level of control over selection of the retirement home, subjects who state much control over retirement home selection will have a higher level of self-esteem on the pre-test than those who state little control over retirement home selection.

The self-esteem level of those who expressed some control over the selection of the retirement home was higher on all measures and for all subjects. (Note inverse relationship.) see Table XVI. 


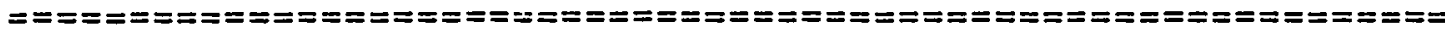

TABLE XVI

SELF-ESTEEM BY LEVEL OF CONTROL

Variables

Control

Mean

No Control Mean

Guttman-Scored Rosenberg

All Subjects

A Home

1.47

1.90

1.29

2.15

B Home

19.63

20.23

Likert-Scored Rosenberg

All subjects

A Home

19.00

21.71

B Home

19.00

21.44

22.20

Likert-Scored Tichy
All subjects
9.23
10.57
A Home
9.95
10.11
B Home
8.48
11.40

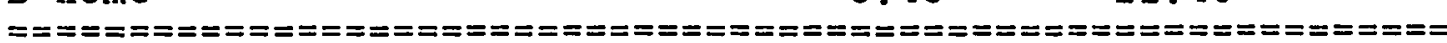

Analysis of variance revealed a statistically significant difference in the means for self-esteem as measured by the Rosenberg self-esteem scale scored according to the likert method in the total group and in the $B$ Home subjects. The hypothesis was not rejected. See Table XVII. 


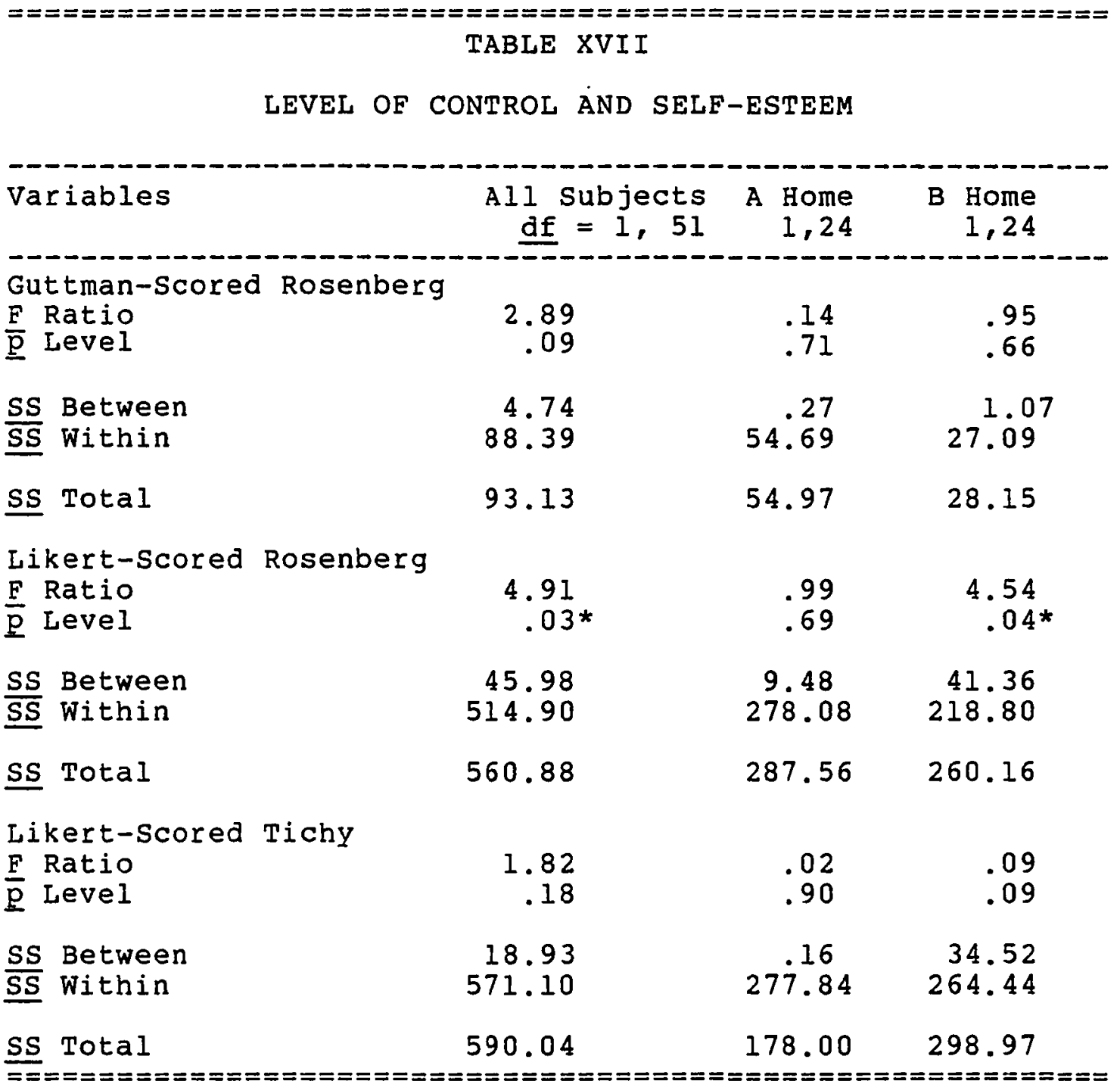

$\star \underline{p} \leq .05$

These findings were consistent with those reported in Rodin (1978, 1980); that is, the feeling of control has important implications for the individual's level of selfesteem. Control over the place of residence is a major adult decision. Yet, there is also the possible health-related 
need for the older individual to make some change of residence that she/he may not be willing or able to accept. For example, one subject who described a lack of control over her move to the retirement home also described the fact that she "didn't know day from night" and that she had "gotten all mixed up and had fallen" prior to her move to the retirement home. still, she felt that she should have been allowed to stay in her own apartment. Martin and Wilson (1976) discussed the fact that some elderly persons persist in living alone when prudence suggests that other living arrangements should be made. The findings do not suggest that some subjects are improperly placed in the retirement home. Rather, they suggest some subjects feel a lack of control in the selection of their place of residence and that this factor is related to level of self-esteem. Session Attendance

The relationship between attendance and self-esteem was examined in two hypotheses as follows:

There is a positive relationship between the pre-test level of self-esteem and the number of exercise sessions attended.

There is a positive relationship between the pre-test level of self-esteem and the number of lecture sessions attended.

No positive statistically significant relationships could be demonstrated between self-esteem and the number of exercise sessions attended. Further, all findings were in 
the negative direction. The hypothesis was rejected. See Table XVIII.

In contrast, significant positive relationships were demonstrated betweeen attendance at the lecture sessions and self-esteem on the Likert scored Tichy instrument. Due to the statistically significant findings being limited to only the Tichy instrument, the hypothesis was rejected. See Table XVIII.

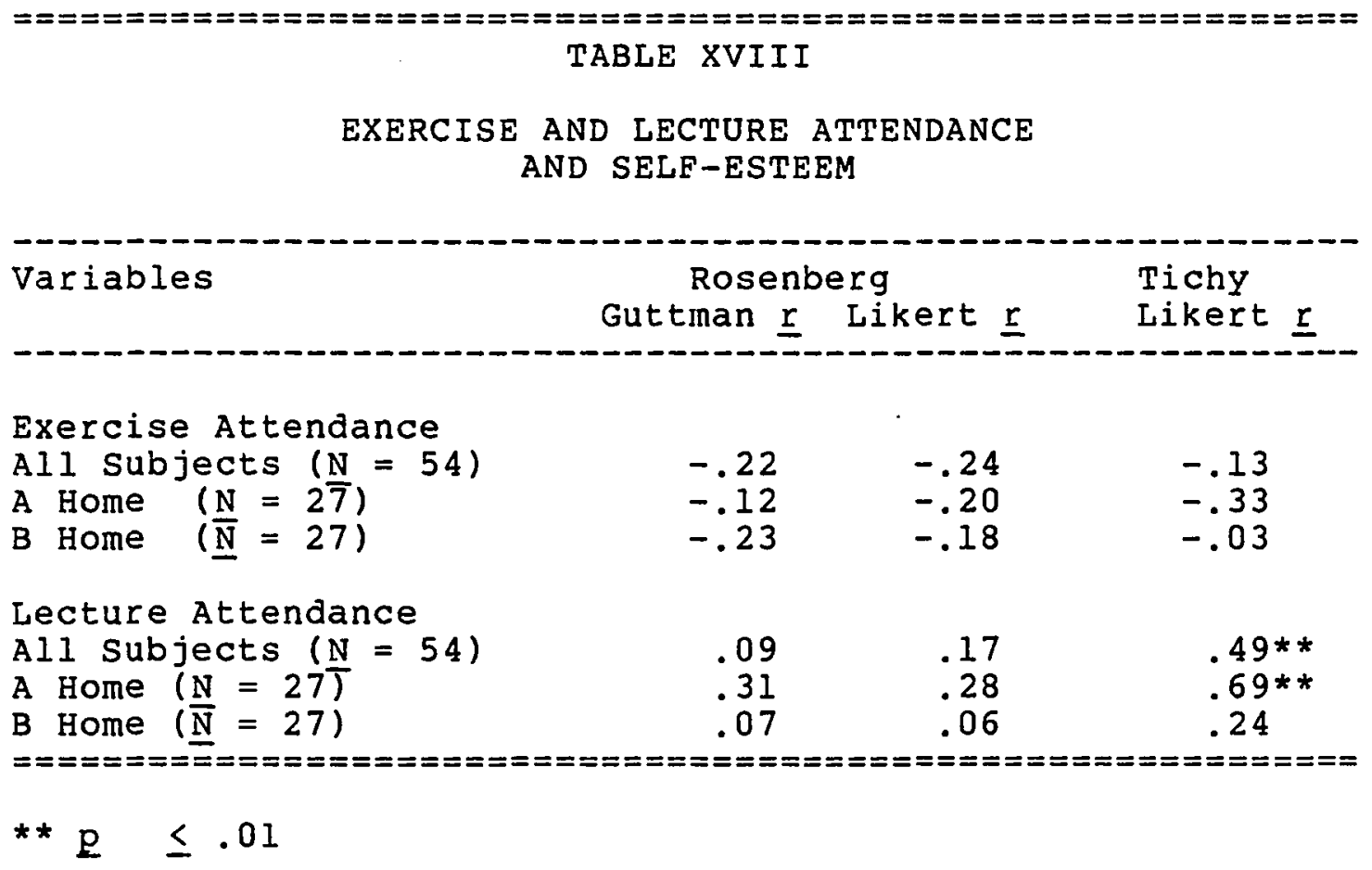

Those who attended exercise sessions were also those who considered themselves "active" or "very active" and spent considerable time out of their rooms. They also had a high attendance at the lecture sessions. The negative relationship between exercise attendance and self-esteem, 
however, was consistent with the findings of Rosenberg (1965) in regard to group participation and self-esteem. He found that there was one group which those with low self-esteem were more likely to join. That group was the glee club or choir. His explanation of this finding was that the person with low self-esteem is more likely to join a group in which there is less time or opportunity for spontaneous interaction. The individual is more often "led" by a director and controlled by the tempo of the music. Further, in a choir or glee club, the individual tends to be integrated into a collective effort rather than to stand out as an individual. Those with low self-esteem would tend to be more comfortable in such a social setting.

The exercise group could be described in a similar manner. The investigator "led" the activities, and there was little time for spontaneous interaction because of the activities provided. In contrast, the lecture setting did provide more opportunity for self-expression and informal interactions between the various group members. The atmosphere of the lecture group was kept as open and informal as possible with questions and discussion encouraged. The relationships between self-esteem of the subjects and attendance at lecture session were all positive and were highly statistically significant on the Likertscored Tichy instrument. 
Examination of the relationship between the subjects' reported illness as a cause for absence from the program sessions with self-esteem was presented in the following hypothesis:

For those subjects who supply a reason for absence from exercise or lecture sessions, the number of time illness is used as an excuse will show an inverse relationship with the pre-test level of self-esteem.

The analysis failed to show any statistically significant relationship in any group. The hypothesis was rejected. See Table XIX.

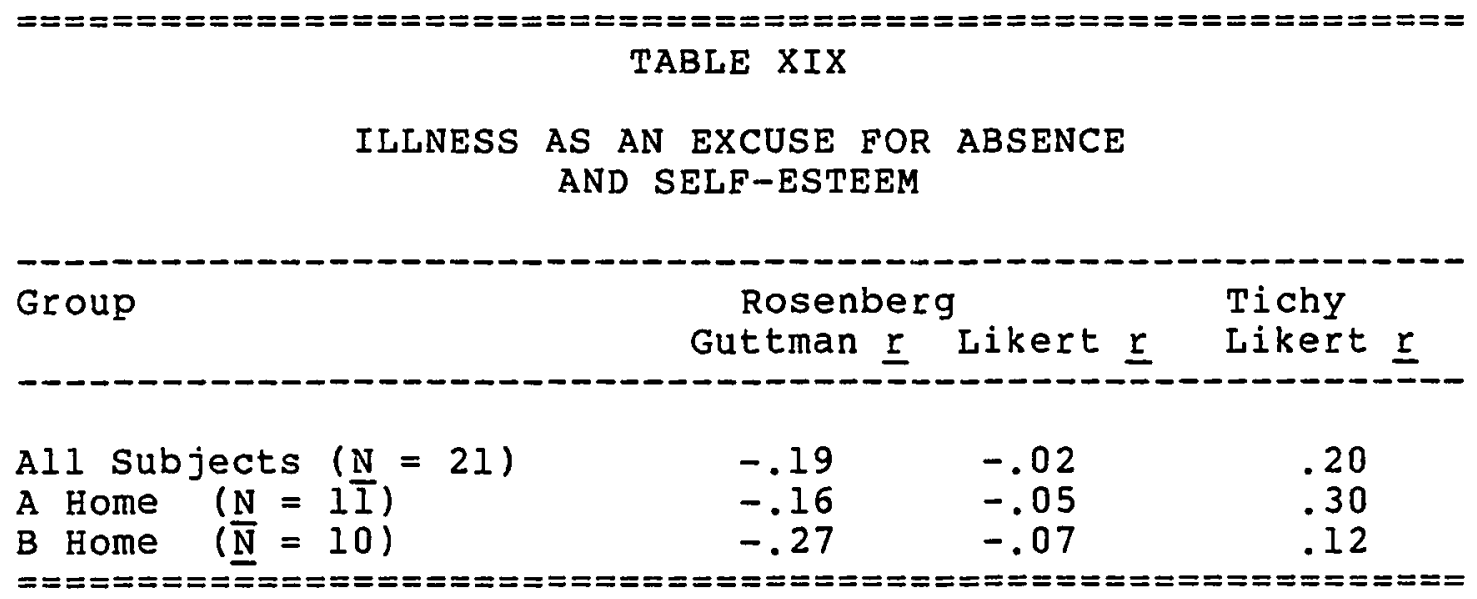

Illness and Death

Several residents in both homes became ill during the period of the study implementation. The impact of sudden serious illness of others seemed to have greater impact on the subjects in the $B$ Home. The B Home members would openly and freely discuss the illness of another resident. The 
occasion of moving three residents to the hospital by ambulance in one day was a very disruptive event as evidenced by the group's response to the program sessions. The A Home subjects, in contrast, seldom discussed the sudden illness of other residents during program sessions. The much closer, daily, physical contact with other residents, the longer term of residence typical in the $B$ Home, and the number of residents suddenly ill may have contributed to this difference in response.

One death occurred in the $A$ Home, a newly arrived resident who had begun to attend the lecture sessions. Many of the residents expressed their shock and disbelief at her sudden and unexpected death. Her death had considerable impact on the group that was not evident when other residents became seriously ill. No deaths occurred in the $B$ Home during the period of the study. Physical Condition and Self Esteem

The relationship between the main variables of the study was expressed in the following hypothesis:

The level of self-esteem and the level of physical condition as measured by the hand grip and by the leg press will show a positive relationship on pre- and post-testing.

No statistically significant correlations were found. The hypothesis was rejected. See Table xx. 


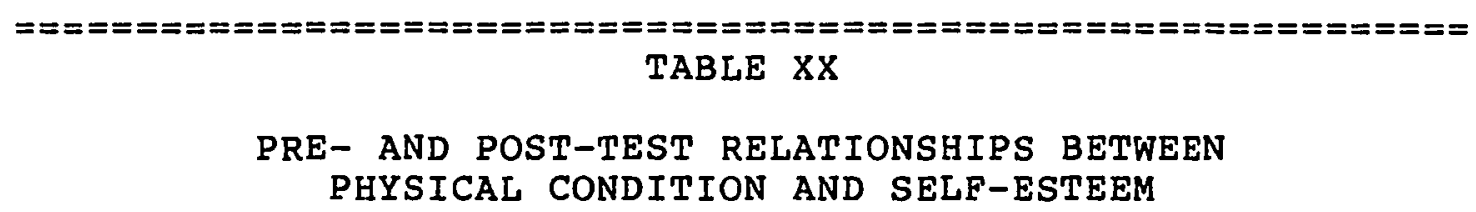

\begin{tabular}{lccc} 
Variables & \multicolumn{2}{c}{ Rosenberg } & Tichy \\
Gikert $\underline{r}$
\end{tabular}

Although the general trend on the post-test was toward a positive relationship between self-esteem and the hand grip, no findings suggested that definitive relationships between these variables existed in the elderly retirement home population. Rather, the overall observational findings of the study suggested that in the elderly, external manifestations of the level of self-esteem can be misleading. Further, the level of self-esteem, rather than being a stagnant characteristic, can be dramatically 
affected by positive and negative events in the life of the elderly person (e.g., impotence and its relief and the occurence of illness). Although the level of self-esteem in the two homes was approximately the same (as measured by the instruments used), many variations in life style, dress, group interactions, and response to the environment did occur independently of the level of self-esteem. 
CHAPTER VII

SUMMARY, CONCLUSIONS, AND IMPLICATIONS

\section{SUMMARY}

This study examined the relationship between physical condition and self-esteem among residents of two retirement homes. Specifically, the study sought to identify the present physical condition of this older population, sometimes called "frail elderly," and determine its level of self-esteem. Further, an attempt was made to determine if a program of exercise conducted four days a week for an eightweek period would have any effect on their physical condition and/or self-esteem.

The measures used to determine physical condition were the leg press measured with an electronic weight scale and the hand grip strength measured with a hand dynamometer. Self-esteem was measured using the Rosenberg self-esteem scale scored according to the Guttman and Likert methods and an investigator-developed, self-esteem behavior-related instrument. Anecdotal records of daily observations were utilized as well as post-test items pertaining to attitude toward exercise, daily activity and rest patterns, control of selection of the retirement home, and self-described activity level. 
The total population in the two homes was 127

residents. From this, 65 subjects were selected and randomly assigned to exercise or one of two control groups (lecture and no treatment). However, during the first week of the study, the residents began to attend the group of their choice. Some in the control group attended both exercise and lecture. At the same time, many of the subjects selected for the exercise groups failed to attend the scheduled sessions. The lack of randomness of the resulting groups made inferential statistical analysis inappropriate. However, the data were analyzed using correlation (Pearson $\underline{r}$ ) and analysis of variance to help identify relationships between the variables selected for study. The data also were analyzed to describe the physical and psychological characteristics of this elderly population.

The two homes selected differed in structural size and design and fundamental philosophy. The difference in size required the A Home residents to walk nearly twice as far to the dining room from their rooms as the B Home subjects. This condition, however, showed no relationship to either hand grip or leg press strength.

There was little difference in ages of the two groups of residents. Length of stay of the $A$ Home residents was affected by a refurbishing project which prevented repiacement of residents as they left the home over a threeyear period. As a result, A Home residents showed either a 
relatively short period of stay (12 months or less) or a long period of stay (over 48 months). Few A Home residents were found between these extremes. In contrast, the length of stay for the B Home residents showed a uniform distribution over a period of 1 month to 8 years. The A Home residents tended to be stronger than the $B$ Home residents. They spent more time out of their rooms and less time sleeping. They much more frequently described walking (in and out of doors) as an activity than did the $B$ Home subjects.

Subjects were asked whether they believed that the body's need for exercise decreases as one gets older. Those who accepted the statement as true had lower hand grip strength than did those who denied it. However, the leg press strength was greater for those who accepted the statement than those who denied it. None of these findings were statistically significant.

The relationship between the daily hours of reported "activity" (time spent out of the subject's room) showed a statistically significant positive relationship with leg press strength for all subjects combined and the $A$ Home subjects. In contrast, the positive relationship of hand grip strength with hours of activity was statistically significant only with the A Home residents. It is likely that the broad definition of "activity" used in this study 
did not result in a valid measure of actual energy expended or movement required.

A statistically significant relationship between hours of "rest" (time reported as napping, resting and/or night sleep) and hand grip strength was found in the A Home subjects. Although all other findings showed a negative correlation (more rest = less strength), none was statistically significant.

When comparing self-reported hours of activity and rest with the self-described level of activity, the subjects were fairly consistent. This is in contrast to reports in the literature (Sidney \& Shephard, 1977), which found much discrepancy between actual and the subjects' description of their level of physical activity. However, the expectation that those who chose more active physical recreational pursuits would be more physically fit was not met.

Throughout the study, few randomly assigned subjects and few volunteers chose to attend the exercise sessions. Those who attended did so with many explanations of their "Iimitations" and/or why they could not do certain activities. Only two subjects even suggested that age contributed to their Iimitations. Both of these were men who resided in the A Home. This was unexpected based on the number of subjects who accepted the statement that the body's need for exercise decreases with age. Few subjects exhibited fundamental knowledge regarding exercise, what to 
do, how to do it, or the presumed advantages of it. Yet, many could describe the serious adverse effects of exercise on themselves or of limitations imposed upon them by physicians.

Although the level of exercise intensity was kept quite low, beneficial effects were identified by the residents and also through the investigator's observations. Regularly attending B Home residents noted that following the intensive work related to getting in and out of a chair, they could "get out of the tub (bathtub) easier." Eurther, observations by the investigator were that those who had the most severe limitations in this activity initially showed the greatest improvement over time. They were better able to rise from a chair without wavering at the end of the exercise program. Likewise, those who were most limited in flexibility on pre-testing made greater progress than those who had less limitation. By their own acknowledgement, the range of motion was easier to do by the exercised subjects by the end of the study.

Lecture session attendance was better attended than the exercise sessions. More of the randomly assigned subjects and volunteers attended lecture on a regular basis than attended exercise.

B Home subjects experienced much more drowsiness during lecture sessions than did those in the A Home. The apparent lesser physical strength of the B Home subjects may 
have contributed to the persistent drowsiness. However, other contributing factors may have been the warmer room and afternoon hours of the $B$ Home lectures. Subjects attending the lecture sessions indicated interest in the topics (even those experiencing much drowsiness). Many asked general and personal health-related questions.

The self-esteem level for residents of both homes was quite high. Nonetheless, there were individuals who scored the lowest possible score on the self-esteem instruments. The level of self-esteem was not always predictable from the observed behavior of the subject. Those who were ill or depressed could be supposed to have low self-esteem from their actions or responses. There were some residents, however, whose appearance and behavior gave the appearance of high self-esteem when, in fact, it was quite low.

The interaction between physical condition and selfesteem was examined. Correlations between the number of times illness was given as an excuse for absence from exercise or lecture sessions and self-esteem revealed no statistically significant relationships.

In the study design, length of stay in the retirement home was expected to have a negative impact on the selfesteem of the subjects. Contrary to the expected relationship, length of stay showed a statistically significant positive relationship with self-esteem on the Guttman- and Likert-scored Rosenberg and the Likert-scored 
Tichy instruments in B Home subjects. Because the length of stay for the B Home subjects was uninterrupted, this finding probably was more suggestive of self-esteem in retirement home populations. Age, however, showed no relationship with self-esteem.

Control over one's life was described by Rodin (1978) as a major factor in the self-esteem and well being of her older subjects. The responses to the question, "Why did you select this retirement home?" provided the basis for analysis of the level of control felt by these subjects. Those who indicated some level of control over their selection of a retirement home (and/or their move into one) had higher self-esteem levels on all measures than those who expressed no control. A positive statistically significant relationship was demonstrated on the Likert-scored Rosenberg for the B Home subjects and the combined group.

Another external clue to detecting underlying selfesteem was expected to be the number of hours spent in "activity" and in "rest." "Activity" (those hours spent outside of the resident's room), however, showed no statistically significant relationship with the subject's self-esteem. The hours of rest (including self-described hours of naps, resting and night sleep), in contrast, showed a statistically significant negative relationship on the Likert-scored Rosenberg for the B Home subjects and for the total group. 
Rosenberg (1965) demonstrated that those with higher self-esteem were more likely to be leaders and participants in social settings. However, the results of this study demonstrated a statistically significant negative relationship between self-esteem and participation in the study exercise sessions. Further examination of the Rosenberg study (1965) revealed that those with low selfesteem were much more likely to participate when the group activities are structured, requiring limited spontaneous interactions between members. The exercise sessions had limited social interaction, and the subjects participated in the investigator-led activities.

The relationship between the physical and psychological characteristics of the subjects was expected to be positive. Those subjects with high self-esteem were expected to demonstrate greater hand grip and leg press strength than those with low self-esteem. However, no statistically significant relationship was found between the post-test physical condition as demonstrated by the hand grip or the leg press and self-esteem.

Table XXI presents a summary of findings related to physical condition, and Table XXII presents a summary of findings related to psychological factors. 


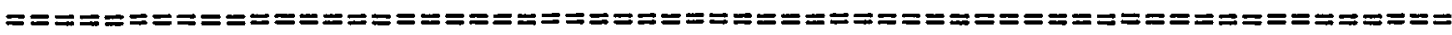

TABLE XXI

\section{SUMMARY CORRELATIONS OF VARIABLES RELATED}

TO PHYSICAL CONDITION

Variables Subjects/N Hand Grip Leg Press

Age

$\begin{array}{lcr}\text { Combined/65 } & -.43 * * & -.06 \\ \text { A Home } / 33 & -.68 * * & -.26 \\ \text { B Home } / 32 & .05 & .00\end{array}$

Distance to Dining Room

$\begin{array}{lrr}\text { Combined } / 65 & .23 & .02 \\ \text { A Home } / 33 & .07 & -.06 \\ \text { B Home } / 32 & .25 & .06\end{array}$

Hours of Activity

$\begin{array}{lll}\text { Combined } / 65 & .21 & .34 * * \\ \text { A Home } / 33 & .43 * & .57 * * \\ \text { B Home } / 32 & .04 & .14\end{array}$

Hours of Rest

$\begin{array}{lll}\text { Combined/65 } & -.18 & -.22 \\ \text { A Home/33 } & -.48 * & -.14 \\ \text { B Home/32 } & -.13 & -.28\end{array}$

Recreational pursuits

$\begin{array}{lrr}\text { Combined } / 54 & .14 & .09 \\ \text { A Home } / 27 & .16 & .09 \\ \text { B Home } / 27 & -.20 & .14\end{array}$

Self-Described Activity Level

$\begin{array}{lrr}\text { Combined } / 54 & .04 & -.23 \\ \text { A Home } / 27 & -.07 & -.23 \\ \text { B Home } / 27 & .26 & -.14\end{array}$

Exercise/Lecture Attendance

Combined/65 $\quad-.12 \quad-.04$

$\begin{array}{lrr}\text { A Home } / 33 & -.15 & .01 \\ \text { B Home } / 32 & .01 & -.13\end{array}$

B Home $/ 32$

$-.13$ 


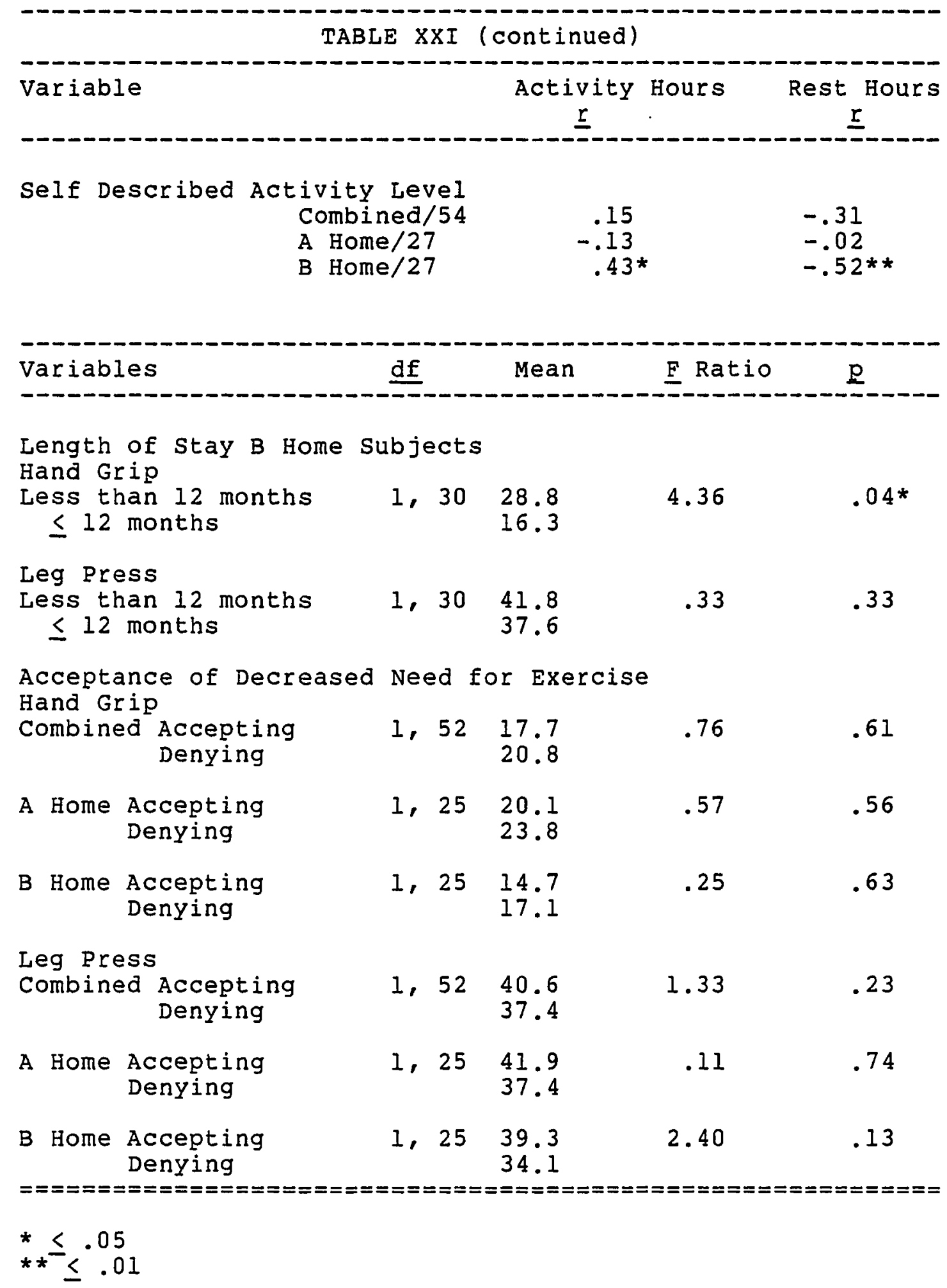




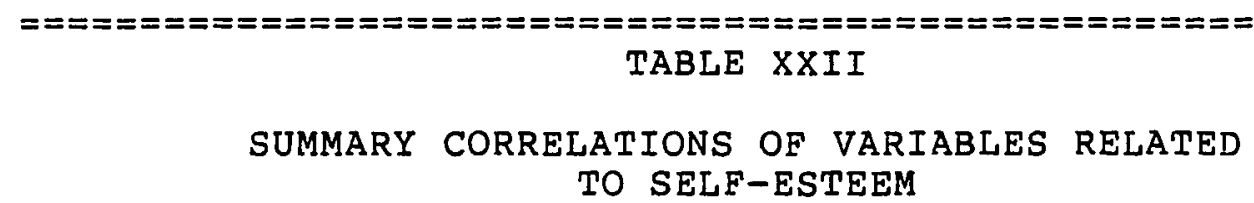

\begin{tabular}{|c|c|c|c|c|}
\hline Variables & subjects/N & Gutt & $\begin{array}{l}\text { rg } \\
\text { ikert }\end{array}$ & $\begin{array}{l}\text { Tichy } \\
\text { Like }\end{array}$ \\
\hline \multicolumn{5}{|l|}{ Age } \\
\hline & $\begin{array}{l}\text { Combined/65 } \\
\text { A Home } / 33 \\
\text { B Home } / 32\end{array}$ & $\begin{array}{r}.07 \\
-.015 \\
.28\end{array}$ & $\begin{array}{r}.09 \\
-.20 \\
.28\end{array}$ & $\begin{array}{r}-.19 \\
-.25 \\
.01\end{array}$ \\
\hline
\end{tabular}

Hours of Activity

$\begin{array}{llll}\text { Combined } / 54 & .09 & .15 & .18 \\ \text { A Home } / 27 & .10 & .18 & .08 \\ \text { B Home } / 27 & .06 & .12 & .30\end{array}$

Hours of Rest

$\begin{array}{llll}\text { Combined/54 } & -.18 & -.31 * & -.18 \\ \text { A Home/27 } & -.03 & -.21 & -.20 \\ \text { B Home } / 27 & -.17 & -.32 * & -.28\end{array}$

Exercise Attendance
Combined/54 -.22
A Home $/ 27 \quad-.12$
$-.24-.13$
B Home $/ 27$
$-.23$
$-.20-. .33$
$-.18-.03$

Lecture Attendance

$\begin{array}{llll}\text { Combined } / 54 & .09 & .17 & .49 * * \\ \text { A Home } / 27 & .32 & .28 & .69 * * \\ \text { B Home } / 27 & .07 & .06 & .24\end{array}$

Illness as An Excuse for Absence

$\begin{array}{llll}\text { Combined/54 } & -.19 & -.02 & .20 \\ \text { A Home } / 27 & -.16 & -.05 & .30 \\ \text { B Home } / 27 & -.27 & -.07 & .12\end{array}$

Pre-Test Hand Grip

$\begin{array}{lrrr}\text { Combined/54 } & -.05 & -.07 & -.05 \\ \text { A Home } / 27 & .17 & .24 & .12 \\ \text { B Home } / 27 & -.31 & -.08 & -.25\end{array}$




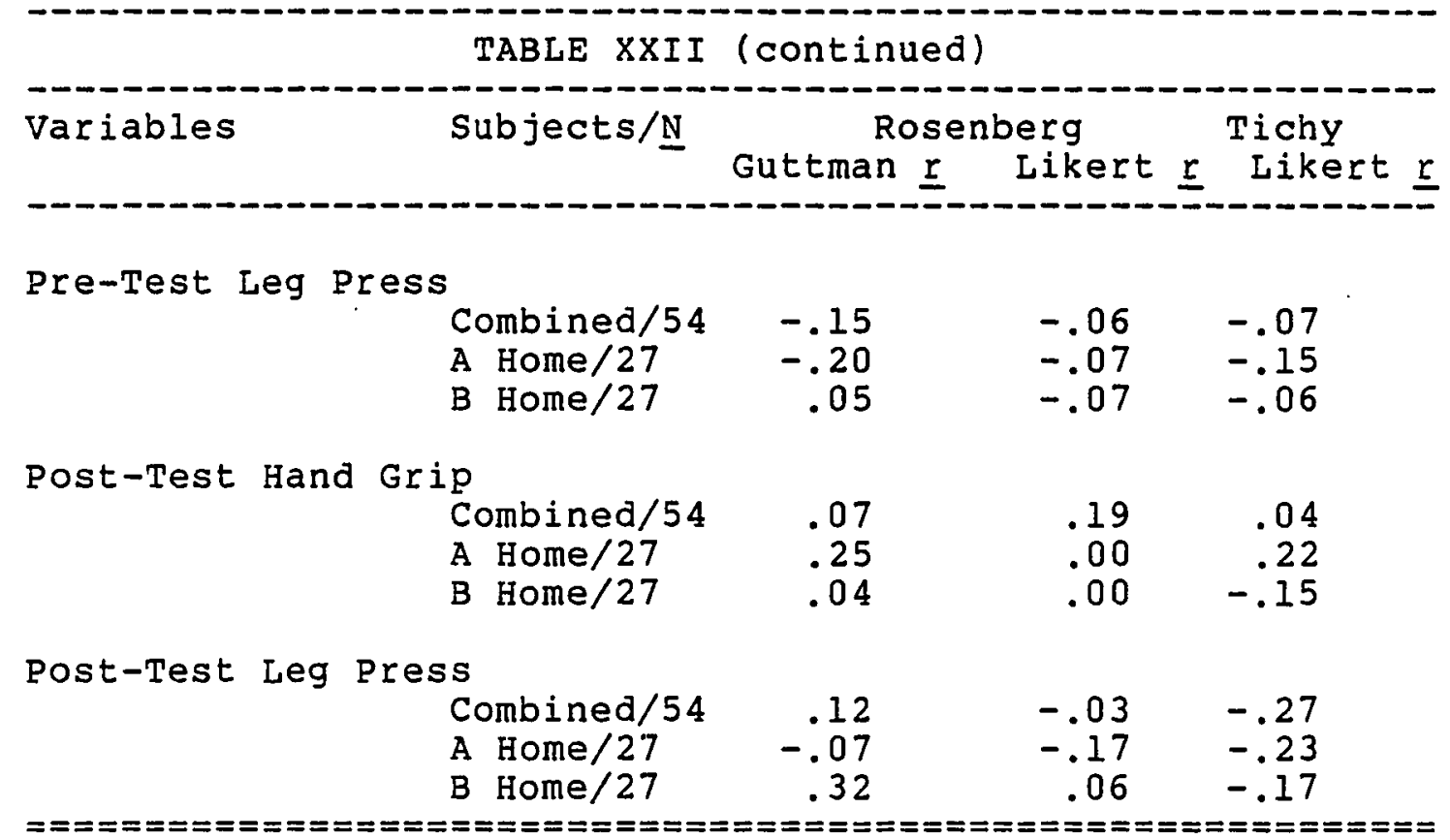


TABLE XXII (continued)

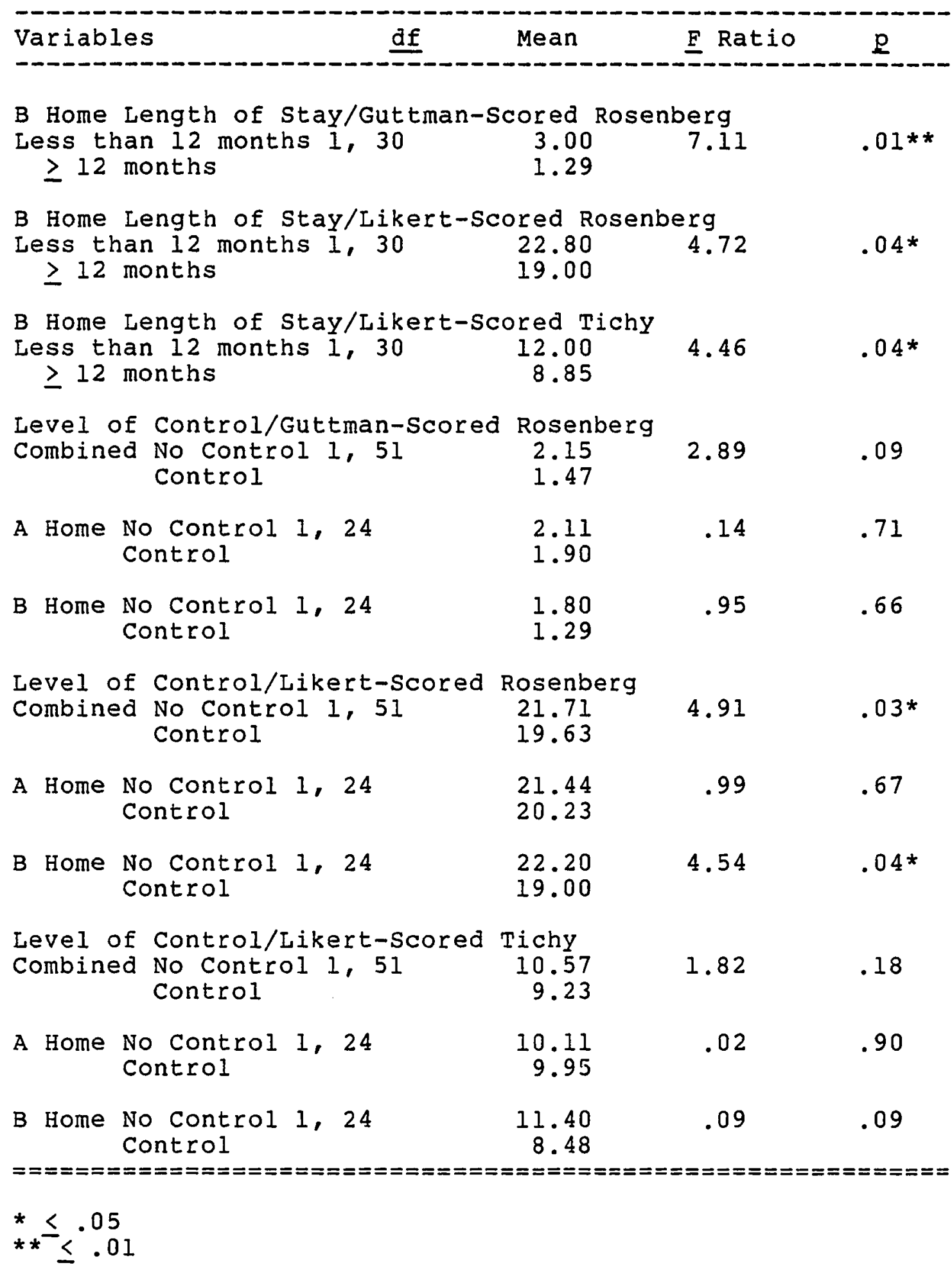




\section{LIMITATIONS OF THE STUDY}

Older persons suffering from some dysfunction, be it physical, emotional, social, or financial, have fewer personal reserves to draw upon. As a result, dysfunction in any one area may have an impact on the person as a functional whole (Murray, 1980). For example, hospital nurses have long noted that elderly patients suffering from relatively mild infections (e.g., urinary tract) often become disoriented and confused. They ofen act "senile." When the disorder is corrected, their mental processes clear, and they often return to their former level of mental and physical functioning (Murray, 1980; Burnside, 1981). The interrelatedness of all of the body's systems and the impact of one system upon the other (including mental and physical) speaks to the focus of this study.

In retrospect, the fundamental design of this study failed to take into sufficient consideration this highly complex, interrelated nature of the elderly person. Particularly affected was self-esteem, a product of many life experiences. Changes in a variety of factors including current physical and/or mental health of the subject or significant others did affect the variable of self-esteem. The magnitude of some changes were small when compared to changes which occurred at other times in the subjects' lives. Due to the limited physical and/or mental reserve 
available to older individuals, however, the effects of the changes confounded the results of the study.

Another important limitation of this study was the lack of information about previous life experiences including education, work experience, social interactions, income, marital status, health, and attitude toward aging. Further study regarding self-esteem in the elderly should include data related to previous life experiences that may have some impact on the older person's self-esteem. Although Wyley (1974) described the reproducibility and selfstability of the Rosenberg instrument as very high, it may be that the instruments used (Rosenberg and Tichy) were not appropriate for this older population.

The inability to reproduce the results of the flexibility testing in this population was a major limitation of the study. Elimination of the flexibility measure left only two measures available to test physical condition (hand grip and leg press). Although the hand grip procedure is standardized, the leg press procedure was designed for this study and not pre-tested or standardized.

Tests of physical condition in the elderly pose serious concerns. First is the safety of the subjects. Second, the willingness and ability of subjects to respond to their maximal level is open to conjecture. What impact fatigue, pain, and fear have on the measures obtained was also difficult to calculate. 
The implementation phase of the study also posed special problems. The persistent reluctance of the study population to participate in the offered exercise program suggests the presence of a lack of knowledge and/or underlying fear of exercise. In addition, many of the subjects believed that they were already as active as others their age and that the need for exercise decreases as one ages. The study failed to provide adequate information regarding the nature and need for exercise to the study subjects before asking them to participate.

Being old does provide a certain level of freedom. The subjects in this study demonstrated their level of independence by attending or not attending the offered activities according to their own desires. There seems to be less willingness to comply with requests when what is asked for does not meet older persons' expectations of what is valuable or necessary.

\section{CONCLUSIONS AND RECOMMENDATIONS}

The physical findings of this study indicated that the residents of these two retirement homes were limited in hand grip and leg press strength. The A Home subjects with their greater propensity for walking, however, did have greater hand grip and leg press strength than the $B$ Home subjects who tended to "rest" more. The results indicated that a prolonged period of regular mild exercise can help to 
maintain some level of fitness in the elderly. Yet, self-motivated and self-directed activity may be inadequate to maintain optimum hand and leg strength in this population described as "frail elderly." Thus, there is a need for structured programs of physical conditioning for the elderly.

The focus of fitness programs for the elderly should be on those exercises and activities that will promote strength and flexibility. These physical attributes are necessary for activities of daily living and enhance the quality of life, health, and well-being of the older adult. The greatest limitation in function observed in the subjects of this study was that of rising from a chair. The loss of leg strength and the resulting increased effort needed to rise from a chair encourages the older adult to reduce further active movement which in turn reduces strength. The resulting downward spiral in physical condition can actually be life-threatening. Falls and the resulting fractures are a frequent cause of death in the elderly (Murray, Huelskoetter, \& O'Driscoll, 1980). Improved physical condition including strength and coordination can help prevent these unfortunate accidents. Freedom from the disabilities resulting from accidents should lead to a more satisfying and happy old age for most people.

A program which seeks to maintain and/or develop physical condition in the elderly population needs first to 
provide an information base regarding fundamentals of exercise. Much of the subjects' resistance to attending the exercise sessions seemed to be related to mis-information and lack of information about exercise and its effects. This was also evident in those who did attend the exercise sessions. Their wide variety of excuses and explanations as to why they could not do one exercise or another seemed to be related to underlying fears. They were reluctant to participate for fear they would cause further damage to some other physical impairment. There was some indication that they were afraid they would not perform as well as some of the others and might look foolish.

A variety of sedentary activities offered in retirement home settings do provide interesting and enlightening entertainment for the residents. More emphasis, however, needs to be placed on providing activities that actually require the resident to participate physically through movement of body parts. Walking tours through the neighborhood, regularly scheduled exercise periods, fishing trips, shopping, and other activities could further improve the physical condition of retirement home residents.

Another conclusion derived from the study relates to the subjects' attitude toward exercise in relation to age. The majority accepted the statement that the body's need for exercise decreases with age. With this attitude, the subjects are better able to justify their lack of physical 
activity as they grow older. . "It isn't necessary." Rather than recognizing that with disuse comes dysfunction, these subjects were ready to accept the concept that lack of use has no relationship with dysfunction. One might say that they were more concerned about "wearing out" than "rusting out."

Further, the cohort group included in this study should be considered in order to understand better the response to the offered exercise program. Women born seventy or eighty years ago were not expected to exercise physically beyond childhood (except in the performance of homemaker kind of responsibilities). Few persons, male or female, needed to, or did, participate in activity merely to "keep fit." The routine requirements of life were generally more physically demanding than the life style to which they were now accustomed. For example, many had to walk or ride the bus to work or shop. Convenience foods were not readily available. The homemaker did the food preparation and preservation. Laundry was more often done by hand and carried outside to hang on the line. Manual labor was a common work requirement. Many of the labor saving devices currently used in all aspects of life did not exist then. Further, entertainment more often required participation of the individual rather than the passive role now characteristic of television viewing. Long walks were ordinary and accepted modes of evening entertainment. 
Dances, picnics, and socials required the individual to be physically active in order to enjoy the recreation in contrast to today's mode of sitting back and "being entertained."

The retirement home setting provides essential services to the residents, yet, at the same time, encourages the residents to be inactive. All sorts of conveniences are provided for them. All of these conveniences reduce their need to be physically active in the on-going pursuit of life. Meals are prepared and served to them; their only requirement is to come to the dining room. Their rooms are cleaned on a regular basis and their laundry is done. Their only requirements include making their own bed each day and dressing themselves. For some, even this aspect of personal hygiene is delegated to the home staff through the assistance provided for bathing.

In the retirement home setting, the very delicate balance that exists between helping older individuals retain some independence and doing "too much" for them is difficult to maintain. Constant reevaluation of the residents' status, strengths, and needs is an ongoing responsibility for the home staff so that the residents' ability to function somewhat independently is maintained. Residents need to be encouraged to use their energies to take an active part in every aspect of daily life. The fact that it is easier, faster, and/or less troublesome to do something for older 
adults cannot be the reason to do more and more for them. The underlying criterion is whether the individuals can do it alone, with help, or not at all. Help should then be provided on the basis of need. The more independence older persons strive to maintain, the more independent they will be. With that independence comes the feeling of control Rodin (1978) describes as so important in the maintenance of self-esteem.

For these subjects, the contribution that the retirement home staff makes to the maintenance of selfesteem can be significant. The staff of these two retirement homes appeared to contribute positively to the self-esteem of the residents. Both groups of residents had relatively high self-esteem. However, the self-esteem seemed to be a rather fragile condition affected by both positive and negative developments. A major change in physical or psychological status was associated with major changes in the scores indicating change in self-esteem status from high to low, or vice versa. Subjects who became ill had a loss in self-esteem; those who had a change for the better in their well-being demonstrated higher self-esteem.

In some subjects, self-esteem develops throughout the lifetime and appears to remain relatively stable. In others, the balance between high and low self-esteem may be more precariously balanced. Further, it was found that the level if self-esteem was not always apparent. The less than astute 
observer could be mistaken as to the level of aslf-esteem in any one individual. Certain characteristics of depression and isolationism might give some clues as to the level of self-esteem. Yet, several subjects had very low self-esteem, but. were congenial, poised, and interactive with others. The older adult, it seems, has learned that certain behaviors are "expected" and "desirable" regardless of how one feels inside about her/himself. It may be that those with low self-esteem act in a socially desirable manner to prevent further loss of esteem from the rebuke of their peers. Long hours spent in sleeping and resting are not "normal" for the older adult. The suggestion by these findings is that prolonged hours of rest in retirement home residents indicates a low level of self-esteem and that some intervention needs to be taken by family, friends, or home staff.

\section{IMPLICATIONS FOR FUTURE RESEARCH}

The projected growth in the population of older persons in the United States and the need to understand better the elements necessary for a satisfactory quality of life has implications for future research. Old age is just another phase of life most persons will experience. Research which seeks to determine how best to meet the needs of this group of citizens seems imperative if the quality of life is 
to be improved and the hope for meaningful and satisfying old age are to be met.

Further, when a large group of society has a reduced quality of life, limited physical abilities, and low selfesteem, others in that society also will be affected. Certainly, the economic impact of a reduced quality of life for the aged will be significant as more and more of the financial resources of the nation are directed toward the care of this growing segment of society. The humanitarian impact lies in the recognition that these persons will experience a less than satisfactory life style due to their physical and mental limitations. As their quality of life becomes increasingly restrictive and dependent, society will experience the loss of productive members.

The frail elderly were the target population for the study. They represent a segment of the older citizens with special needs. As society continues to age and the physical condition of some members deteriorates, more and more older persons may eventually need retirement home facilities as a "step down" from truly independent living. The frail elderly found in retirement home settings are also the ones most at risk for continued physical deterioration, loss of selfesteem, and diminished quality of life due to their already compromised physical and mental health status.

Although the loss of the experimental design prevented detection of the direct effect of exercise on self-esteem 
and physical condition, general trends and areas for further study were identified. Studies which examine the special needs of the older population can provide the foundation for select educational programs. These programs should focus first on preparing everyone in the population for the inevitable process of aging. Second, they should identify and seek to promote those life-time activities and/or precautions which will delay or even eliminate factors of dysfunction and/or disease.

Because the research variables used with older populations are so inherently complex and interrelated, development of instruments which provide the necessary validity and reliability is essential. Focus on actual performance of activities of daily living, while complex and difficult, would provide a better measure of the quality of life than the two measures of strength used in this study. The development of reliable and valid instruments for the measurement of leg press strength and flexibility, however, would be necessary for the comprehensive physical assessment of elderly subjects and their ability to perform activities of daily living.

A pre-test of the subjects' attitudes would aid in the examination of change as a result of interventions. Included for study should be attitudes toward aging, exercise, mental and physical health status, past experiences with exercise, health practices, and education level. 
The need to maintain randomly selected groups in future studies of the elderly will be difficult to achieve in the retirement home setting. Given the inclination of older persons to participate at whatever level they find acceptable, the more effective solution is to select different homes for the experimental and control groups. The underlying characteristics of the homes including size, physical plant design, general practices, and population size are major considerations in matching the subjects. The opportunity for physical activity within the home environment and the support for residents' self-esteem are also important.

The Role of Community Colleges

The community college as a resource to society is unique. As one of its functions, the community college provides educational preparation for a wide variety of health care providers as well as occupational upgrading for many vocations and businesses. As the number of aged in the population continues to increase, interactions between all members of society with this "new generation" will increase. A better understanding of normal aging and the pathological conditions that frequently are associated with aging must be developed in the younger as well as the older citizens. As the educational center for many communities, the community college has the responsibility to meet the changing needs in regard to the aging population. Curricula 
designed for educational preparation of health care providers must include appropriate orientation to the special needs of the elderly. The demands of the older members of our society upon the health care system is greater than any other group. Health care providers must be aware of what is normal and abnormal function and how best to meet the special needs of the elderly. Likewise, professional updating must be directed toward maintaining the delivery of high quality care for this population. Likewise, the increasing numbers of independent elderly living in the community must be served. How best to maintain and actually increase their ability to meet the demands of independent living is a special challenge for community college educational programs. Information and demonstration of health practices important in the maintenance of health and fitness should be offered in locations available and convenient to the older citizens under community college auspices. Financial and safety concerns and many other aspects of life affect the elderly as well as others in the community. These issues also can be effectively and efficiently addressed through the community college comprehensive plan.

\section{The Future}

In order to preserve and enhance the quality of life for persons in this stage of human development, research which will promote a higher level of physical and mental 
function than currently found in the aged must be undertaken. The definition of needs, expectations, and hopes of this segment of the population can be addressed by a wide variety of community resources including, but not limited to, the health care industry, elementary, secondary and postsecondary education, industry, and private and public social services. Since a long, productive, and healthy life is a goal appropriate for all citizens, it is also appropriate that all aspects of society work toward an understanding of the aging population, its changing needs, and better ways to meet them. 
Adrian, M. J. (1981). Flexibility in the aging adult. In E. L. Smith, \& Serfass, R. C. (Eds.). Exercise and aging. Hillside, NJ: Enslow.

Aniansson, A. (1980). Muscle function in old age with special reference to muscle morphology, effect of training and capacity in daily living. Thesis, Departments of Rehabilitation Medicine and Geriatric and Long-Term Medicine, University of Goteborg, Sweden.

Atchley, R. (1977). The social forces in later life (2nd Ed.) Belmont, CA: Wadsworth.

Bar-or, 0. (1977). Age-related changes in exercise perception. In Borg, G. (Ed). Physical work and effort. New York: Pergamon Press.

Burke, W. E., Tuttle, W. W., Thompson, C. W., Janney, C. D., \& Weber, R. J. (1953). The relation of grip-strength endurance to age. Journal of Applied Physiology, 5,629 .

Burnside, I. R. (1981). Nursing and the aged. New York: McGraw-Hill.

Buros, O. K. (1974). Tests in print II. Highland Park, NJ: Gryphon Press.

Busse, E. \& Pfeiffey, E., (Eds.). (1969). Behavior and adaptation in late life. Boston: Little, Brown.

Butler, R. N. (1978). To find the answers. In Gross, R., , Gross, B., \& Seidman, S. (Eds), The new old:

Struggling for decent aging. Garden City, N. Y.: Anchor Press.

Cameron, M. (1976). Views of aging. Ann Arbor, MI: University of Michigan Institute of Gerontology.

Carnevali, D. L., \& Patrick, M. (1979). Nursing management for the elderly. Philadelphia: J. B. Lippincott. 
Carrol, D. (1965). A quantitative test of upper extremity function. Journal of Chronic Disease, 18, 479.

Cattell, R. B., \& Warburton, F. W.(1967). Objective personality and motivation tests. Urbana, IL: University of Illinois Press.

Clarke, H. H. (Ed.). (1973). National adult physical fitness survey. President's council on physical fitness and sports newsletter.

Clarke, H. H. (Ed.). (1977). Exercise and aging. Physical Fitness Research Digest, 7,2 .

Conrad, C.C. (1976). "When you're young at heart." Aging, $\underline{258}, 11-13$.

Corbin, C., \& Lindsey, R. (1983). Fitness for life (2nd ed.). Glenview, IL: Scott, Foresman.

Daniewicz, C. (1974). Outreach program minimizes premature institutionalization. Hospital Progress, 55, 26-35.

deVries, H. A. (1974). Vigor regained. Englewood Cliffs, N. J.: Prentice-Hall.

deVries, H. A. (1970). "Physiological effects of an exercise training regimen upon men aged 52-88. Journal of Gerontology, 25,335 .

Ebel, H., Sol, N., Bailey, D., \& Schechter, S., (Eds.). (1983). Presidential sports award fitness manual. Haverton, PA: FitCom Corporation.

Falk, G., Falk, V., \& Tomashevich, G. V. (1981). Aging in America and other cultures. Sartoga, CA: Century Twenty One.

Falls, H., Baylor, A., \& Dishman, R. (1980). Essentials of fitness. Philadelphia: Saunder College/Holt, Rinehart and Winston.

Fitts, R. H. (1981). Aging and skeletal muscle. In Smith, E. L. \& Serfass, R. C. (Eds.). Exercise and aging. Hillside, NJ: Enslow, 124-25.

Frankel, L. J., \& Richard, B. B. (1977). Gerokinesiatrics--A pharmacopoea of exercises for the elderly. In L. J. Frankel \& R. Harris (Eds.), Guide to fitness after fifty. New York: Plenum.

Fromm, E. (1947). Escape from freedom. New York: Rinehart. 
Gallagher, D., Thompson, I. W. \& Levy, S. M. (1980). Clinical psychological assessment of older adults. In L. W. Poon (Ed.). Aging in the 1980s. Washington, DC: American Psychological Association.

Garn, S. M. (1975). Bone-loss and aging. In R. Goldman \& M. Rockstein (Eds.), The physiology and pathology of human aging. New York: Academic Press.

Graham, R. (1973). Diseases of the joints. In J. C. Brocklehurse (Ed.), Textbook of geriatric medicine and gerontology. London: Churchill Livingstone.

Hales, D. (1980). The complete book of sleep. Menlo Park, CA: Addison-Wesley.

Hejda, S. (1963). Skinfold in old and longlived individuals. Gerontologia, 18.

Heyman, D., \& Polansky, G. (1969). Social casework and community services for the aged. In E. Busse \& $E$. Pfeiffer (Eds.), Behavior and adaptation in late life. Boston: Little, Brown \& Co.

Hinkle, D. E., Wiersma, W. \& \& Jurs, S. G. (1979). Applied statistics for the behavioral sciences. Dallas, TX: Houghton Mifflin Co.

Hollifield, G. \& Parson, W. (1959). Overweight in the aged. American Journal of Clinical Nutrition, 7,127 .

Horney, K. (1950). Neurosis and human growth. New York: Norton.

Jackson, O. (Ed.). (1983). Physical therapy of the geriatric patient. New York: Churchill Livingstone.

Jette, A. M. \& Branch, L. G. (1981). Physical disability among the aging. The Framingham disability study: II. American Journal of Public Health, 71, 11 .

Kales, A., \& Kales, J. (1972). The relevance of sleep research to clinical practice. In G. Usdin (Ed.), Sleep research and clinical practice. New York: Brunner/Mazel.

Katch, R. I., \& McArdle, W. D. (1977). Nutrition, weight control and exercise. Boston: Houghton Mifflin.

Kreitler, H. \& Kreitler, S. (1970). Movement and aging: a psychological approach. In D. Brunner \& E. Jokl 
(Eds.), Physical activitiy and aging. Baltimore: University Park Press.

Lake, D. G., Miles, M. B. \& Earle, Jr., R. B., (Eds.).

(1973). Measuring human behavior. New York: Teachers College press.

Langer, E. (1979). Old age: An artifact? Biology, Behavior and Aging. Washington, D. C. National Research Council Publication.

Larson, R. (1978). Thirty years of research on the subjective well-being of older Americans. Journal of Gerontology, 33, 109-125.

Leinbach, R. (1977). The aging participants in an area planning effort, The Gerontologist, 17, 453-48.

Lieberman, M. A., \& Tobin, S. S. (1983). The experience of old age: stress, coping and survival. New York: Basic Book, Inc.

Litman, T. J. (1962). The aging participants in an area planning effort, The Gerontologist, 17, 453-48.

Lowenthal, M. F. (1968). The relationship between social factors and mental health in the aged. In W. E. Fann \& L. I. Madox (Eds.), Aging in modern society.

Psychiatric Research Report 23. American Psychiatric Association. .

Martin, R. \& Wilson, L. (1976). Transitions of aging. New York: Plenum Press.

Master, A. N., Lasser, R. P. \& Beckman, G. (1960). Tables of average weight and height of americans, aged 65 to 94. Journal of American Medical Association, 172, 658 .

Mayer, B. L. (1983). Age prejudice in America, In H. Cox, Ed., Aging, 3rd ed.. Guilford, CT: Dashkin Publishing Group, 73.

Meyers, C., Golding, L. A., \& Sinning, W. (Eds.). (1973). The Y's way to physical fitness. National Council YMCA, U.S.A./Rodale Press.

Mitchell, Jr., J. V. (Ed.). (1983). Tests in print III. Lincoln, NB: Buros Institute of Mental Measurements, University of Nebraska. 
Montoye, H. J., \& Lamphiear, D. F. (1977). Grip and arm strength in Males and females, age 10-69. In Practical measurements for evaluation in physical education. Minneapolis: Burgess Publishing.

Moore, B. G. (1976). A physiological, psychological, and sociological profile of physically fit older individuals (Doctoral dissertation, University of Chicago, 1981). Dissertation Abstracts International, 42, 6-A, 1796 .

Murray, R., Huelskoetter, M. M. \& O'Driscoll, D. (1980). The nursing process in later maturity. Englewood Cliffs: Prentice-Hall.

Nunnally, J. (1967). Psychometric theory. Princeton: Princeton University Press.

Ostrow, A. C. (1984). Physical activity and the older adult. Princeton: Princeton Book Co.

Parker, G. (1978). The bonds of depression. Sidney, Australia: Angus \& Robertson.

Parks, C. J. (1980). The effects of a physical fitness program on body composition, flexibility, heart rate, blood pressure, and anxiety levels of senior citizens (Doctoral dissertation, University of Illinois, 1979). Abstracts International, 41, 1-A, 157.

Peery, J. (1976). Exercises for retirees. Clackamas, OR: North Clackamas Print Shop.

Petrofsky, J. S., Burse, R. L. \& Lind, A. R. (1975). Comparison of physiological responses of women and men to isometric exercise. Journal of Applied physiology, 38, 863 .

Petrofsky, J. S. \& Lind, A. R. (1975). Isometric strength, endurance and the blood pressure and heart rate responses during isometric exercise in healthy men and women with special reference to age and body fat content. Pfluegers Archives, 360, 49 .

Pickles, B. (1983). Biological aspects of aging. In Livingstone, C. (Ed.). Physical therapy of the geriatric patient. New York: Churchill Livingstone.

Piscopo, J. (1981). Aging and human performance. In E. J. Burke (Ed.), Exercise, science and Eitness. Ithaca, NY: Mouvenment Publications. 
Piscopo, J. (1985). Fitness and aging. New York: John Wiley \& Sons.

Prinz, P. (1977). Sleep patterns in the healthy aged: Relationship with intellectual function. Journal of Gerontology, 32, 2 .

Randal1, O. A. (1977). Aging in America today--new aspects in aging. Gerontologists, 17, 6-11.

Reichard, S, Livson, F, \& Peterson, P. (1962). Aging and personality. New York: John Wiley \& Sons, Inc.

Robinson, J. P. \& Shaver, P. R. (1980). Measure of social psychological attitudes. Ann Arbor: Institute for Social Research, University of Michigan.

Rodin, J. (1978). Somatopsychics and attribution. Personality and Social Psychology Bulletin, 4 , 531-540.

Rodin, J. (1980). Managing the stress of aging: The role of control and coping. In Levine, S. \& Ursin, H. (Eds.). NATO conference on coping and health. New York: Academic Press.

Rosenberg, M. (1965). Society and the adolescent self-image. Princeton: Princeton University press.

Rosow, I. \& Breslau, H. H. (1966). A Guttman health scale for the aged. Gerontologist, $21,556$.

Rossman, I. (1979). Clinical geriatrics. Philadelphia: J. B. Lippincott.

Saltin, B., Blomquist, G., Mitchell, B., Johnson, Jr., R. L., Wildenthal, K. \& Chapman, C. B. (1968). Response to exercise after bedrest and after training. Circulation, $\underline{7}, 38-44$.

Saxon, S. \& Etten, M. J. (1978). Physical change and aging. New York: Tiresias Press.

Shadow, L. W. (1980). The relationship of exercise and aerobic fitness to self concept (Doctoral disseration, University of Missouri). Dissertation Abstracts International, 40, 9-B, 4509 .

Sharkey, Brian J. (1979). Physiology of fitness. Champaign, II: Human Kinetics Publishers. 
Shephard, R. J. (1978). Physical activity and aging. Chicago: Year Book Medical Publishers.

Sidney, K. H., \& Shephard, R. J. (1978). Attitudes toward health and physical activity in the elderly: Effects of a physical training program. Medicine and science in sports, $8,246-252$.

Silber, E. \& Tibbet, J. S. (1965). Self-esteem; Clinical assessments and measurement validation, Psychological Reports, 16, 1017-1071.

Snyder, M. (1980). A reflection on commitment and patterns of disengagement from recreational physical activity. Paper presented to the North American Society for the Sociology of sport convention, Denver, CO.

Snyder, N., \& Swann, W. (1978). Behavioral confirmation in social interaction: From social perception to social psychology, Journal of Experimental Social Psychology, 14, 148-162.

Sperling, L. (1980). Evaluation of upper extremity function in 70 year old men and women. Scandinavian Journal of Rehabilitative Medicine, 12, 139-144.

Standards of geriatric nursing practice. (1979). American Journal of Nursing, 70,9 .

Sweetland, R. C., \& Keyser, D. J. (Eds). (1983). Tests. Kansas City: Test Corporation of American.

Thomas, C. L., (Ed.). (1982). Taber's cyclopedic medical dictionary, 15th Edition. Philadelphia: F. A. Davis.

Turner, R. W., Ward, M. F. \& Turner, J. (1979). Behavioral treatment for depression: An evaluation of therapeutic components. Journal of Clinical Psychology, 35, 170 .

U. S. Department of Commerce, Bureau of the Census. (1981). 1980 Census of The Population, Vol. l. Washington, D. C.: U. S. Government Printing Office.

Vais, A. \& Anasey, J. (1965). Modes of intermolecular cross linking in mature insoluble collagen. Journal of Biological Chemistry, 240, 3899-3900.

Wylie, R. C. (1974). The self concept, revised edition, vol. 1 Lincoln: University of Nebraska Press. 
MEASURES OF SELF-ESTEEM

Bills, R., Vance, E., \& McLean, O. (1951). An index of adjustment and values. Journal of Consulting Psychology, 15, 257-261.

Butler, J. \& Haigh, G. (1954). Changes in the relation between self-concepts and ideal concepts consequent upon client-centered counseling. In P. Ragess \& I. Dymond (Eds.), Psychotherapy and personality change. Chicago: University of Chicago Press.

Coopersmith, S. (1967). The antecedents of self-esteem. San Francisco: W. H. Freeman.

Crowne, D. \& Marlowe, D. (1964). The approval motive. New York: Wiley.

Cutick, F. \& Diggory, J. (1966). Self-evaluation: concepts and studies. New York: Wiley.

Edwards, A. (1957). The social desirability variable in personality assessment and research. New York: Dryden. The actual items in this scale are part of the copywrited MMPI, which is available from the Psychoogical Corporation in New York city.)

Kaplan, H. B. \& Meyerowitz, J. H. (1969). Self-derogation and psychosocial adjustment. Journal of Nervous and Mental Diseases., 149, 421-434.

Rosenberg, M. (1965). Society and the adolescent self-image. Princeton, N. J.: Princeton University Press.

Tennessee self concept scale. (1964-65). William H. Fitts, Counselor Recordings and Tests. 
APPENDIX A

TESTING INSTRUMENTS 
PHYSICAL MEASURES

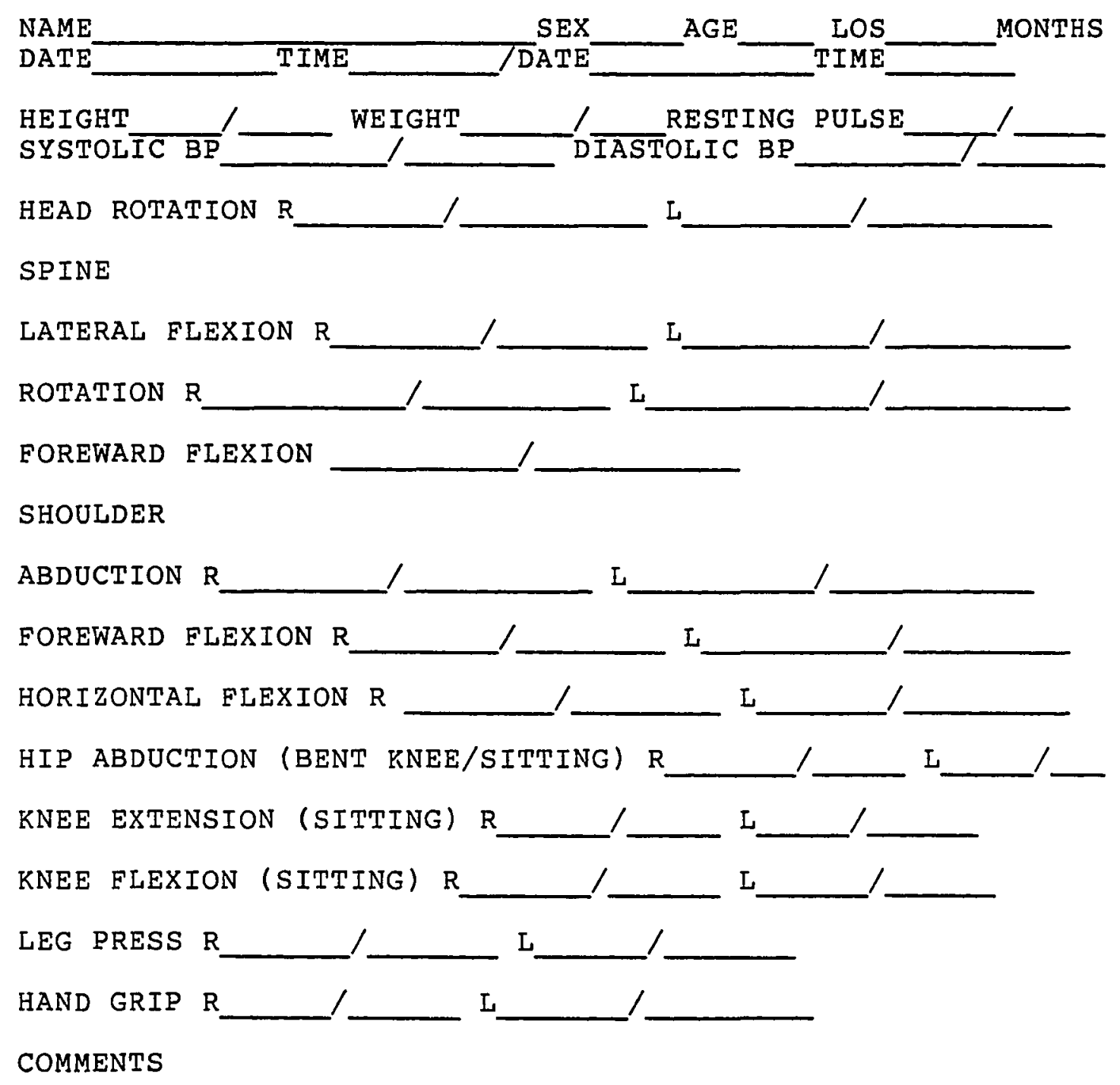


NAME DATE TIME

SELECT THE ANSWER THAT BEST REELECTS YOUR FEELINGS IN RESPONSE TO THE STATEMENT.

1. On the whole: I am satisfied with myself.

2. At times I think I am no good at all.

3. I feel that I have a number of good qualities

4. I am able to do things as well as most other people.

5. I feel I do not have much to be proud of.

6. I certainly feel useless at times.

7. I feel that I am a person of worth, at least on an equal plane with others.

8. I wish I could have more respect for myself.

9. All in all, I am inclined to feel that I am a failure.

10. I take a positive attitude toward myself.

$4:=$ very unlikely $3:=$ unlikely $2:=$ likely $1:=$ very likely

$S \quad D \quad A \quad S$

T $\quad I \quad G \quad T$

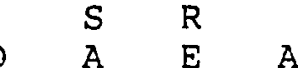

I $\quad G \quad E \quad G$

$S \quad R \quad R$

A $\quad E \quad E$

G $\quad \mathrm{E} \quad \mathrm{E}$

1. How likely are you to join in activities held here in the retirement home?

2. How likely would you be to volunteer to help with a party at the retirement home?

3. How likely would you be to express a personal opinion in a group discussion regarding a topic of interest?

4. If someone new was seated at your table in the dining room, how likely would you be to speak first?

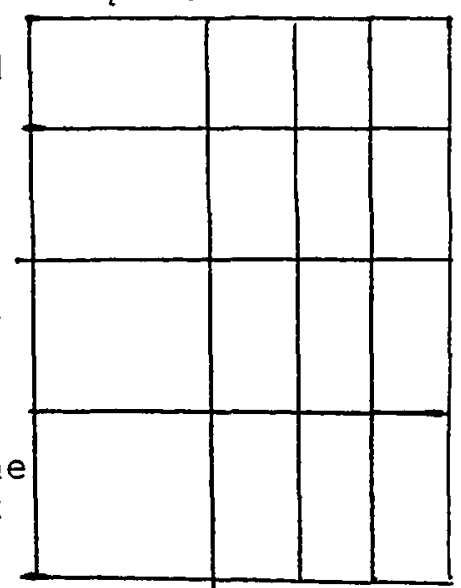

5. When was the last time you bought something just for yourself?

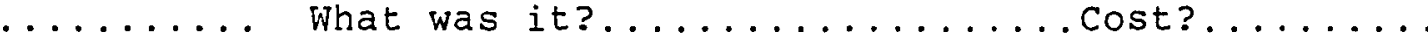


1. Where were you living just before you came to this retirement home?

2. Why did you choose this retirement home as a place to live?

3. Indicate the three recreational pursuits you would be most likely to do.

\section{reading}

visiting

resting

walking

watching television

shopping

going out to eat at a resturant

physical exercise

crafts (crochet, sewing, painting, etc.)

listening to music (or playing an instrument)

4. In comparison to most other persons your age, how would you describe your activity level?

very inactive inactive active very active

5. Listen to the following statement and indicate whether you agree or disagree.

The body's need for physical exercise decreases as one grows older.

strongly disagree disagree agree strongly agree

6. Were you aware of the health program being presented here? Yes No

7. Did you attend any sessions? Yes No

8. If yes, why did you attend?

9. If no, why did you not attend? 


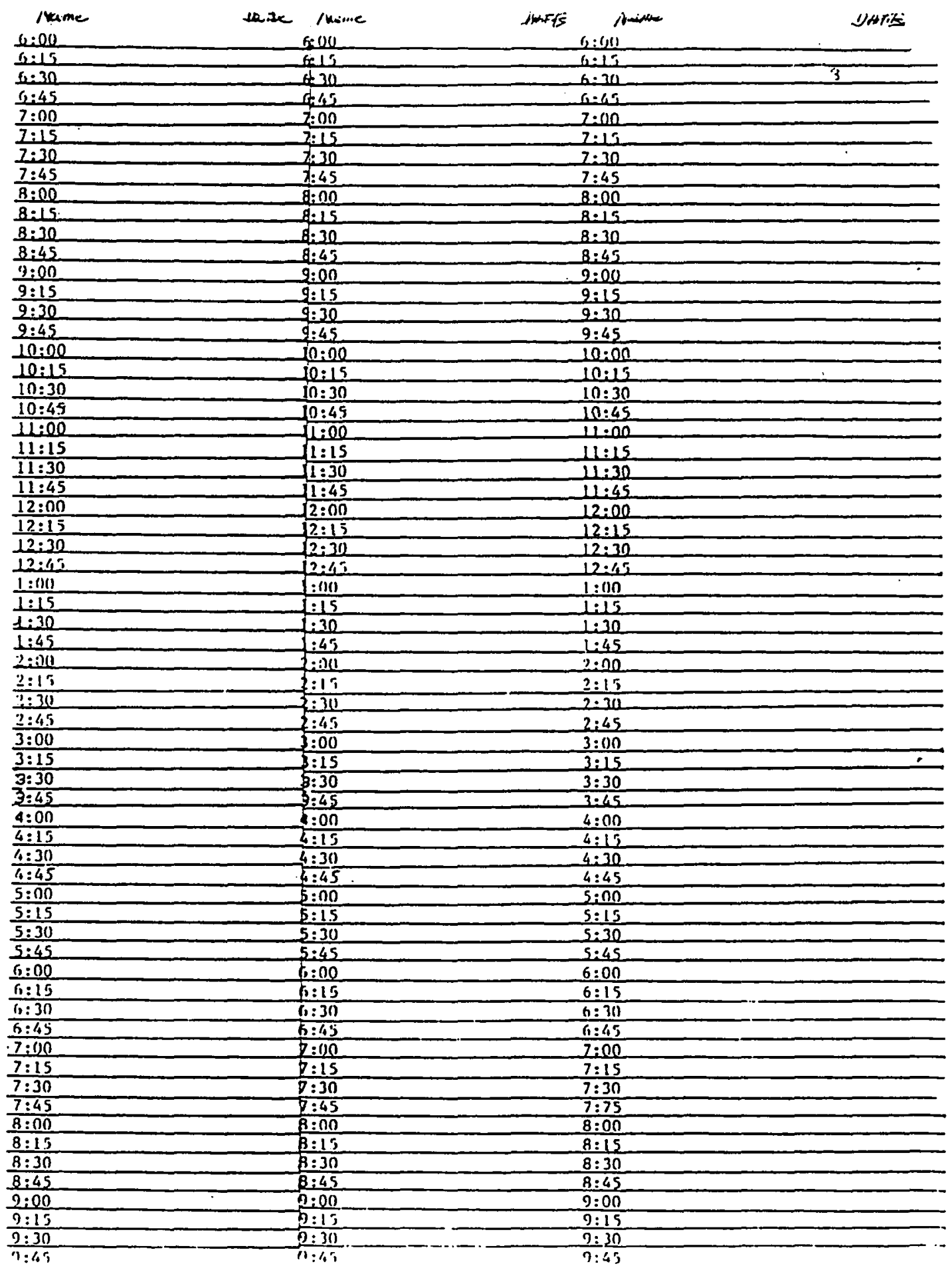




\section{INFORMED CONSENT}

I. - hereby agree to serve as a subject in the research project on the effect of regular chair exercises vs. health information presentations on depression and self-esteem in the elderly conducted by Anna Mae Tichy.

I understand that the study involves participation in chair exercises or lecture sessions four times a week for a period of eight weeks. I will answer questionnaires before and after the exercise/lecture sessions are presented.

I understand that the possible risks to me associated wih this study are possible over-exertion and/or muscle strain, fatigue or over excitement, shortness of breath, chest pain, palpitations, and/or sweating if I participate in the exercise group. If I participate in the lecture group, I understand that I will spend one half hour four days a week listening to and participating in discussions of health topics.

It has been explained to me that the purpose of the study is to learn about the special health needs of the elderly.

I may not receive any direct benefit from participation in this study, but my participation may help to increase knowledge which may benefit others in the future.

Anna Mae Tichy has offered to answer any questions I may have about the study. I have been assured that all information I give will be kept confidential and that the identity of all subjects will remain anonymous. I understand that I am free to withdraw from participation in this study at any time without jeopardizing my relationship with Portland State University.

I have read and understand the foregoing information.

Data Signature 


\section{HEALTH PROGRAM QUESTIONNAIRE}

NAME......................... DATE....TIME... . INTERVIEWER.....

1. Which health program sessions did you attend? ...exercise ...lecture

2. If you missed some sessions, please state the reasons why you did not attend.

3. How did you feel about the sessions you attended?

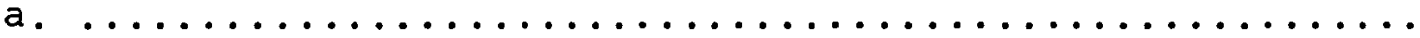

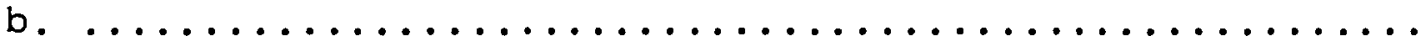

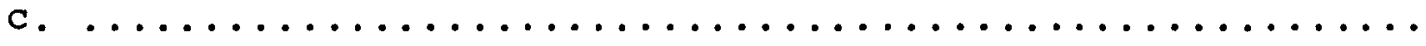

4. 4. What were the better aspects of the sessions you attended?

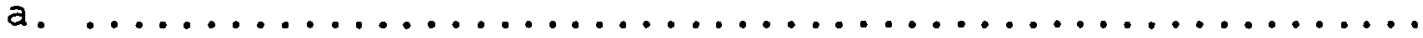

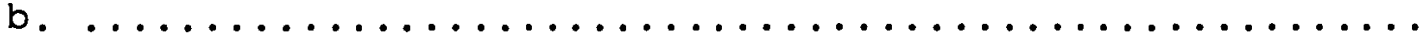

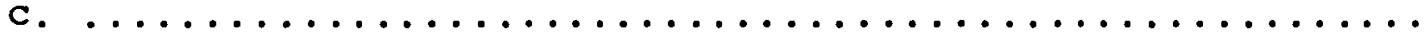

5. 5. What could have improved the sessions you attended?

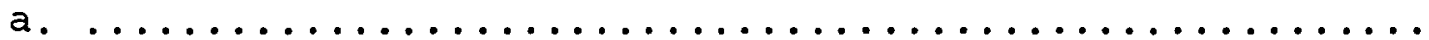

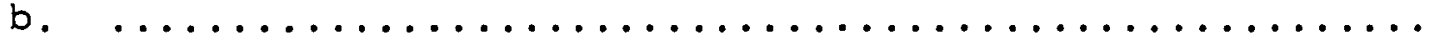

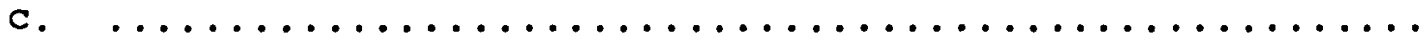

6. How would you describe the time of day of the sessions?

too early.... too late.... t. about right....

7. How would you describe the length of the sessions?

too long.... too short.... about right....

8. How would you describe the frequency of the sessions?

too often..... too infrequent.... t. about right....

9. How would you describe the room setting of the sessions?

too hot.... too cold.... t. about right... too small.... too large.... t. about right... too dark..... too bright.... t. about right.... chairs uncomfortable... chairs comfortable...

sound did not carry..... sound too loud..... sound ok.....

10. Please add any comments you feel might make the sessions better. 
APPENDIX B

FLEXIBILITY 


\section{FLEXIBILITY}

Flexibility is a necessary factor in physical fitness and the ability to perform activities of daily living for the elderly. The original study design included certain measurements of flexibility and range of motion of a variety of joints with a goniometer. Because of lack of reliability and reproducibility of the measures, this parameter of the population's fitness was abandoned.

The measures attempted were head/neck rotation, spinal lateral flexion, horizontal rotation and foreward flexion, shoulder abduction, flexion and horizontal adduction, hip abduction and knee extension and flexion. When measurements of various joint functions were attempted, the subjects began to complain of a variety of limitations imposed on them by injury or disease conditions. For example, they often complained of pain when asked to turn their head from one side and then to the other. This also occurred when performing the range of motion for the shoulder and knee or movements of other joints.

When repeated measures of the same joint were made, those with complaints of pain showed wide variation in ability to perform. In some, movement caused the joint to 
become more flexible on repeated measures. In others, the joint movement became more limited. As a result, the variability on repeated measures was as much as 25 degrees in the same joint on the same day. Another consideration for variability in the test results might lie in the concern that the elderly express regarding the possibility of "failing" in a testing situation.(Burnside, 1981) To protect themselves, some older persons may provide excuses for poor performance before testing. When they find that they are able to do the required task the first time, they gain added confidence and, thus, may try harder to succeed in later attempts. The effect of this possible influence upon results in the study was undetermined. 
APPENDIX C

ANECDOTAL RECORDS 


\section{ANECDOTAL RECORDS}

Anecdotal records were written each day following the presentations of exercise and lecture in each home. An effort was made to include the activities presented, the subjects' reactions to the activities and other pertinent information gained by interactions with staff and/or residents. The notes are presented verbatim and are organized according to days in each week with each home's notations identified. The identity of various residents and staff will be indicated by assigned initials to protect their anonymity.

EXERCISE

WEER 1

\section{$\underline{\text { Day } 1}$}

A Home: Thank you's and invitations written to each resident. Some confusion as to what they meant.

Spoke on the microphone at breakfast after introduction by administrator. Many complained afterward that they "couldn't understand one word said" (either by the administrator or by me).

Provided name tags and pinned these on as subjects arrived. Only six came to the exercise group. Three indicated that they would not come again. come.

EE came only to tell me that he was "too sick" to 
EJ seemed mildly interested; he is quite active on his own; likes to sit outside in the morning.

BX stated that she was hit on the head (prior to admission to the retirement home) which has prevented her from "thinking too well;" worried about lying on back, afraid that she will "pass out."

JE late; states he may or may not come. Very stiff movements, (Arthritis ?) Reluctant to participate.

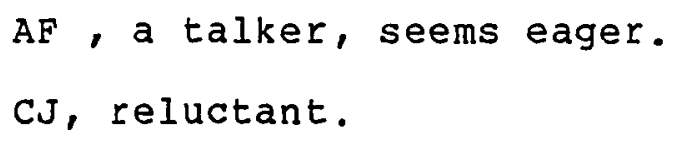

Discussed exercise and the types used for this program. Demonstrated the gloves. Asked subjects about personal goals achievable through exercise. Most had no ideas. IV (age 99) wanted to "lose her sagging abdomen;" said that she had once been a model and feels bad about her appearance now. Served refreshments but few had any interest in them.

B Home: Thank you's and invitations written. No announcements at meal time. Name tags provided and pinned in place by me as they came in. Showed books about types of exercise and discussed various kinds of exercises. Group is non-verbal but shows mild interest. Demonstrated some of Perry's exercises and had them do a few. They enjoyed the treats especially.

(TB ?). Said that he wouldn't come back.

RU came late and then left; said "I came for the test

DT discussed daughter with cancer.

FE said she can do exercises in her own room but likes (and needs) group support.

OR willingly participates but cannot hear, is supposed to be in lecture.

Received many rejections: "I must help them clean my room today:" "I am NOT coming!" etc. Continued discussion about types of exercise and demonstrated some. Showed slides "Basic Exercises for People over sixty." Twenty-five minute presentation with talk and demostration and some participation. Some showed more eagerness to do exercise but most had many tales of limitations and the large amount of exercise they already do. 
today."

EJ slept through most of presentation. Stated "Tired

WF came but suffering from memory loss. Cannot find her way around the home, even her own room. Found her wandering in the hall outside of library; encouraged her to come in and participate. She was somewhat resistive at first but later seemed flattered that $I$ had an interest in her.

JE discussed injuries and limitations in movement. Has difficulty following directions. Stiff and limited movement. Music might help.

AF talks much; good participation; complains of pain in movement.

IP is not part of assigned members but attended. Seems very eager to participate.

B Home: TU came; smiles and laughs but does not do any exercises. Seems active; moves easily. come back.

BQ came looking for TB test; said that he wouldn't

FE said she can do exercises in her own room but likes (and needs) groups support.

OR willingly participates but cannot hear, is randomly assigned to lecture group.

Showed slides (as in A Home). Did some demonstration and a few wanted to try some of the exercises.

$\underline{\operatorname{Day} 3}$

A Home: Talked with ME (staff and activity leader). Anxious to help, disappointed that more don't come. Noted that MF came to her exercise group Tuesday.

EI "hides out" according to staff; chain smoker.

IP approached with many complaints about mastectomy as reason why she wouldn't come to exercise (she is not part of randomly selected exercise group).

DM profoundly deaf; did come; seemed pleased; made little jokes; participated well. 
EJ has difficulty following directions; seems somewhat pleased to be asked to participate.

JE came nearly on time (unusual for him). Son arrived near end of class to take him out for day.

IV (very deaf) came because they were cleaning her room; stated that she wouldn't come again because she can't hear.

MH came to exercise, participated. She called me aside after class to confide that she didn't sleep last night because her next door neighbor was pounding on the wall. She was afraid to tell administration. I told her that the administration would want to know about her neighbor's night activities and asked her permission to tell them. She said OK and so I told MC.

B Home: Perry exercises with scarves. Quite good participation, much limitation with most residents.

LC supposed to be in control group, came to exercise. States she has ischemic heart disease. States she can't get enough oxygen; reminded to alternate exercise and rest periods and to limit amount of activity. one eye.

TU did do some exercises; states can see only with

SM much limitation in movement (stroke), does try; wants to please.

LC returned, complaining of fatigue. suggested that she not come today or any other time she was tired.

Used scarves; group more animated and participated better.

Day 4

A Home: AF called me aside as $I$ was passing out invitations; stated that she would not come to exercise--her hernia had "come out" and her rheumatism bothered her last night. (Presumably from exercising yesterday.)

MH came late; stated she had slept better last night; noise didn't start until A.M. 
Told administration that I could no longer had an experimental study due to loss of subjects and cross contamination of groups.

B Home: TU came early (before dinner) to ask if I would "lose your job" if he didn't show up. When I reassured him that I wouldn't, he said "That's good because I can't promise I'Il come." He didn't show for class. I wonder if others are coming because they think I will "lose my job" if they don't.

IY came for the first time; sat on the davenport; refused straight back chair. She did try some exercises; seemed more encouraged and less depressed afterwards.

FE (age 94). When I commented that we had missed her the day before said, "Now don't go trying to box me in!" She had gone out for lunch and shopping the day before so had missed exercise.

SM still having much difficulty with exercises due to fatigue; encouraged her to slow down and not do all of them.

ER had difficulty doing some leg exercises due to pain in legs. Wears very heavy boot-type shoes.

SK came and participated some. She has collapsed vertebrae so her motion is very limited. Tried hard to participate.

Overall, group is more vital and interested than $A$ Home exercise group. Able to stimulate a few smiles, etc. Got a laugh with scooter ride will do again. Used bar bells with good participation.

WEEK 2

DAY 1

A Home: JE and $M H$ came very late but did participate well while there.

CG came late and sat and watched. I asked him to come back "to watch" in hopes that he might come and eventualiy participate. Stated that he is "9I" and very hard of hearing. 
B home: TU camplains of hurt knee; refuses to come.

LQ doesn't look good today; confused; unable to follow directions; on a new medication? Dressed all in dark blue clothes with many layers (dress, blouse, sweater, jacket).

FE quick and agile in movement; complains of right shoulder bursitis.

LC came late; worried about "losing her mind" due to not finding her music. Eventually did find her music and came back later to class.

NE groaning and panting with each move (?)

"Blue" Monday; many not doing well; lethargic; unable to comprehend and follow directions. Over all, a bad day. Used wands as props.

Day 2

A Home: EJ stopped by to say he was going downtown to get his German crossword puzzle magazine. If he gets there too late, they are sold out and then he wouldn't be able to get it.

B Home: TU proudly showing a slight bump on left side of forehead; said ran into cabinet and so cannot come to exercise today.

SM came to tell me she couldn't come today; staggering gait; assisted to chair and then upstairs to room. Notified staff of condition.

Discussed LQ's condidtion with staff; state that she has episodes like that observed yesterday: dresses "funny"; all in one color.

OR eager; tries hard; does most things well. 
Day 3

A Home: EJ does not follow verbal commands or directions well; imitates others in class.

JE still says he is "stiff" but appears better able to do range of motion.

MH does all exercises.

IV attended because they were cleaning her room; did not join group; had stated she wasn't much interested and did her own (exercises) in her room. She sat behind me where I couldn't see her. After the exercise session said that she did them with the group and that they were "good."

Provided treats, but little interest in them. Used balls today; good exercise; able to do several standup exercises; strong group.

B Home: Talked with MN (staff): stated that they had Fourth of July party with games, etc. Expected 30, prepared for 40; got 50! She feels that this may be due to the fact that few other activities have been offered this year and residents have need for stimulation. Stated that "Nothing else was going on this year." Volunteer activities (in the home) have been greatly reduced under leadership of "new young person." ML is now trying to rejuvenate the program.

Met $T U, L Y, H J, L Q$, and $C C$ before dinner and asked them to come to exercise.

LQ is more oriented today.

LY said, "You have helped me so much!"

CC anxious to come.

Told MN about SM and CC. She said that they were about the same. SM has these attacks often. CC waits until others leave the dining room and then goes to each table to eat the leftover food. She takes no medicine; no one checks urine or blood sugar (diabetic). exercises.

A very large group today. TU came and did some

HJ came; talks much but otherwise OK. 
LQ is in slow motion always (drugs ?)

Reviewed all props used with the group; they indicated no special favorites but seem to enjoy all. Did not do stand ups today; group too slow in range of motion. More hesitation in movements and following directions.

overall, B group is slow, less conditioned, with limited understanding, vigor, and force.

Day 4

A Home: Only JE showed up at nine. No invitations at breakfast. Found IP, $\mathrm{DM}$ and $\mathrm{MH}$, invited them to exercise. When they came, started exercises at 9:10. No props used today. Need to do more standing exercises and hand exercises each day. Need more work on slow stand ups. overall group is looking better.

JE brought me three books on health and fitness (zoman, Blue Cross, and Dairy Council); wanted to share; seems to enjoy coming and was only one who came without a reminder and on time.

Saw EJ after exercise at the main office. He was talking with staff regarding bill; worried about finances; told by staff that he had enough money to pay rent. He began complaining of bowel problems and loss of appetite to me. Told me that he was out sitting in the sun rather than coming to exercise.

B Home: Tried to do some standing exercises today. This group is nearly one week behind group A. Standing exercises were near disaster. SM could hardly stand up. Even when going from flat foot to tip toes, chairs wobbled everywhere. Group very dependent upon the chairs for support. Knee bends were not good.

NE had several episodes of severe coughing. She is asthmatic and mouth breathes. Suggested that she breathe in though her nose to warm air and reduce laryngospasm. Did seem to help temporarily.

Saw JN before class and asked him to come. He smiled benignly and said, "Well, I have something going on today; maybe tomorrow." I know he has no intention of coming. lifts.

ER continues to have cramps whenever she does leg 

chest.

FE has bursitis; unable to raise right arm above

WEEK 3

Day 1

A Home: EJ came to library but complains of stomach pains and vomiting; states he has had it for some time. He is also worried about money as his third wife "took so much." He is seeing an attorney about his affairs. Repeats story about friend who is coming here to live but whose wife is ill (?). Advised to see M.D. regarding health.

JE says that EJ smokes all the time.

DM seems better able to move right arm upward although he still complains of some pain.

LV states that right after breakfast is bad for her because of her bowel habits.

Group exercised well; used wands; up out of chairs for five minutes today; strong performance.

B Home: Good participation but many pants of effort. Group seemed tired today; Monday syndrome?

NE's asthma some better today; no violent coughing.

SM made good effort; still unsteady on feet.

FE demonstrated some exercises that she had done before. Had the group do them, too. She seemed pleased.

LY stopped by to say that she is now using only one sleeping pill; she feels that change is due to exercise. The verbal associations of swimming, bicycling, scooter riding, etc. make her feel more positive and all the "bad thoughts (of dying if she falls asleep) are going away." states it is easier to think more positive thoughts now.

FN participated some; has no real joint limitations.

SM seemed fatigued at end of session. Wanted to come to lecture; fell asleep in chair after exercise and slept until and during lecture. 
All seemed to like the use of wands; did stand up exercise only once; did slow rises out of chair times five.

\section{Day 2}

DM showed up in sport coat and tie with bottle of after shave in pocket. No explanation for "dress up." Participated well; seems better able to raise right arm over head. Can cross one leg over the other only with extreme effort and assist with hands.

JE said that he was "too old" to make much improvement. He speaks so rapidly and with so much accent that I am not quite certain what he is saying all of the time.

IP participates well; is having much problem with hearing aid which interferred with concentration on exercise; needs new batteries.

MH always appears anxious and worried; does participate. I wonder if neighbor is pounding on wall again.

EJ complaining bitterly of abdominal pain, bowels, etc; unshaven; looks worried and tired. He showed me his right calf with some dull redness, complained of pain; frequently crosses legs. I told him firmly that he must go to MD today. He said he couldn't because he couldn' $t$ speak English and that he needed to go to a lawyer tomorrow. Not sure what else I could do with him.

AF came early for lecture but sat and watched exercise. I would guess that she feels that she has exercised when she watches others do it.

B Home: Arived at 11:05 to find exercise leader from Park Bureau here. LY, RB, SM, and one or two others all involved in parachute and ball activity. Talked with leader who said that sometimes she gets as many as twelve or thirteen residents. How come? less frequency; more intercommunication; better activities; more freedom; more diversity? Leader says that Park Bureau does this each summer. Administration orginally said that they wouldn't be coming. (?)

Following our exercise session, FE (age 94) stated that four times a week was too often for her--one time less would be better. 
Further discussion led to finding out that she did not like to "get tied down" so much. I reminded her that she was free to come or not come; this seemed to be a hard choice for her. She stated that she would have liked to have gone shopping today but came to exercise instead. She went downtown in the morning to shop instead of the PM as she would have preferred. I reminded her of the day's temperature which she acknowledge was a factor (currently it was 78 degrees in the recreation room).

FE also said that she would prefer to have the lecture start "right after the exercise" because she "doesn't like to sit around and wait." If it were that way, (immediately following exercise instead of the half hour time lag), she could "be doing something else." She also stated that residents here were "less able" than those at another retirement home where she Iived three and a half years ago. DT (another resident who moved here at the same time she did) concurs with this impression.

$\underline{\operatorname{Day} 3}$

A Home: EJ still unshaven; stated he slept last night; talked of going to lawyer yesterday; seemed to be much relieved. He is still complaining that third wife was "no good;" no other physical complaints. Talks of taking peppermint for relief of most problems: constipation, adominal pain, tooth pain, etc. Has much difficulty processing information and directions; often performs exercises in reverse e.g., puts legs apart when others are putting theirs together-puts legs together when others are apart. He states that sitting outside in the air is good for him (in contrast to exercise). I will try to convince him to exercise first and then go outside.

JE still complains of being "too old." I told him that he looks younger than his age (which is true); he seemed to enjoy the compliment. He tries hard but range of motion is very limited. Usually comes late.

MH and IP do exercises easily. MH particularily enjoyed kneading the soft ball like bread dough.

DM very stiff; little improvement today.

B Home: Good participation in exercise. Used soft balls for hands and also did five count stand up and sit down three times. No unsteadiness noted. SM not present. (The most unsteady person.) 
ER still having severe leg cramps which limit most leg lifting activities.

WY and HJ both showed up for first time. seemed to enjoy participating in exercises.

EN still says "no" to many suggestions. He said, "You treat me like I am worth something. . . nobody else does." Countered by MN (staff) who said, "That's not true." I left the conversation. group.

Still see no ability to do standing exercises as a

FE brought her elastic strap which helps her get her right arm up over her head. Fail to see any real effort on her part without elastic. Also said she wants to stand for some exercises. Had FN stand, too. I remained seated. I feel that standing would put undue pressure on rest of group to stand and possibly put some at risk of falling. I am not willing to do that. looks lost.

LQ arrived wearing two watches, three sweaters; still Day 4

A Home: EJ came in and talked at length about third wife; no money; more friends at other retirement home; attorney. States that he is "too old to exercise." If he "were 60 or 70 or so, it would be all right. . . too old. . too old." "Nobody here to talk to. The other piace had lots to talk to. . " He has a friend who lives in this neighborhood who takes him to the doctor, attorney, etc. I feel he won't come to exercise anymore.

MH can barely dent racquetball with either thumb or fingers. Encouraged to keep trying. She was able to process Perry's exercises much faster. Was able to keep up. A good day.

AF showed up again today midway through the session. Did not participate; states now has arm pain, etc.

B Home: Began racquetball exercises. ER, OR, HJ, and SM had much difficulty in trying to dent ball; used thumbs, four fingers and foot press times two. Also used five count 
stand up five times. Less unsteadiness; better able to get up. . maybe some progress is being made (?).

ER seems to have increasing difficulty understanding directions. Perhaps she is less competent than I assumed her to be.

NE wanted the soft balls.

Did pick up the pace a bit; need to devise more chair exercises to use time wisely; look for more leg strength activities rather than arm exercises.

\section{WEEK 4}

Day 1

A Home: Four members still interested and participating well. Used both large and small balls. Did only five minutes of stand ups.

DM still has much problem with flexibility; great difficulty crossing legs.

MH has greatest difficulty with hand strength; can barely dent racketbalis (hard balls) with thumbs or fingers. Switched to a softer ball for her (football).

EJ came to talk and complain. I will pay less attention to him unless he comes to participate. He sits and watches for about 10 minutes and then leaves. He says he is "too old. . exercise is for younger persons $(70$ years or less). He has multiple complaints: eye, ear, stomach, no appetite, shopping needs; lawyer, etc. Yet, he looks like he is getting bigger each day---bloat? fluid? fat?

CG and FY to the hospital this week.

B Home: Regional administrator of agency retirement homes here today. Introduced to her by home administrator and talked briefiy about the study. She asked that I give them a finished copy of the study; I promised to do so. Only four came to exercise. HJ showed up very late. 
OR had difficulty in processing information even when I pointed to the joint involved and demonstrated the exercise; even had difficulty making circles.

$\mathrm{NE}$ states she had collapsed lung before coming here to retirement home. She expressed sorrow in leaving her own apartment--"never had a place that was so handy. . several small stores in the area for shopping, etc. "Talked of being confused between day and night. . . not able to understand. States niece takes care of money, etc. Expresses some concern for what is happening to her money. states that niece gives her "so much" each month to spend. says she doesn't know if niece is spending it or not. A little wobbley in stand up exercise.

HJ cannot dent racketball; has difficulty processing information, e.g. tried to place ball on top of foot instead of under it for leg press exercise.

Taught about valsalva maneuver. Did two complete stand ups today.

\section{$\underline{\text { Day } 2}$}

A Home: MI came early to lecture and stayed for exercise. First time attended. Very wobbly on legs but did most of the exercises.

WF confused again and came to the library by accident. She was trying to find her way to her room (on second floor, main building).

MH and IP both doing very well. IP says that she does exercises in her room and that she does not need any medications at any time, not even aspirin.

B Home: OR, HJ, WY, ER all used soft footballs instead of racketbalis. Preferred to use them. FE also wanted one but I was one short.

ER looks lost in her own thoughts; difficulty following directions and short attention span.

HJ has difficulty following directions.

Did five three-count slow standups and three five-count stand ups. Group performance good, no wobble or staggering. Making progress. 
$\underline{\text { Day } 3}$

A Home: Met CL in hall; invited him to exercise. He said that he wasn't going to come unless he got an invitation. I told him that he was invited even if he didn't get a written invitation (he was in the original control group). Doubt if he will really show up.

DM is now able to cross legs with less help from hands. Cannot abduct hips.

JE upset because of flatus and urine leak from collection bag. Talks much about how hard his mother worked. Stated, "I never thought I would live like this.. ." (Too good? Too long? Guilt?)

B Home: More ball exercises. Several still complaining that they are too hard. FE, NE, ER and SM used footballs. movements.

SM has difficulty with perception of right sided

ER disinterested. Talked to her after exercise. She complains of severe weakness and lethargy. Asked her about her potassium level. States that she has been low on it before; encouraged her to eat extra high potassium foods. She was also concerned about previous "borderline diabetic" diagnosis. She did modify her diet by reducing sugar intake after receiving diagnosis. No problems since. She had difficulty understanding concept of "boarderline" and its relationship to diet.

\section{Day 4}

A Home: Worked with DM regarding stiffness in hips. Indicates that he has had no hip surgery or fracture. Denies arthritis. Relates problem to heavy ditch digging labor in work. Used wall exercises with side bends against wall; wall push ups with hip extension. Later learned that he has been a baker most of his 1 ife.

Other exercises as usual with increased emphasis on hand and leg strength.

B Home: Talked at length with administrator. He suggested that if it was oK with me that I could work with 
MN. I feel that she should be coming to exercise sessions in order to learn exercise and how to lead it and how to use props. Will see.

Later, administrator came back to say that he had told MN that it was important to come to exercise sessions. She said, "How come this interferes with my program?" He wanted me to reinforce the fact that she is invited; will do.

Termination party plans initiated; administrator told me to just tell the kitchen what is wanted and they will provide and prepare it.

Did more stand ups today. feet.

SM a little stronger but still very unsteady on her

ER a little more with it but still not as active as previously.

NE puffing and groaning.

AU came for the last five minutes.

\section{WEEK 5}

Day 1

A Home: Ten minutes stand up exercises with knee bends; leg extension and toe push ups. Did leg lifts from sitting position. Exercises were more vigorous and rapid; need to repeat routine times two.

B Home: MN attended most of session; seemed to enjoy it and said that she had learned from it; even led a few exercises.

Tempo just a little Easter; used five stand ups and about five minutes of standing exercises.

SM did fairly well but unable to do many of the standing exercises.

LQ lost in her own thoughts.

NE still huffs and puffs with activity. 
Day 2

A Home: $M H$ not well.

MI came and participated some but was limited in activity when compared to others.

Did toe stands, mid-knee bends, forward and backward leg swings; knee bends with toe stands. Good stability, strength, no problems with standing exercises except MI.

B Home: Park activities director here today at 10:30 AM. SM and NE attended and were tired at time of exercise session in $P M$.

$O R$ and $A U$ participated in exercise session as well as park activities. Tired.

Did no standing exercises today because of fatigue. Five stand ups only. Used hard balls and bar bells.

Day 3

A Hone: Ip upset about room cleaning and not being able to find her things now.

Did same leg exercises as before except that now we did the leg press using two racquetballs. subjects found it much harder to do leg press with the two balls. Not sure if it was the coordination or the added effort needed. Did a lot of standing exercises including five leg cross overs. Group showed good balance and strength.

B Home: MP attended for first time. Stated, "I didn't know I would be here for exercise." Really a disorientated lady in spite of appearances.

Session was interrupted by staff call for help when GN collapsed in hall. Asked FE to lead in my absence. When I returned ten minutes later, they were all sitting in the chairs. AU said that FE had tired her out.

I led the group with five stand ups and the ball exercises.

SM not as steady today. 
ER attempts to exercise but still has cramps.

OR out shopping with family.

$\underline{\text { Day } 4}$

A Home: Used hand, wands, balls. Did standing exercises with leg swings, abduction, knee bends, etc. for at least seven and one half minutes. Good exercise session.

B Home: Of the three sent to the hospital by ambulances yesterday, only GN remains in the hospital. She had a cardiac arrest while they were trying to get her in the ambulance. Is in critical condition in ICU.

Long conversation with LU. She is looking forward to getting hearing aid next week. Reported that someone had said, "She's no chicken" when she mentioned getting one (as if she were too old to spend that much money). Stated that her Aunt had always worked hard and looked foreward to retirement so that she could do lots of nice things. However, she developed cancer and died at a relatively young age. Her Aunt's advice to LU was, "Take your pleasures as they come along. . don't wait to enjoy them." LU states she wants to start going back to church as soon as she has her hearing aid. Reports "fear of falling" as her only fear but that that fear does limit her walking activities. Plans to start walking in the halls without cane to see if she can manage.

I commented on her severely scratched glasses; suggested that she consider replacing them as her next investment. Stated that the administrator also told her to. she said, "I didn't know that anyone cared about me but, I guess they do."

\section{WEEK 6}

$\underline{\text { Day } 1}$

A Home: DM indicated again that he has increased movement in right shoulder.

MH appears upset again. I believe there must have been pounding again last night. I think staff is attempting to modify the resident's behavior. 
Ten minutes standing exercises with vigorous arm and leg routines.

B Home: Seven and one half minutes standing

exercises; $S M$ seems stronger and steadier. She is able to rise and do standing exercise with better balance.

LQ still slow; shoes on wrong feet.

FN watches. Used direct confrontation to get him to participate in exercise, e.g. "Show me how you can do this. - Bet you can't do this one. . Show me." Usually works.

Day 2

A Home: Went to MH's room. She was crying when she came to the door. She stated, "Why do I always get shit on? Now they are all talking about me." problem with neighbor (?) or disorientated (?) Did come to participate even though she was upset. Seemed a little calmer afterwards.

Otherwise, good exercise period.

B Home: Seven and one half minutes standing exercises. Better balance and strength, expecially on standing exercises.

ER still has severe leg cramps.

SM ; teadier today.

FN refused to participate today.

NE has knee pain. Told her to modify exercises to prevent occurance of pain. Most noticeable with knee bends.

$\underline{\text { Day } 3}$

A Home: Everyone late today. JE states "I am not well today. . no use saying it again. . I'm not young anymore."

MH more positive today, or at least not so negative. 
B Home: SM balanced improved when directed to move feet a little farther apart for a wider base.

WY enjoyed "skooter ride and swim." Laughed and participated actively.

\section{Day 4}

A Home: Did standing arm swings with no loss of balance. Began jogging with ten steps in place three times. Good.

B Home: Used racquet and soft balls. Did standing exercises times for a total of ten minutes.

ER going to MD about leg cramps and potassium level.

\section{WEEK 7}

Day 1

A Home: Very slow stand ups using no hands, did very well. Used standing arm swings and jogging in place (ten steps) three times.

B Home: Ten minutes standing with arm swings.

RB said that she can get out of the bathtub easier. dea $1 . "$

LY said, "It (the exercise) has helped me a great

NE still has pain in knee.

AU came late but counted out loud and participated well.

FN did not come today. Much animosity in group toward him. I will allow him to come to sessions but not urge him to participate. When I try to get him to participate, several other women in the group start nagging him as if he were a child and he becomes much more resistive. 
Day 2

A Home: IO and MI came and participated but rather skeptical. They did most of the exercises as I worked them into the group although they stated that they had come "to watch."

MI unsteady on her feet.

Io did not do stand up exercises. States that she wears a heavy corset for osteoporosis. She has an 86-yearold physician who prescribed the corset for her many years ago.

B Home: FN carried chairs from furnace room for me to set up for exercise. Looks for me at the door. Got upset during exercise because I didn't have a soft ball for him.

LY tends to go too fast but gets carried away by counting out the exercises.

DT sat in room and watched during exercise and then came up to me to ask why I didn't bring treats anymore. I told her that administrator asked me not to.

Day 3

A Home: NV came in while her room was being cleaned. She tried two or three exercises and then said that her knee hurt. Watched the rest of the session. Otherwise the routine was the same with jogging increased to ten steps times four.

B Home: ER brought out her stationary bicycle for herself and others to use. Said that her doctor told her to start using it to see if she could relieve the leg cramps. staff then brought out a broken one with a large, uncomfortable seat. Spent some time identifying various problems with it and made some suggestions for repairs to staff. It has been around a long time but nobody had fixed it.

Much sleepiness in the group as well as petty fighting and arguments between each other. Quite a few upset by FN and picking on him. 
Exercises went OK; no additional progress.

Day 4

A Home: Administration scheduled hearing aid examinations in the library. Had to post signs regarding the change in room location for exercise and lecture; finally contacted each subject personally. All arrived although $\mathrm{MH}$ and JE were late as usual.

Did some high knee lifts while standing times ten. Used ten minutes of standing exercises with no real problems.

B Home: I saw DT, EE, and AT returning from walk at 1I:30 AM. Would be interested to find out what they usually do for exercise.

Exercise session was as usual.

WEEK 8

$\underline{\operatorname{Day} 1}$

A Home: DM and IP only. MF ill. Did ten minutes standing; ten steps jogging in place times five and arm exercises while standing. Seemed easy for these two. volunteer.

B Home: DT, EE, OR and others going for walk with

GO and DT sat in the room and carried on a conversation during exercise class. Administrator and other staff in and out of the room while I attempted to conduct exercise session; noisy; distracting. However, was a good exercise period with jogging ten steps in place with chairs. Group had good balance.

\section{Day 2}

A Home: DM had gone fishing with group from home; $\mathrm{MH}$, ill; JE checking about hearing aids. IP arrived on time. MI and EJ showed up later. MI very slow: EJ very fast. I found it hard to gear exercises for two extreme levels of skill. 
B Home: MN led most of exercises and did a good job. I gave clues and hints regarding basic priniples and practices of leading exercise to MN. Very receptive. Had group members give her a round of applause for her leadership. She seemed pleased.

Day 3

$A$ and B Home: Conducted program evaluation with subject. Asked each question on form provided and asked them to respond. I told them that it was ok to be critical because I wanted to learn how I could improve. Then, MN and I went around to each person and helped them fill in their answers if they were not able to do it alone. Most were positive but did get some useful criticisms. Felt that both groups were quite open although a little too complimentary. A copy of the form used is in Appendix A. Results tabulated in Chapter VI.

\section{Day 4}

A Home: Provided special invitations to members of both groups (anyone who had ever attended) to come for a party in the library. Served refreshments to both groups at 10:00AM. All arrived in a party spirit and seemed to enjoy themselves. Some asked if I was coming back again. Told them that I was going on vacation first and then if they wanted me to come afterwards that I would be glad to.

Met the newly hired activity director. She is a LPN who has never done anything like this before. Offered to be a resource if she needed or wanted one. Suggested that she call me if she would like to have some presentations regarding health and/or exercise. Seems to be a congenial person.

Provided little gifts for all of the subjects which included door stoppers, dental powder and pictures of each of them in their groups. They all seemed to enjoy them.

Termination with many of the residents was hard. I will really miss them.

B Home: Special refreshments were planned to be served following dinner as the dessert. Staff did a very nice job of preparation and serving. Provided little gifts 
for everyone even if they were not participants in the study. Also gave pictures to the members of each group. They were very appreciative.

I read a little poem before dinner as a blessing and then a funny one. I thanked them all and told them that I would miss seeing them.

Many asked if I would come back, including the administrator and some of the staff. Replied in the affirmative. They wanted some specific dates and so I provided some.

Termination is a most difficult aspect of a prolonged study where close personal contacts are made on a continuing basis.

LECTURE

WEEK 1

$\underline{\text { Day } 1}$

A Home: Group seems very interested with much verbalization and activity. Eight members of the selected group arrived with two volunteers. Listed topics for discussion and asked them if they were interested in them. They seemed to enjoy the refreshments; stayed one half hour beyond the meeting time.

B Home: Six of the randomly selected group arrived with four volunteers. Discussed topics to be included. Refreshments were a big hit. Group seems interested.

$\underline{\text { Day } 2}$

A Home: Showed slides on hypertension. Group enthusiastic and interested; much discussion and volunteer comments. Most stated that they were glad that they came. KN expressed dismay at having to miss the next session. She is blind but was very pleased to have attended. 
B Home: Showed slides on hypertension. Many new members; six from randomly selected group, eight volunteers. Some seemed interested. Others made comments on how much I was doing for them.

$\underline{\operatorname{Day} 3}$

A Home: $A O$ is a smoker. Arrived after breakfast, has much difficulty walking; found it hard to get to library. Sat through the session; said that he had "heard all of that before at the VA (hospital)." stated that he had had an arteciogram.

This is a questioning group; interested; enjoyed handouts; seemed to understand heart anatomy discussion.

B Home: Discussed anatomy of the heart and provided blood pressure record and heart drawing handouts. Eairly interested group. I requested that they give back the handouts so that we would have then for the next session to discuss heart disorders.

LC stayed for lecture but slept on couch (lying down) most of the time.

$\underline{\operatorname{Day} 4}$

A Home: Lecture discussion of heart problems, (MI, arrythmias, heart failure and valve problems). Group interested but I am not sure that they understood all I was talking about. They stated that I was a good teacher. . . "knew more than their doctors!"

B Home: Same topics as A Home. Group seemed interested and listened mostly. Not as many questions.

WEER 2

Day 1

A Home: Good turnout; much interest in diuretics and hypertension. Only got one third of the way through the visuals. 

they take.

Met with $M D$ and $E G$ individually regarding meds that

A complains of dry mouth and weakness; is on lanoxin and diuril; advised to consult MD.

AF (slept through most of lecture) complains of backache; wants a physical; encouraged her to get a board under her mattress and call MD for appointment.

AU began to weep after lecture; stated that this topic caused her to remember her son's death (at 67 years) and her husband's leukemia. I suggested that she not come until we are finished with this topic. She agreed.

MU comes in each day to tell me about her liver condition and her walk but does not attend lecture.

Ao told me at the breakfast table that he couldn't come. I believe it is because it is so painful for him to walk; too bad he can't find a wheelchair.

B Home: Same topic as A Home. Several came to "watch what they do (?)." still some confusion as to what I am doing here.

RB sleeping most of time during lecture.

SN appeared to be sleeping most of the time. states that she did not want to come to talk about antihypertensives; only interested in potassium.

Unidentified resident who described herself as diabetic talked about dry, split tongue and numb fingers. Told to contact MD.

Group seemed interested but unable to stay awake.

Provided cards on potassium sources in diet. Very interested in having their own cards.

MN wants to pass out the invitations and suggested a poster with the names listed for each randomly selected group to see if they would come. I feel that it is too late to worry about random groups. Will just encourage anyone who wants to, to come. 
Day 2

A Home: No notes.

B Home: $H J, A U, L C$ and $S N$ slept much of the time. Several asked questions. Talked about centrally acting drugs and vasodilators; passed out information from American Heart Association on hypertension.

Warm day ( 83 degrees in room). Found out that former activity director had Tupperware or herb party much of Saturday. Most of the residents attended. Could be the reason that some are so fatigued and sleepy.

Agency provided watermelon after the session. Eaten eagerly by the residents.

Day 3

A Home: Discussed digitalis and other drugs. Interested response; taught how to take own pulse; OK response. All positive comments from group; growing interest. Group seems comfortable in asking questions.

AF brought a slip with "triglycerides" written on it; wanted to know what drug it was; discussed it in relation to atherosclerosis and diet. states that she is having breathing problems because she is 30 pounds heavier than she used to be. Says that she is "always on a diet to lose weight but can't pass up treats."

VC comes very late; shows little interest and asks no questions.

AI is on Lanoxin, is interested in discussion.

Talked with administrator who said that they had a big Fourth of July party with buffett, etc. She was disappointed because all the residents wanted to be served rather than pick out their own food. She said that they had decorated the table, had garnishes for the food, and that the table looked nice. They even had heipers to carry the trays for the residents after they had picked out their food, but that they (the residents) just wanted to be "waited on." 
B Home: Taught same topics as in A home. Good interest with questions. Taught how to take pulses with limited success. Three of thirteen could not count pulse; will try again.

$A U, C C$ and $S N$ sleeping.

MN said, "Thank you. . . so many are now enthusiastic about coming." Also mentioned that one person (LJ (?) wanted to come but said that she couldn't because she wasn't invited.

Some questions asked about drugs and heart problems. Generally good response.

CC said, "I know how well prepared you are and how hard you work. I was a teacher, too. You are doing a fine job." She had slept for most of the class. In fact, I put another chair along the side of her because I was afraid that she would fall over in her sound sleep.

Day 4

A Home: Poor attendance, no invitations passed out today. No intercom here. Even the major staff did not krow I was having lecture today.

EF helped fold chairs after session; wanted to talk about sick daughter. Stated that she wishes that her daughter could come to lecture to learn (daughter is 50 years old, often hospitalized, possibly multiple sclerosis and/or many other disorders). EF seems depressed over daughter's condition. States she likes me to talk; expressed frustration "that others want to talk too much."

EJ asked me to look at her foot. Looked like hammer toe with a corn on top; recommended non-medicated corn plaster and an appointment with podiatrist. She then took me to her room to show me her piano and tried to play for me. Husband was president of local college, and they had a good life together (he is deceased now). EJ extremely frustrated and upset because she cannot make sense of written material; used to be an accompanyist but now cannot read music. "The notes don't make sense anymore." When she does play, she plays by memory "for the women" (other residents). "More and more I just play in my room."

$C F$ is a new resident and comes to lecture. Talks much about family, needs time for ventilation. Participates in home execise group. 
B Home: Much drowsiness. SN, CC, HJ, RB dozed off and on. WY showed up just as the session ended; was disappointed. Attendance may have been affected by no invitations being distributed at dinner.

Had long talk with LY who has just moved here from her own apartment. Feels that the move was unnecessary; angry and feels useless; resents the fact that she doesn't know what her medications are for or what their names are. states that night girls (staff) don't know either. While she is still upset, she does seem some better than she was during the pre-test week.

LU, AT and Go are all former nurses.

WEEK 3

$\underline{\text { Day } 1}$

A Home: More group interaction before lecture. Previously, residents came in individually and sat in the chairs without talking to each other. Today some came together and visited while waiting for the lecture to begin. Lecture announced at breakfast. Arthritis is the topic and good response.

CF very talkative and disruptive; asks questions repeatedly.

IP came late.

JE came to listen; seemed interested; possibly came because he felt his own limitations in movement may be due to arthritis.

EF told me that she had turned down "many invitations" so that she could come to the lectures. She said that learning bout her body was most important to her.

AU seems interested but depressed.

EJ came but seems depressed and unresponsive today.

ED was very interested; said she didn't know that the room was so close (to her room). 
HO states she feels some better but still has a cold; didn't want to come last week "to give it to others."

KN said that she had much business to attend to last week so she couldn't come.

time now.

ME got up and left early.

CC came late; vocal in apologies; thanked me afterwards again. Told me that she taught basic anatomy and so has interest in lectures.

Met $A L$ in hall; invited her to lecture; she did come and seemed to enjoy it.

still much drowsiness in group.

CT (lives in other rental units and comes to the home for meals and recreation) started playing pool in the middle of lecture. Go asked him to please refrain; he continued. Then I repeated the request and suggested that he come and join the group (usually is not an attendee). He did.

\section{$\underline{\text { Day } 2}$}

A Home: Full attendance with some questions asked regarding muscles, joint and back problems.

NOTE: DO NOT USE RED INK PENS; DOES NOT SHOW ON FLIP CHART

EJ less disturbed today; states that she gets very

tired from exercise class and so she skipped it today.

EF and MD helped put away chairs.

AU reminded me MD had never been married ( I called

her "Mrs.").

NV pale and weak; went to bed to rest.

B Home: Much interest in the group but I didn't get into the topic very well, a little flat. 
Shortly before lecture time, CT stopped by to say that he was going to come back later but he didn't show at lecture time.

FN said, "You are a God-send here. Glad you are here." He wanders in and out; does come to some exercise sessions but attention span is very short; Always volunteers to help but then doesn't unless told specifically, "Come, help carry this chair to the furnace room."

Day 3

A Home: Asked ML to come to lecture (blind); told her $\mathrm{KN}$ comes and seems to enjoy it ( $\mathrm{KN}$ also blind). Stated that she gets "too nervous" to come to things like that.

$A F$ and $E J$ sleeping most of lecture time.

DM (deaf) came and sat in front row.

CF came. Efforts (mine) directed at eliminating excessive talking have helped tone her down some. After the lecture session she showed me picture of her car accident. Said that she fell asleep while driving and hit a tree (suicide attempt?). When did her husband die? she keeps bringing his problems into the discussion.

VC seems to have a personality conflict with $C F$. Holds her head and shrugs her shoulders each time CF says something.

KN continues to talk of minor arm injury.

HO seems depressed; comforted by EF. Considerable interaction prior to lecture.

AU continues to appear distressed and depressed but convesation does not indicate a problem. Perhaps she is in pain. lecture.

LV, new person, showed up and seemed to enjoy

HO still concerned about "passing out." Getting emotional support from EF and AF.

DM came and seemed to enjoy session. Gave him a book on diet. He sat in front row and watched the flip chart attentively. I doubt that he can lip read. 
More and more group interaction before lecture. Took forty minutes to complete lecture and get the group to where group $B$ is and will be by the end of today. Frequent questions from group slow presentation but are too important to ignore.

B Home: Presentation on arthritis was little better
today.

ME complained that she couldn't hear or see. "What is the use for me to come?" Rather cross; did stay for all the lecture. She sat behind me, refused to move to better location. I placed the flip chart in front of her but she said that she couldn't read it. I doubt if she will come back.

Watercolor session to follow lecture in the craft room. SN refused to come to lecture so that she could go to watercolor class. Beautiful weather outside; perhaps another cause of low attendance.

\section{Day 4}

A Home: CE came; another new person; seemed to enjoy the session. Otherwise the same group attended.

AD fell fast asleep; snored.

ve drowsy.

CF talkative; spoke five times but briefly and more to the point.

EF worried about daughter and relationship of aspirin and insulin. Told her I would look it up.

HO came back to talk about "passing out." Wants to know reason. I explained various possible reasons. She will bring name of medication she is taking for identification.

EJ had wax removal yesterday. Hears much better now and is thrilled by the result. Wonder if I should present a session on ears, etc.?

B Home: ME did not show. Slightly smaller group today. SN went to water color class today instead of lecture. 
Some residents are sending someone else to pick up materials for them rather than coming themselves.

WEEK 4

$\underline{\text { Day } 1}$

A Home: NV pale, weak, complaining of chest pain and muscle and joint soreness. Short of breath. Advised to call MD for immediate appointment.

EJ also has sore throat; weakness; could not participate.

Found WF wandering down the hall; invited her to lecture; confused; didn't seem to enjoy lecture; wandered off before I could take her to her room.

AF slept almost continuously.

KN seemed very interested; not very much understanding about disease.

AU complained of weak, shakey arms when I took her back to her room. Asked what arm exercises could help. I suggested chair arm lifts.

B Home: Smaller group. Losing interest? Outside activities? Poorer presentations? Many sleeping. . . too hot last night? Used microphone for first time. Several said that they had no trouble hearing me but I had no complaints previously (?).

\section{Day 2}

A Home: Several were out on home sponsored trip. Group much more attentive today; less sleeping; cooler breeze in room. Discussed diet; few questions; not certain they understood. They looked interested but not a lot of response.

CE came today; seemed interested.

EF and CE helped put chairs away. 
B Home: Administrator stopped by to ask me about seating diabetic residents together at meal times. MN will contact me about it. I see some problems as well as benefits: trying to get a compatible group; peer pressure toward compliance with diet; ability to keep sugar and desserts off table; other residents seeing the diet as "special treatment"

Only nine present; wonder if drop in attendance is due to use of housewide broadcast with mic. Topic was OK; no goofs.

AI is one diabetic who watches diet closely; disgusted with ME who doesn't. AG tried to get me into the argument of diet control with ME during the lecture. ME missed it all because of her hearing problem. Too bad.

\section{Day 3}

A Home: Good attendance. MO and Io showed up. I told them that they were welcome anytime they wished to coine.

Mo alternates between saying that she gets too much sugar and that she is under control. "Honey is OK" according to her doctor (?).

B Home: Nine only. Still using microphone. One of the staff dropped by to tell me how much he enjoyed listening to $\mathrm{my}$ lecture over the intercom. I plan not to use it next week to see if attendance picks up.

No discussion from group and few questions.

$\underline{\text { Day } 4}$

A Home: Good attendance; some questions. Finished diabetes and began introduction to gastrointestinal presentation. Kept room cooler and that seemed to result in better attention ( 72 degrees in room); most were in sweaters.

B Home: Up to sixteen attending today; used mic; quiet group; passive. Will continue to use mic. 
WEER 5

\section{Day 1}

A Home: Did anatomy and physiology of the gastrointestinal system. Group participated in discussion about hepatitis; apparently a common experience for many. Pernicious anemia made impact on group; very interested.

AU shared information regarding salivary gland stone that she had experienced.

B Home: Large group present, most of them sleeping.

Go said that her MD wanted to cut more nerve endings in her left side because of her intractable pain.

stated, "If I was going to sleep like they do (other residents), I'd stay in my room."

\section{$\underline{\text { Day } 2}$}

A Home: Discussed hiatus hernia; good interest; some questions.

JE and DM came.

Io upset that nobody at her table gets an invitation. I put her on the list.

JE offered book so that I could learn more about "rare disease."

CF brought newspaper article regarding some new procedure in treatment of atherosclerosis.

Several helped put away chairs.

B Home: No notes.

$\underline{\operatorname{Day} 3}$

A Home: Much sleepiness; JE, AF, HO and others. Questions from ED, IO, and AI. All seem eager to meet my 
husband (told them that he will be coming to take pictures.) Eull house.

Io said that she had attended only two lectures, but was sorry that she had not started coming sooner.

Met EJ in hall; upset. Said that everyone was telling her what to do; said that she had walked out of the room; she had never done that before. I walked with her to the library; said that she wanted me to.

NV still pale, confused, sitting in dining room with basket of ribbon flowers she had made.

Mo refused personal invitation to come to lecture. said "I know all that."

B Home: Four to hospitals today by ambulance; only six attended; group disrupted and passive.

WY glanced out of the window and said, "There is G. They are taking her out (by stretcher)." the group.

Poor presentation on my part, and poor response by Day 4

A Home: Usual group. Good interaction.

WD asked about chronic constipation; discussed bulk-formers and need for increased fluids and roughage in diet. Also discussed problems for those who have fluid retention and must limit fluids.

Introduced my husband to each member of the group. He took pictures. They applauded him, and seemed to enjoy having their pictures taken.

B Home: Much better attendance; attention good; many questions at the end.

Introduced husband. Took pictures of small groups of residents. They seemed to enjoy being the center of attention. 
LN wanted to discuss personal problems with constipation; suggested that we talk about it privately after the lecture session.

Reviewed much of yesterday's lecture and then moved on to drugs. Need to include information on lacrimal system.

Home provided peanuts (unsalted) and raisins for treats as well as orange wedges. First time to my knowledge. Enjoyed by residents.

WEEK 6

$\underline{\operatorname{Day} 1}$

A Home: Discused anatomy and physiolog of the eye; much interest from group but a weak prsentation.

Had a long talk with VC who said, "I don't believe that you can prevent anything. - I know too many people who had things happen to them that you wouldn't believe." Fatalistic? Loss of control and/or self esteem?

CF discussed change in diet and problem with constipation (privately). Told of eating much fruit and the good results.

B Home: No notes.

$\underline{\operatorname{Day} 2}$

A Home: $A D$ came for the first time; said she didn't know about the lecture sessions; however, when she was asked previously, she had refused to participate.

EJ very upset with problem "seeing." Unequal pupils; wrote letter to son to mention my concern; feel that she may have inoperable brain tumor, stroke, or? She feels deterioration is occuring rapidy.

KN told of using boric acid and eye cup to wash out eyes. Discussed proper eye care.

B Home: Good interest. 
RB is recruiting persons to attend lecture group. Brought IJ and VF. LH critical and negative in comments. VF said nothing.

SN asked questions regarding cataracts but then was unwilling to discuss the topic further. She argued about glaucoma and the amount of pain that accompanies it.

\section{$\underline{\text { Day } 3}$}

A Home: NV stated "Some friends are coming to take me out for lunch. I don't know when to meet them." (It was then 8:00 AM.) Told her to wait in her room for them, and they would find her.

AF told me and three others she couldn't come today.

HO complained of headache.

Smaller group to begin with; normal size later; many late; why?

WD many questions.

$\mathrm{KN}$ has many outdated health practices. There seems to be a special need to work with blind elderly to update personal health care.

Much interest in ear topic.

EJ chagrined that EF mentioned her experience with wax removal but then was delighted to say that she could now hear.

B Home: Sleeping abounds. Few questions. Interest seems there but no observable response.

$\underline{\text { Day } 4}$

A Home: Finished ear problems; took 40 minutes; good discussion.

B Home: No record. 
WEEK 7

$\underline{\text { Day } 1}$

A Home Discussed angina; too short of time allowed for topic but otherwise good. Small group today.

KN and HO missing today.

Brought NV by the hand; still confused; appreciated invitation and personal attention.

Much sleeping.

B Home: GO and DT talking. Go recalling angina attack (of last week) and how MD had told her that the home was responsible for sending her to the hospital and that he wasn't. I was there when home called MD, and he ordered them to send her in.

\section{Day 2}

A Home: Discussed urinary tract infections and other problems. Spent much time on anatomy and physiology. Many questions; new people.

CF brought WF and her sister.

NV came by herself today; looks brighter; more encouraged; needs to feel important.

Had both windows open today; less sleeping.

B Home: No notes.

Day 3

A Home: Finished urinary tract; good interest; many questions regarding sensitivity and drugs. process.

Future topic of interest: infection and infectious 
Observed many small group interactions of two and three persons. Very chatty. So much noise that EF covered her ears and laughed.

NV refused to come today.

Although it was warm today ( 78 degrees), not much sleeping.

B Home: Room warm ( 84 degrees). Smaller group but good interest and some discussion. Overall, this group asks few questions. Somewhat passive. Usual group sleeping.

Day 4

A Home Had to move to recreation room due to hearing aid appraisals. Most arrived on time in spite of move. Focus was on posture and body mechanics.

Chairs seemed high to me. AI and AF both complained of leg cramps after sitting on them for a time.

DM hit MD on the head with hand when she tried to correct him while he was trying to put the chairs away. Afterward, DM and KN walked away, arm in arm.

B Home: No notes.

WEEK 8

Day 1

A Home: Much sleepiness in group.

Good interest in topic of sleep. Much talk about dreams, dead relatives, nightmares, etc.

B Home: Much group disruption and minor conflicts between members. (Room temperature 80 degrees)

AT cried as she told me about arthritis in her neck and that MD had told her not to take trip to Sweden as planned because of it. I told her to take prescribed medications regularly to reduce pain and inflammation and to watch for ringing in ears and easy bruising. 
$\underline{\text { Day } 2}$

A Home: CF dropped dead yesterday while talking to AO. Much discussion in group.

Fz fell and broke his hip; hospitalized.

Home sponsored fishing trip; low attendance at lecture but good interest.

B Home: Talked to administrator regarding sheltered workshop for FN. Seemed receptive and will inquire.

Finished discussion of sleep.

$\operatorname{Day} 3$

A and B Homes: Did program evaluation. Assisted group by reading the questions and then going from person to person to assist if they couldn't write their responses. MN helped. Encouaged them to be critical so that "I could learn from my mistakes."

Day 4

$A$ and B Homes: Parties and termination as previously discussed in "Exercise" section. 
APPENDIX D

EXERCISE PROGRAM 


\section{THE EXERCISE PROGRAM}

The exercise program was designed to develop flexibility and muscle strength in the hands and legs. Perry's range of motion exercises and Frankel and Richards sitting and standing exercises were used. In addition, various props or devices were used to provide variety and stimulate interest.

Since no medical examination was required of the subjects, certain limitations in the amount and nature of the exercises were implemented. Exercises which would tax the cardiovascular system (such as endurance, aerobic-type activities) were avoided. Subjects were told to work within their own limits and not to cause themselves distress or symptoms of over-exertion. When it was evident that the subject was experiencing difficulty with a particular activity, an alternate activity was recommended. For example, several subjects had severe limitation in range of motion of the shoulder due to injury or disease. They were advised to only lift their arms "as far as it is comfort-able" or to assist the less able arm with the other arm through the range of motion. No comparisons in performance were made 
between subjects and any improvement in performance was acknowledged.

Acknowledgement of subjects' efforts was made either by direct eye contact and a smile or affirmative nodding. Even when subjects had to rest or otherwise could not. perform, eye contact was made to acknowledge acceptance of their limitation in performance.

If other residents came to the exercise room, they were invited to participate. Extra chairs were always provided for potential participants when setting up for the exercise sessions. If necessary, additional chairs would be brought into the circle to make room for new members. Subjects who had participated in other exercise programs were encouraged to share their experiences with the group and demonstrate particular exercises they especially liked. If appropriate, these exercises were then included in future presentations.

Each session began with a head to toe series of circles, lifts, stretches, swings and twists described by Perry (1976). Progression in the program was implemented by increasing the number of repetitions. Once the ability of various members of the groups were ascertained, standing exercises while holding on to chair support were introduced. A variety of exercises included in Frankel and Richards work were used. (1977) In addition, certain exercises using the props were introduced. These 
specialized exercises included kneading bread, riding a scooter, swimming strokes, squeezing a firm rubber ball, incorporation of wands and scarves in range of motion exercises.

The intensity of certain exercises could be raised by increasing the speed of the exercise. However, this method was used with much caution because of the loss of elasticity of muscular and ligament tissue with age. With loss of elasticity the danger of injury to muscles and ligaments is greater in exercise. Thus, a long period of warm up and cool down is advised. (devries, 1976)

Progression in strength building exercises for the hands was developed by verbal encouragement of the members of the group to "squeeze the ball as hard as you can." The number of repetitions and the time spent in holding the contractions were gradually increased. Exercisers were frequently reminded not to hold their breath when under exertion. (Valsalva manuever)

Development of leg strength was encouraged by Frankel and Richards quadricep exercise (p. 112). This exercise was initiated by beginning with two repetitions and gradually. increasing to five. In addition to the increased number of repetitions, the count was gradually slowed so as to increase the time of muscle tension throughout the action. This exercise was used to develop leg strength and stability before the subjects were exercised from a 
standing position with chair support. When needed leg strength, balance and stability were developed to the point of ensuring subject safety, standing exercises were gradually introduced.

Another leg strength developicnt exercise using the firm rubber ball was implemented. This exercise required that the subjects place the firm ball under the ball of the foot. To a count of five, the subjects would gradually press down on the ball with the foot and then gradually release it. The muscles of the anterior lower leg and the quadricep were contracted during this activity.

In the A home, standing exercises were begun at the end of the second week for a period of three minutes. Thereafter, standing exercises were used each period and the time was gradually increased from three to five and finally to ten minutes. The members of the exercise group in the $B$ home, however, were unable to do the quadricep exercise safely until the fourth week and did standing exercises at the end of the fifth week.

Jogging in place while holding onto the chair for one to two minutes was begun the first day of the seventh week in the $A$ home. This was tolerated well. The one to two minute sessions of jogging in place were gradually increased in repetitions until, at the end of the eighth week, three periods of jogging were used in the half-hour 
session. The periods of jogging were interspersed with other types of standing exercises.

In the $B$ home, jogging in place was not begun until the beginning of the eighth week. This group used the jogging activity only during this last week.

The variety of standing exercises were also selected from Frankel and Richards work. The subjects seemed to enjoy standing exercises and even became playful and teasing in their relations with one another during these activities. For example, some of the taller subjects would pretend to kick the subject ahead of them when doing leg swings.

In addition to the different kinds of exercises used during the sessions, props were used to stimulate interest and provide variety. Included were $24^{\prime \prime}$ wands, soft and medium firm balls, barbells (made of rubber balls glued onto the ends of 8" wooden dowels), brightly colored, filmy-material scarves which were used to toss up into the air and catch or in a manner similar to wands and, cardboard "gloves" which fit onto each hand and provided visual stimulation while performing a variety of Perry exercises.

Each exercise session began with range of motion exercises from head to toe. Perry's circles were begun with the head, then to the shoulders, upper body, arms, wrists, legs, ankles, and toes. The exercises then proceeded to the 
lift type of movements using the same parts of the body and so on with the stretch, swing and twist movements as appropriate for various body parts. The emphasis was on achieving as wide a range of motion as possible and comfortable.

When the Frankel and Richards exercises were introduced particular attention was paid to sequencing the use of various body parts so as to prevent fatigue and over-use of any one part. The exercises used were the following:

Thigh exercise to tone and strengthen the muscles inside and outside the thighs: for the abductors and adductors.

Posture and flexibility drills for shoulder girdle: for enhancing posture and strengthening the flexor muscles of hands (using a 24 inch wand) from the sitting position. Half knee bend: to strengthen the thigh muscles while avoiding over stretching of the knee joint while holding onto a chair.

Quadricep exercise from sitting to standing position. Forward and backward leg swinging: to improve flexibility of the hip muscles.

Side leg swinging. Abdominal exercise for the side of the waist. Bicycling from chair sitting position. 
Gastrocnemius exercise: to strengthen the calf muscle and to help stimulate the flow of blood back toward the heart.

Other exercises included were adaptations of standing exercises that could be done from a chair sitting position. For example:

Foreward crawl swimming movement of arms. Backstroke arm movement. Side leg lifts from chair sitting position. In the following outline of the exercise presentation, "Perry" refers to all of the range of motion exercises presented by Perry (1974). "Quadricep" and "standing" refers to Frankel and Richards (1977) exercises previously described. Since the subjects in each home participated within their own limits, some exercises will be followed by an "A" or a "B." This means that only that home performed that particular portion of the exercises. Unless otherwise indicated, the exercise named was performed by residents in both homes.

A brief outline of the exercise presentation in each home follows: 


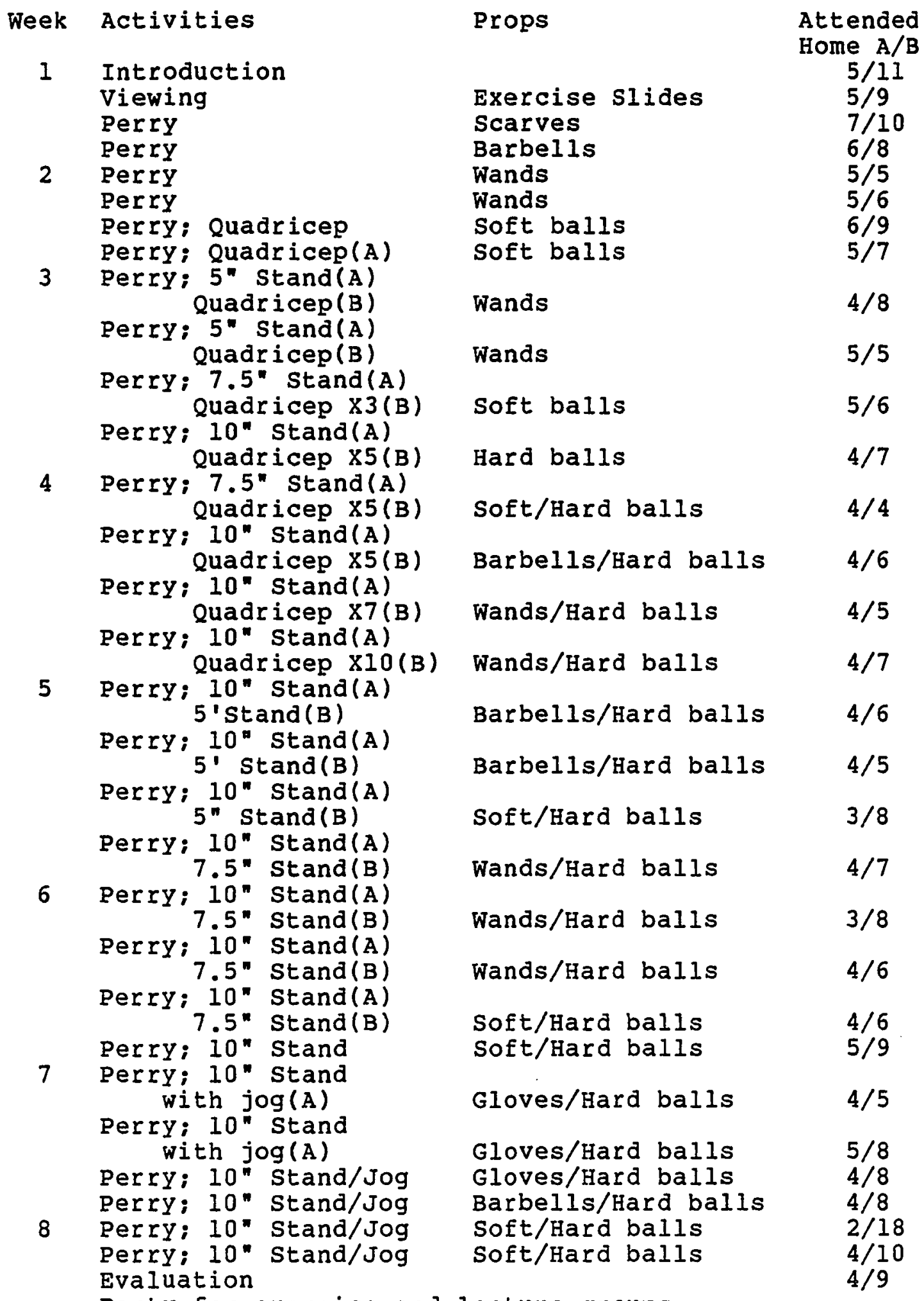

Party for exercise and lecture groups 
Props and Routines

In order to better understand the conduction of the exercise program, the following explanation of the props used and the various routines is provided.

Stand ups: These exercises are conducted with the subject seated in a straight back chair. She is directed to move slightly forward on the chair seat and to place both feet firmly on the floor, one slightly ahead of the other. With hands holding onto both sides of the chair seat and leaning slightly forward from the hips, the subject is instructed to gradually raise her buttocks from the chair seat to the count of three.

At the count of three, the subject is told to "hold the position" for another count of three. Upon the completion of that count, another count of three is said while the subject gradually lowers her buttocks to the chair seat.

The purpose of this exercise is to increase the strength of the quadriceps. These muscles are used when rising from and sitting in a chair.

Variation in this exercise includes increasing the count to five and instructing the subject to prolong each stage of the routine.

Another variation is to increase the count to five and instruct the subject to rise to a standing position. If this variation is used, the subject is also told to "stand 
straight and tall" in order to focus on a more upright posture.

Standing Exercise: This is a fully upright posture assumed by the subject. A wide variety of exercises previously described can be used while the subject is standing. The subject is instructed to hold onto the back of the chair for support and balance during all exercises except those which require hand and arm movements. As the balance and strength of the subject improves, less reliance on this support is necessary.

Chair Exercise: These exercises are conducted from a sitting position in a sturdy chair. Chairs should be placed far enough apart so that the subject has full freedom of arm and leg movements without encountering any other object or person. Reminders to assume correct sitting posture while exercising are given. Specific exercises used from the sitting position have been described previously.

Props: A variety of devices were used to encourage participation and provide stimulation in the exercises. A brief description of the prop and the routines used with each follow: 
1. Soft, big balls: Multicolored cloth balls of eight inch diameter and stuffed with nylon, polyester fill and/or plastic foam. These primarily were used to increase hand strength. They were also used to provide variety in exercises which focused on other body parts. A variety of activities using the balls follow:

a. "Knead like dough." The ball is placed on the lap and the hands squeeze and press down on the ball and then rotate it as though it were a ball of bread dough.

b. "Massage the ball." The ball is placed on the lap as before. The hands squeeze and press downward on the ball as though one were massaging some body part.

c. While in a sitting position, place the ball between the knees and squeeze it by contracting the adductor muscles of the inner thigh. Alternate between contraction and relaxation.

d. While in a sitting position, toss the ball lightly upward and catch it several times to "fluff it." Improves hand-eye coordination, provides some range of motion for the arms and shoulders. 
e. "Squeeze" the ball to make it as small as possible with both hand, then relax. This exercise focuses on hand strength, particularily on the fingers.

f. From either a standing or sitting position, grasp the ball with both hands, elbows raised and outward from the body. Rotate hands inward and outward. Provides a range of motion for the wrists.

9. While in a sitting position, place the ball in the 1ap. Then, lay the upper body over the ball and attempt to squeeze down on the ball. Then lift upper body to erect sitting position. This increases hip flexion and provides another variation of the perry lift for the upper body.

h. While in a sitting position, hold the ball with both hands outward from the body and at shoulder height. Twist from the waist to each side. This increases range of motion of the upper back and provides variation of the Perry twist for the upper back.

i. Place the ball between the hands with the arms held at shoulder height and just in front of the chest. squeeze the ball between the hands and release. The muscles used include the anterior chest and upper back. 
2. Hard balls (racketballs) These are small, rubber balls of approximately two and one half inch diameter. They are more difficult to compress than the soft balls and were used primarily for hand strength. In addition, they were used in an attempt to increase the subject's leg strength for rising and sitting in a chair.

a. Hold the ball in one hand. Attempt to dent the ball with the thumb and then relax. Finger strength development was attempted by having the subject hold the ball and try to compress it with fingers only (not using the thumb).

b. Development of leg strength was attempted by placing the ball on the floor under the ball of the foot. While keeping the heel on the floor and leaning forward slightly, the subject was directed to compress the ball with the foot. The subject was told to allow the hands to hang freely downward along side of the chair and not to hold her breath, thus, preventing the Valsalva maneuver.

c. For some subjects, the racketballs were too hard to use. For them, small "footballs" made of various colored soft plastic were provided. The same routines were used with these softer balls as with the racketballs. 
3. Gloves: Oval shaped, cardboard "gloves" were constructed into which the subject inserted her hands. Each side of the "glove" was colored (one side was red and one, black). Most of Perry's exercises for range of motion of the arms and shoulders could be performed with the gloves on. In addition, the subject could perform "swimming" motions with the gloves. Another exercise was stretching upward with the arms as far as possible from either a standing or sitting position. The two different colored sides of the gloves provided additional visual stimulation during the exercises.

4. Wands: The wands were constructed of 24 inch pieces of white plastic pipe with colorful tape applied to the cut ends. Most subjects associated these with "physical education classes" from their childhood and found the exercises enjoyable.

a. The subject was instructed to hold each end of the wand outward at shoulder height, raise the wand high overhead and then return to the starting position.

b. From the overhead stretch position the subject was instructed to gradually lower the wand first to the anterior chest and then back upward. Then, from the upward 
position, to lower the wand again but to bring it behind the head and neck as far downward as possible.

c. From a slightly forward sitting position on the chair, the subject was directed to extend one end of the wand downward, behind the head and along the spine. With the free hand, the subject was directed to reach behind the back and attempt to grasp the lower end of the wand. If successful in grasping the wand from below, the subject was then directed to move the wand up and down the spine while holding on to both ends.

If the subject could not grasp the lower end of the wand, she was directed to move the wand up and down the spine while reaching back with the other hand. These movements increased the range of motion of the shoulder and upper back.

d. From a sitting position, holding on to each end of the wand at shoulder height, the subject was directed to place the wand on the chest and "roll" it downward over the abdomen, thighs, lower legs and feet and place it on the floor. From this position the subject was then directed to "roll" the wand back upward over the body to assume the beginning position. This aided in the forward flexion and lift movements of the upper and lower back. 
e. From a sitting position, holding on to one end of the wand, the subject was directed to place the other end on the floor eight to ten inches laterally from the foot. Keeping the wand anchored in that location, the subject was then directed to make large circles with the upper end of the wand which she was holding. This movement provided range of motion of the elbow and shoulder.

f. "Rowing" motions were made by having the subject hold one end of the wand with both hands and reach forward and draw backward as though rowing a boat. This activity provided some range of motion in the elbow and shoulder.

g. From a sitting position, the subject was directed to hold onto each end of the wand at shoulder level. Then by lowering one hand and raising the other, the subject was to "twist" the wand. This provided range of motion for both shoulders and wrists.

h. Pretending that the wand was a broom, rake or snow shovel and with the appropriate movements for each implement, the subject could attain additional range of motion for the shoulder, elbow and wrist.

i. The wands could also be used as handlebars for the "scooter ride." 
5. Barbells were constructed of eight inch wooden dowels of $5 / 8$ inch diameter. Black rubber racketballs were fitted on to each end and glued in place. All of the range of motion exercises using the wands and gloves were also used with the barbells. These, like the wands, brought back memories of school days for most of the residents and were enjoyed. There also seemed to be a special feeling of "strength" associated with using the barbells that made the subjects expecially interested in using these devices.

6. Scarves were made of extremely light-weight fabric and brightly colored. They were used to provide visual stimulation and additional range of motion activities. Throwing the scarves upward overhead and catching them as they slowly drifted downward also provided some hand-eye coordination activity. The subjects like to select their own color scarf.

The scarves could also be substituted for wands in some of the previously described activities. 
APPENDIX E

LECTURE PROGRAM 


\section{LECTURE PROGRAM}

The lecture program was designed to control for time spent with the subjects. An equal amount of time was allotted for the lecture sessions as was allotted for the exercise sessions. Since the primary focus was on the time spent with the subjects, no pre- or post-testing of learning was done.

The topics selected were believed to be of interest to the subjects and this was confirmed in the initial meeting with them. Some changes in topics were made when particular areas of interest became apparent through interaction with the subjects.

While every effort was made to keep the sessions interesting and worthwhile to the subjects, learning content was secondary to the primary purpose of the sessions, i.e. personal contact.

A general outline of the material presented in the lecture sessions according to the week follows. Although there was some variation in exact presentations from day to day in each home, topic and content were essentially the same for both homes. 
Week

Topic

Attended

Home $A / B$

1 Orientation

Slides on High Blood Pressure

Normal Anatomy/Physiology of Heart

$10 / 10$

Abnormal Heart Function and Disease

$3 / 14$

$9 / 8$

$7 / 10$

2 Drugs used for Heart Problems

Prevention of Heart Disease

$12 / 12$

$9 / 14$

$9 / 13$

Relationship of Diet and Heart Disease

$7 / 12$

3 Anatomy and Physiology of Bone

Arthritis

Osteoporosis

other Bone and Joint Problems

$13 / 13$

$11 / 15$

$13 / 16$

$15 / 10$

4 Diabetes: Types and Defined

$11 / 17$

Importance of Diet Control

$12 / 8$

Drug Therapy in Diabetes

Complications of Diabetes

$12 / 10$

$16 / 16$

5 Anatomy and Physiology of GI Tract

$14 / 18$

Upper GI Problems

$18 / 12$

Lower GI Problems

$18 / 6$

Laxatives

$16 / 14$

6 Anatomy and Physiology of the Eye

Eye Problems

Anatomy and Physiology of the Ear

Ear Problems

$16 / 21$

$14 / 17$

$14 / 16$

$14 / 14$

Angina: Causes and Treatment

$13 / 15$

Back Problems

Anatomy and Physiology of Renal system

$20 / 15$

$15 / 14$

Bladder and Kidney problems

$15 / 21$

8

Sleep Defined and Stages

sleep problems

$16 / 18$

$10 / 21$ 
APPENDIX F

DESCRIPTIVE DATA 


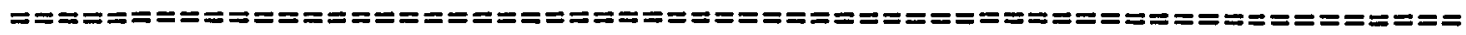

TABLE XXIII

DEMOGRAPHIC CHARACTERISTICS OF THE SAMPLE (PRE-TEST)

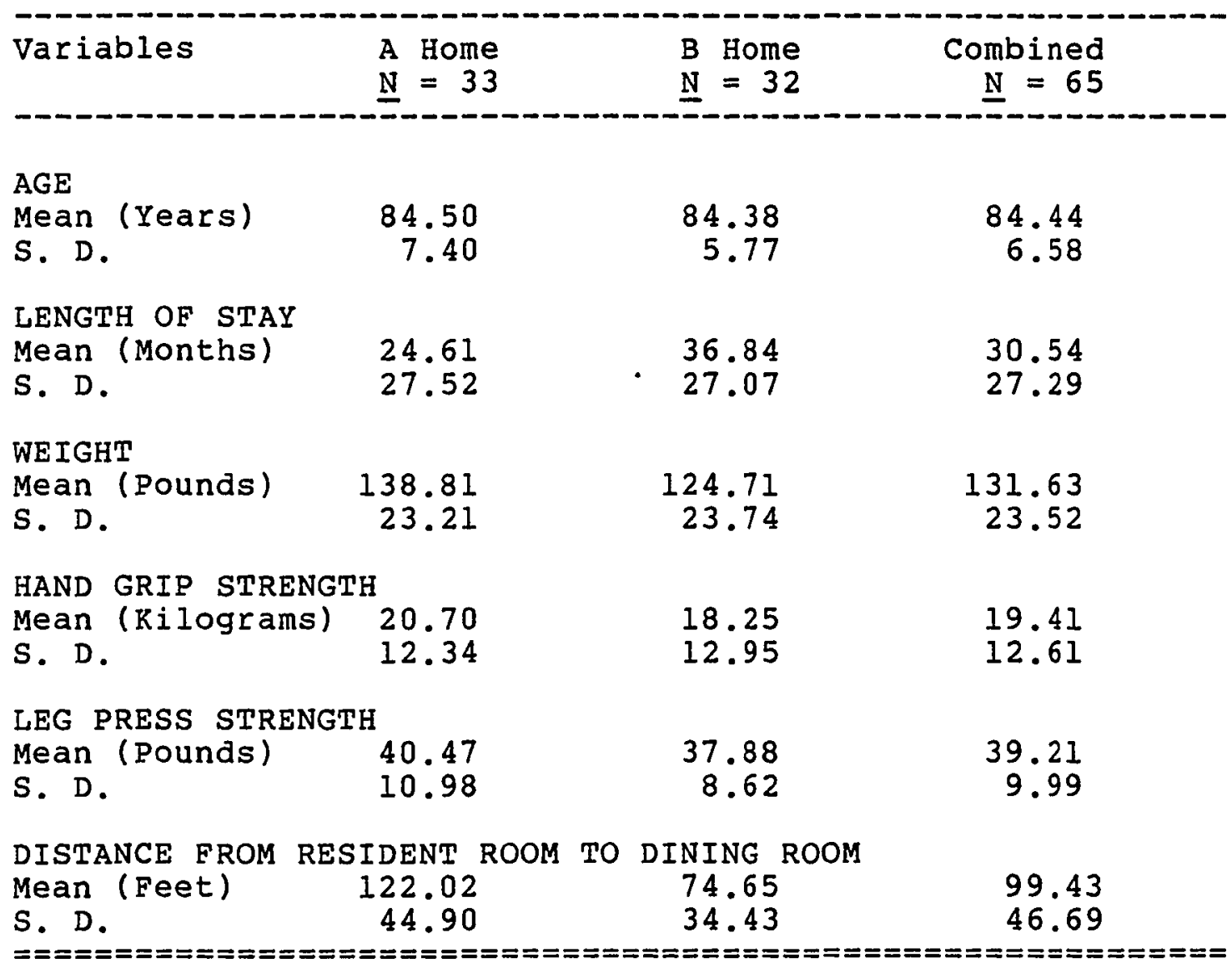




\begin{tabular}{|c|c|c|c|c|}
\hline \multicolumn{5}{|c|}{$\begin{array}{c}\text { TABLE XXIV } \\
\text { ANALYSIS OF VARIANCE BETWEEN } \\
\text { PHYSICAL MEASURES }\end{array}$} \\
\hline Variables & df & Mean & $\underline{F}$ ratio & p \\
\hline $\begin{array}{r}\text { Weight } \\
\text { A Home } \\
\text { B Home }\end{array}$ & $1 \& 63$ & $\begin{array}{l}139.87 \\
123.38\end{array}$ & 5.77 & $.02 *$ \\
\hline $\begin{array}{l}\text { Hand Grip } \\
\text { A Home } \\
\text { B Home }\end{array}$ & $1 \& 63$ & $\begin{array}{l}20.70 \\
18.25\end{array}$ & .61 & .56 \\
\hline $\begin{array}{l}\text { Hand Grip } \\
\text { All Males } \\
\text { All Females }\end{array}$ & $1 \& 63$ & $\begin{array}{l}37.70 \\
16.18\end{array}$ & 39.47 & $.00 * *$ \\
\hline $\begin{array}{l}\text { Leg Press } \\
\text { A Home } \\
\text { B Home }\end{array}$ & $1 \& 63$ & $\begin{array}{l}41.39 \\
38.28\end{array}$ & 1.59 & .21 \\
\hline 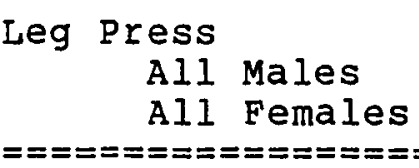 & $\begin{array}{l}1 \& 63 \\
======\end{array}$ & $=\begin{array}{r}37.70 \\
39.83 \\
=====\end{array}$ & 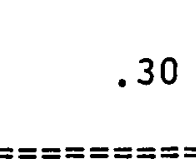 & $\begin{array}{c}.59 \\
=======1\end{array}$ \\
\hline
\end{tabular}




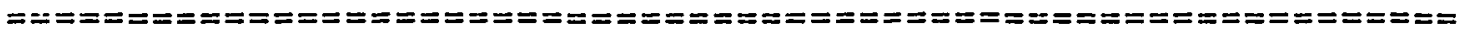
TABLE XXV

COVARIANCE BETWEEN PHYSICAL MEASURES

\begin{tabular}{|c|c|c|}
\hline $\begin{array}{l}\text { A Home } \\
\underline{N}=33\end{array}$ & $\begin{array}{l}\text { Pearson } \underline{r} \\
B \text { Home } \\
\underline{N}=32\end{array}$ & $\begin{array}{c}\text { Combined } \\
\underline{N}=65\end{array}$ \\
\hline $\begin{array}{c}\text { Age Vs. Length of Stay } \\
.14\end{array}$ & .29 & .22 \\
\hline Weight Vs. Hand Grip Strength & .09 & .17 \\
\hline $\begin{array}{c}\text { Weight Vs. Leg Press strength } \\
.46 * *\end{array}$ & $.42 \star \star$ & $.43 * *$ \\
\hline
\end{tabular}

$* * \leq .01$ 


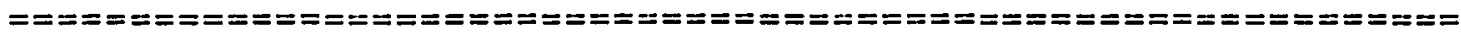 \\ TABLE XXVI \\ DEMOGRAPHIC CHARACTERISTICS, ATTITUDE \\ TOWARD EXERCISE, AND DAILY HOURS \\ OF ACTIVITY AND REST \\ (POST-TEST)}

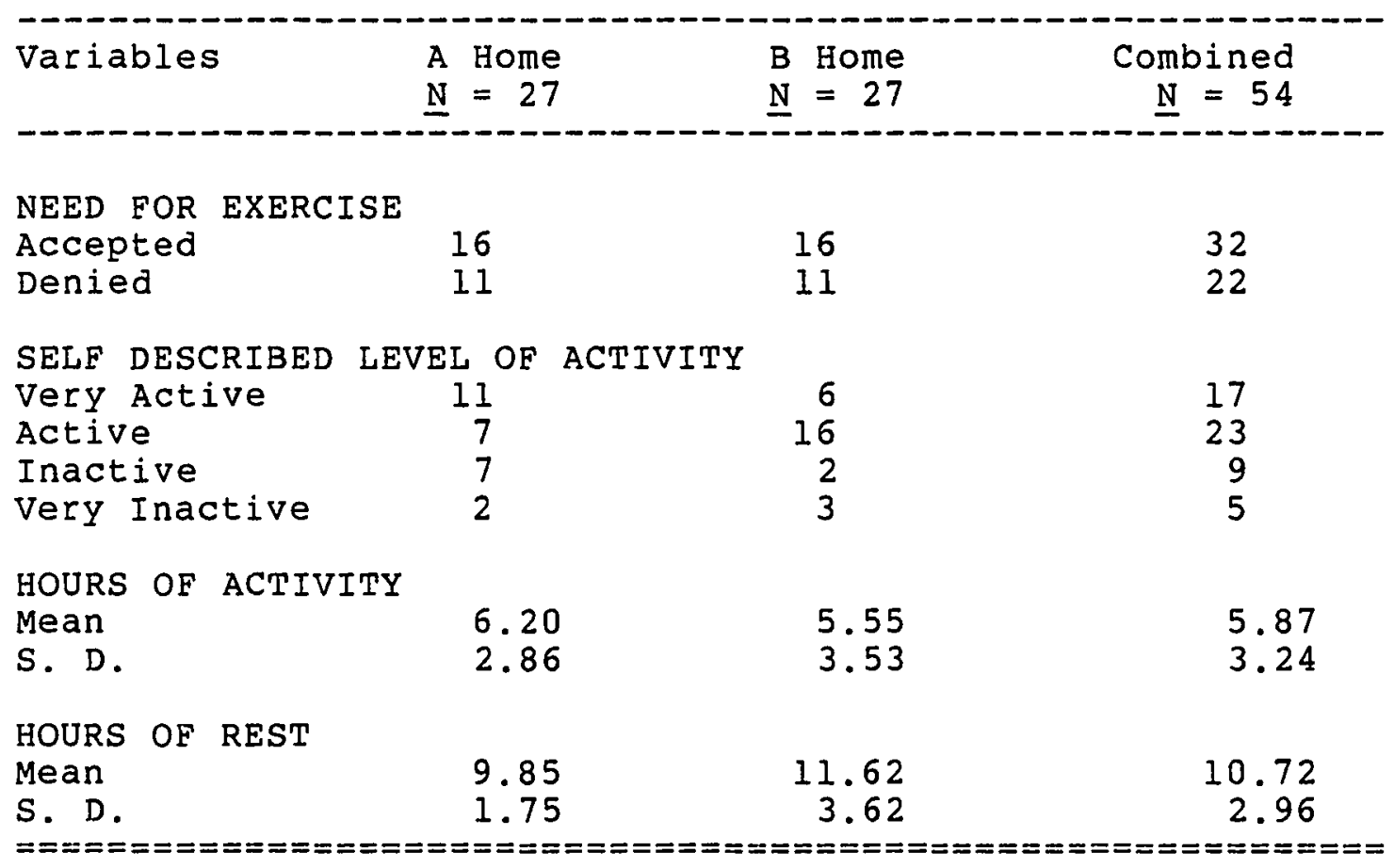




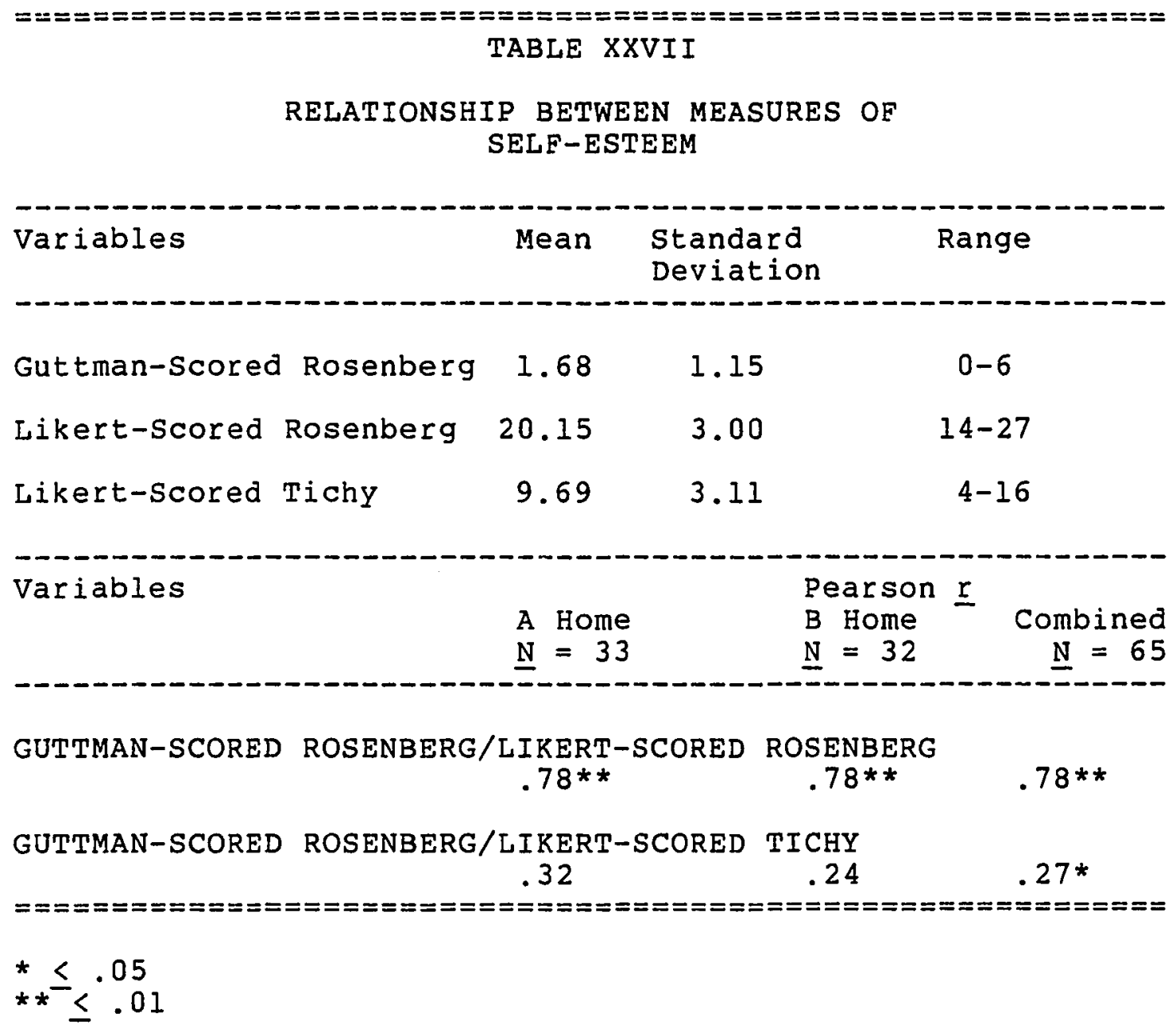


APPENDIX G

ASSISTANT'S OBSERVATIONS 


\section{ASSISTANT'S OBSERVATIONS}

The following observations and comments are offered by the assistant who met with each subject in the study. As a result of the formal interview and informal discussions with them, certain observations related to aging in the retirement home environment were made.

\section{Surroundings}

The persons who seemed the most satisfied with themselves and others were those who had evidence of their interests surrounding them. For example, the possessions such as books, newspapers, knitting, bible, family pictures, plants, piano, etc. present in the room.

Some had specific complaints and statments related to the home environment that they shared. The comments follow:

Some of the windows in the rooms were too high for a resident to be able to sit in a chair and see out of doors.

Some rooms had no shower or tub. Those persons had to wait for bath day.

Some complained that they were seated at tables where they could not communicate with anyone because the others were hard of hearing. This lead to no conversation at all during meals. For some residents, this was the only time they were out of their rooms and saw others. 
At one home, there was no place to walk except on the street. There was no nearby shopping or any incentive for most residents to leave the premises.

Generally, however, most residents seemed content with the staff and the cleanliness of their surroundings. Most also thought the food was "good."

$\underline{\text { Eamily }}$

Those who still had family interested in them expressed greater contentment. A vast majority of the residents seemed to have children or brothers and sisters who visited with them, took them shopping, looked after their needs. I experienced a nice feeling when they (the subjects) would speak lovingly of their children; they knew that they were not rejected. Those with no friends or family seemed the most desolate, and yet they retained the desire to survive.

Religion

Those residents who had religious backgrounds seemed more content. They seemed to derive much comfort from bible reading. They were not the defeatists. They had come here (to the retirement home) to live out their lives, and to accept what God has in store for them.

Physical Disability

Physical disabilities appeared to be the most prevalent problem. So many (of the residents) stated how much their lives changed since becoming disabled. They were 
unable to take walks, exercise, communicate, read, shop, see. Most seemed able to cope with the fact that they could not do what they were able to do before disability. It was enlightening to observe that they expressed no regrets about their lives. Rather, they had become resigned to the realization that things could not be changed, so they accepted them.

\section{Inertia}

It seemed that the residents who were the most inactive were the ones who complained the most about not being able to sleep, the other residents, the food, the sourroundings, their health, etc. They were unlikely to join in activities, walk, visit others. When asked about a routine day, they would respond, "I go to meals and then return to my room." Most would go back to bed until next meal time. Quite a few laid the blame on physical disabilities, such as not being able to read because of poor eyesight, or being hard of hearing, unable to communicate with others. They often gave up trying because others would lose patience with them. For some, television was the only recreation available that they could see or hear. The group lacked creativity or willingness to serve. Although I found it very difficult to communicate with those who had problems hearing, they were the most anxious to talk. They had led good lives, had lots to be proud of, had been active, and had a good sense of humor. 
They savored every moment of time and conversation I shared with them. If only they could hear again or see again, how different their lives would be. Those with other physical disabilities did not seem to be as badly affected as those without hearing.

I found a way of communication with the residents that they did not find patronizing; it was touching. They seemed to reach out more and feel your sincerity. This was especially true of those that hearing problems. Death

Most of the residents felt "This is where I am going to die." Although it seemed that they did not dwell on the subject, they did seem more or less resigned to the inevitability of death. For them, there seemed to be great comfort in religion. It was difficult to determine whether this was a new phase in their lives. Quite often there was a reference to bible reading, church going, and praying.

No one that I spoke with communicated any fear of death. If anything, it was resignation.

$\underline{\text { Age }}$

It was a wonderful experience to be greeted by the question, "How old do you think I am?" I knew when they asked that they were proud of the way they looked. I was always astonished when they would reveal their ages. It was nearly always the persons who were 80 to 99 years old. I called them "The Survivors." Most could be taken for 20 years younger. They were the "doers" and the "givers." 